\title{
Perceptions of Wood Product Supply and Demand for Affordable Building and Green Construction Markets
}

Gregory D. Estep

Follow this and additional works at: https://researchrepository.wvu.edu/etd

\section{Recommended Citation}

Estep, Gregory D., "Perceptions of Wood Product Supply and Demand for Affordable Building and Green Construction Markets" (2015). Graduate Theses, Dissertations, and Problem Reports. 7082.

https://researchrepository.wvu.edu/etd/7082

This Dissertation is protected by copyright and/or related rights. It has been brought to you by the The Research Repository @ WVU with permission from the rights-holder(s). You are free to use this Dissertation in any way that is permitted by the copyright and related rights legislation that applies to your use. For other uses you must obtain permission from the rights-holder(s) directly, unless additional rights are indicated by a Creative Commons license in the record and/ or on the work itself. This Dissertation has been accepted for inclusion in WVU Graduate Theses, Dissertations, and Problem Reports collection by an authorized administrator of The Research Repository @ WVU.

For more information, please contact researchrepository@mail.wvu.edu. 


\title{
Perceptions of Wood Product Supply and Demand for Affordable
}

\section{Building and Green Construction Markets}

\author{
Gregory D. Estep \\ Dissertation submitted \\ to the Davis College of Agriculture, Natural Resources and Design at \\ West Virginia University \\ in partial fulfillment of the requirements for the degree of \\ Doctor of Philosophy in \\ Forest Resources Science
}

David B. DeVallance, Ph.D., Chair

J. Chris Haddox, Ph.D.

M. Paula Fitzgerald, Ph.D.

Shawn T. Grushecky, Ph.D.

Jingxin Wang, Ph.D.

Division of Forestry and Natural Resources

Morgantown, West Virginia

2015

Keywords: Certified Wood Product, Green Building, Spatial Analysis, Purposeful Sampling, Affordable Housing, Specifiers, Manufacturers, LEED 


\title{
ABSTRACT
}

\section{Perceptions of Wood Product Supply and Demand for Affordable}

\author{
Building and Green Construction Markets
}

\author{
Gregory D. Estep
}

Decreased housing starts between 2005 and 2012 have caused decreased demand for wood-based products such as flooring, cabinetry, and moulding produced from Appalachian hardwoods. However, there may be opportunities to increase demand for these products as demand in the green building sector increases within the United States. Due to this increased demand in green building, wood product manufacturers are presented with an opportunity to further diversify their sales portfolios. The overall goal of this research was to identify wood product opportunities within the affordable and green building industries. Through surveying techniques and spatial analysis of existing commercial green building projects, opportunities have been identified to increase the use of wood products in the green building sector.

Survey results from builder respondents, in the affordable housing sector of the Appalachian region, have indicated a preference for following green building standards as well as the use of certified wood products (CWPs) in their construction projects. Respondents indicated a higher willingness-to-pay for local and certified wood products and that the environmental attributes of CWPs was the most indicated reason for their use. Additionally, respondents chose local retailers, websites, and magazines as the top media for marketing communications used to learn about new wood products.

Commercial LEED certified projects constructed between 2000 and 2013, which obtained the certified wood credit, were analyzed and determined to have an increasingly clustered growth pattern. This result indicated that new commercial LEED certified projects, that obtain the certified wood credit, will likely be located near these existing projects. Furthermore, statistically significant groupings of commercial green building projects, called Hot Spots (based on the number of projects in a given area), were found primarily near large urban areas. These Hot Spots may further indicate specific future markets for wood products manufacturers. The same analysis was used to analyze these projects in the Appalachian region. Results indicated two Hot Spot areas: Pittsburgh, PA and Greenville, SC. 
Specifier perceptions of commercial LEED certified projects in the two Hot Spot areas indicated that respondents generally had a positive perception towards wood-based building materials and felt wood offers the environmental and physical attributes needed in green building practices. Specifiers also felt that the main barrier to wood use in commercial green building projects lie in the building type and building code restrictions. Additionally, respondents felt the green building market would continue to grow and were interested in increasing the use of structural wood-based products such as cross laminated timbers (CLTs).

Manufacturers in the Appalachian region also felt, in general, that the green building market would continue to grow but are doing little to specifically target this sector with their current marketing approaches either due to lack of interest in pursuing this market or lack of knowing the right people to approach. Also, manufacturers, in general, felt the environmental certification of wood products was unnecessary. The difference in perceptions of wood product certification differs from builder and specifer responses in this study and may indicate an opportunity for increase wood product sales. Additionally, manufacturers indicated low efforts, in general, toward marketing their products and placed little value on websites and ads in printed materials. Builders and specifers however, often looked to these same media for marketing communications to learn about new and existing wood products.

Material specifiers for both affordable housing and commercial green building projects have indicated preferences for using certified wood products and prefer the environmental friendliness of the material when compared to alternative materials such as metal or concrete. These specifiers along with wood product manufacturers agree that the green building market will continue to grow. To meet the need and preferences of material specifiers, manufacturers interested in pursuing this growing market are encouraged to include the environmental attributes of their wood products. Adding technical data such as a Life Cycle Assessment (LCA) will further substantiate the claim of lower environmental impact when compared to other materials. Additionally, manufactures are encouraged to supply marketing and promotional materials such as up-to-date websites, advertisements in trade magazines, and information to local retailers, as these are common media for marketing communications for specifiers to use when learning about new products. 


\section{Acknowledgements}

I would first like to thank my major professor Dr. David DeVallance for providing the opportunity and the exceptional guidance throughout my time at West Virginia University. He has provided numerous opportunities to grow personally as well as professionally. I am very grateful to have had the pleasure of working and studying under him. I would also like to thank

my committee members: Dr. Chris Haddox, Dr. Paula Fitzgerald, Dr. Shawn T. Grushecky, and Dr. Jingxin Wang for their time, valuable comments and advice.

Additionally, I would like to thank my family for the support that they have given. Most importantly, my beautiful wife, Lindsey, who selflessly provides endless encouragement and support during the pursuit of this degree and beyond. 


\section{TABLE OF CONTENTS}

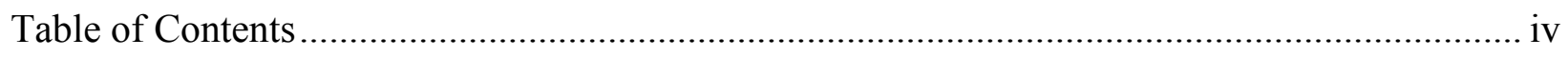

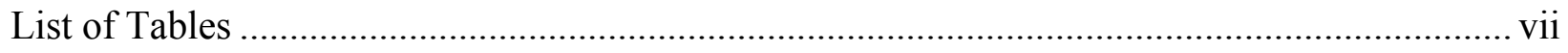

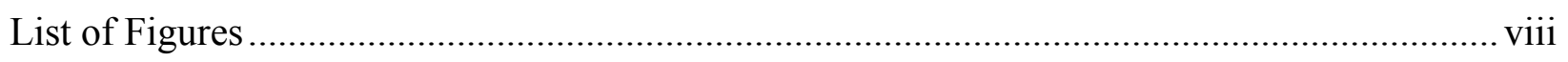

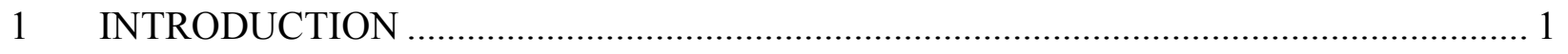

2 AFFORDABLE HOME BUILDER DEMAND FOR GREEN AND CERTIFIED WOOD

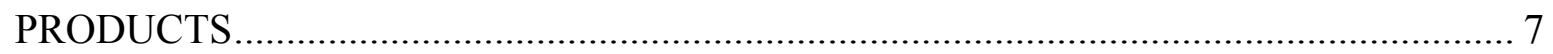

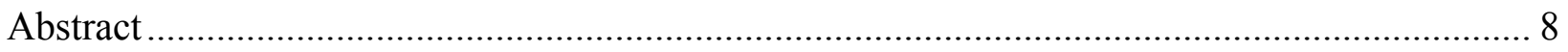

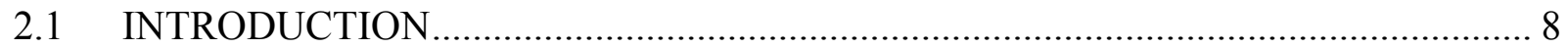

2.2 METHODS AND MATERIALS ......................................................................... 12

2.3 RESULTS AND DISCUSSION ...................................................................... 16

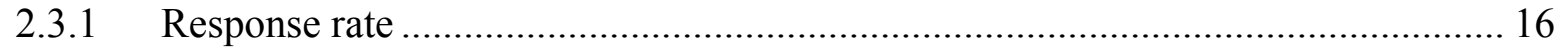

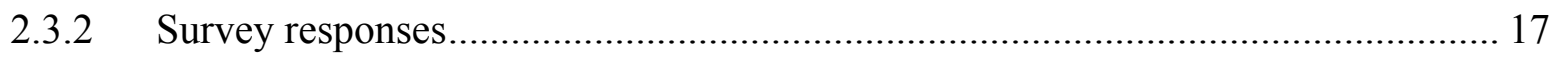

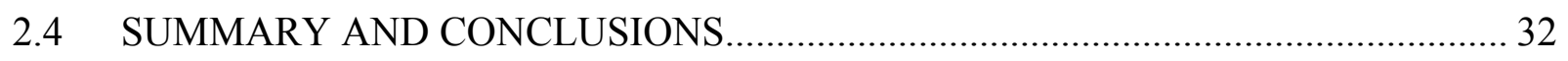

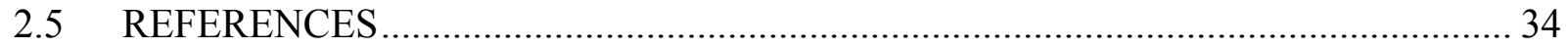

3 SPATIAL ANALYSIS OF CERTIFIED WOOD PRODUCT USE IN COMMERCIAL

LEED GREEN BUILDING PROJECTS.................................................................. 38

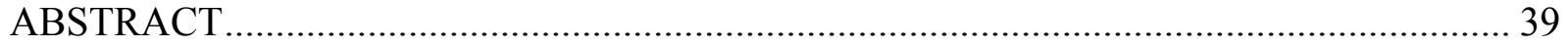

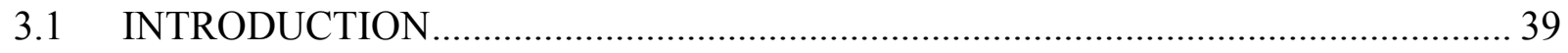

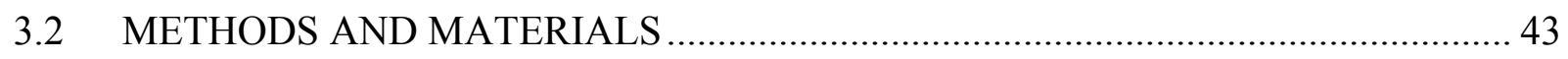

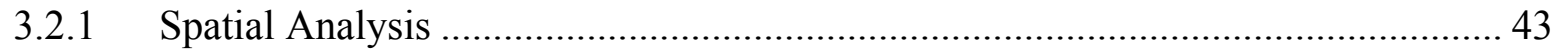

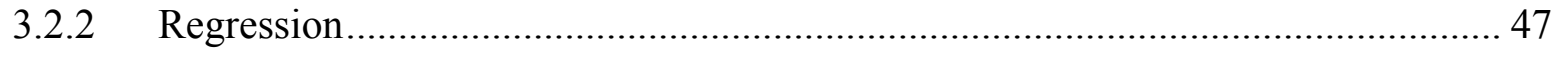

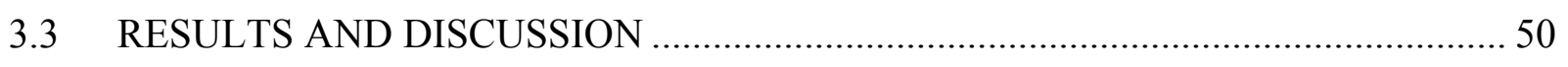

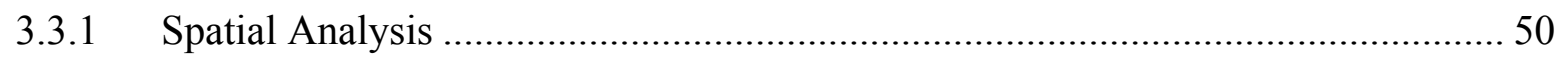

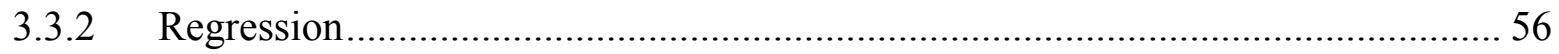

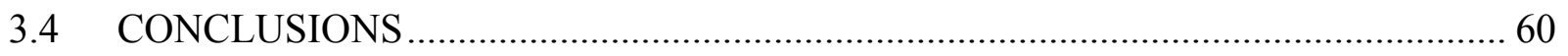

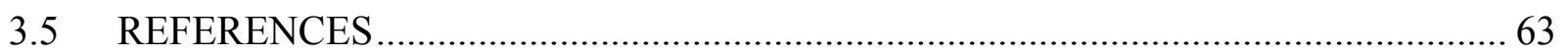

4 SPECIFIER PERCEPTIONS OF WOOD PRODUCT USE IN COMMERCIAL LEED

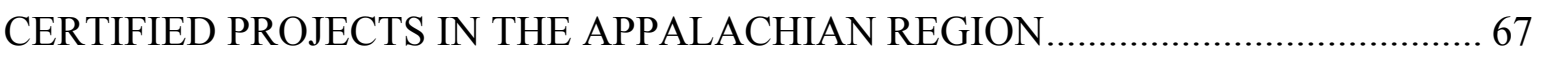




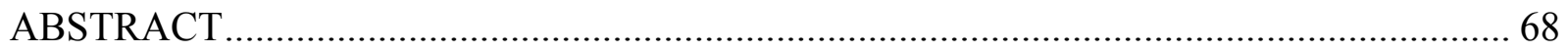

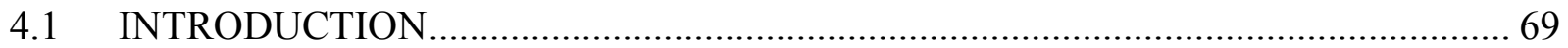

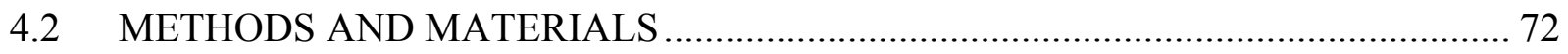

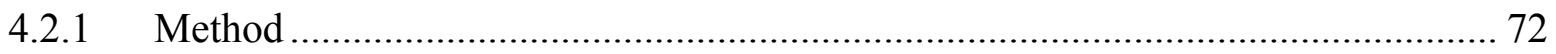

4.2.2 Purposeful Sampling ..................................................................................... 73

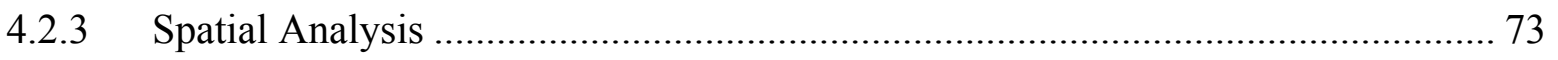

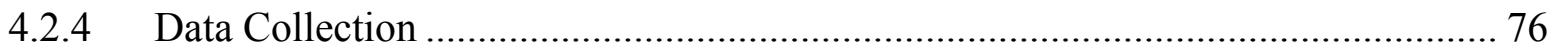

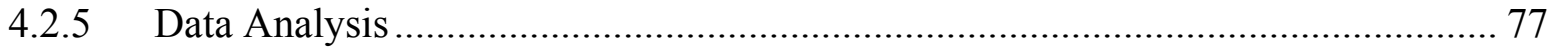

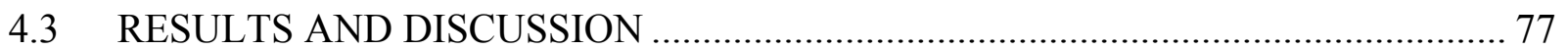

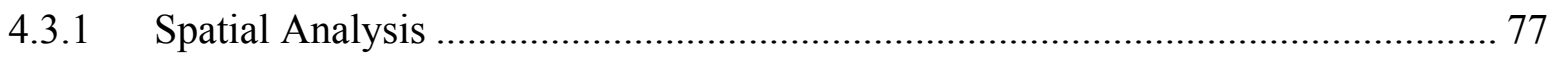

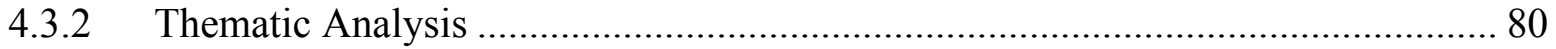

4.3.3 Wood Product Use in Green Building .................................................................... 81

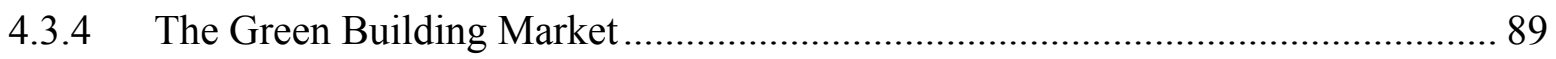

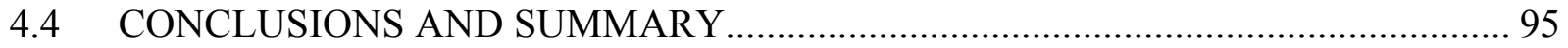

4.5 FUTURE RESEARCH RECOMMENDATIONS ...................................................... 96

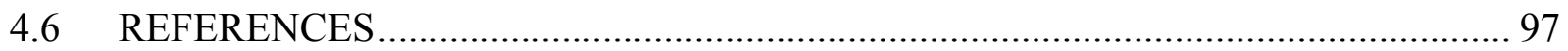

5 SECONDARY WOOD PRODUCT MANUFACTURERS PERCEPTION AND

MARKETING EFFORTS TOWARD THE GREEN BUILDING MARKET.................... 102

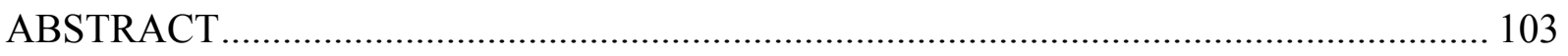

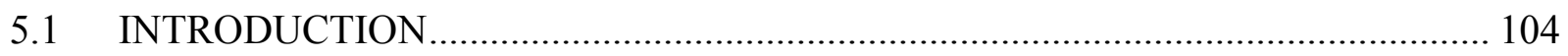

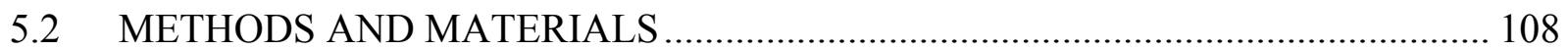

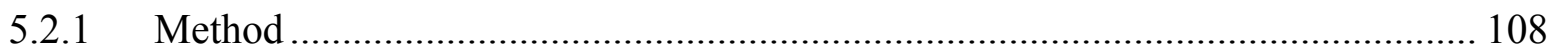

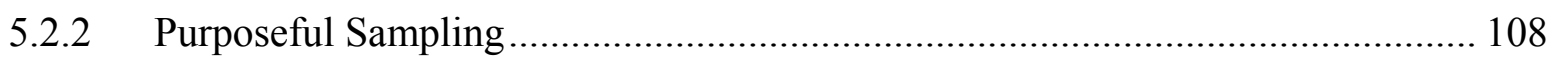

5.2.3 Question Development.................................................................................. 110

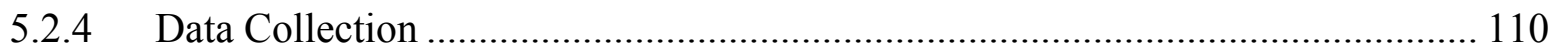

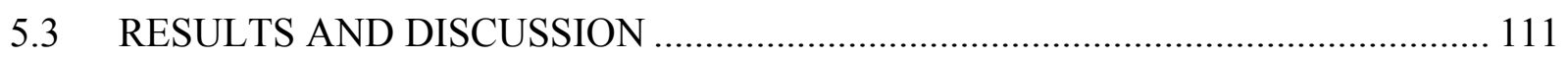

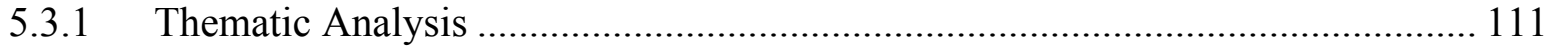

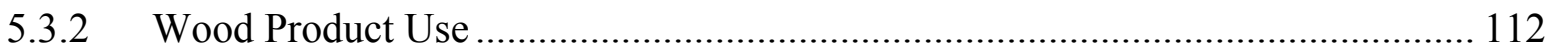

5.3.3 Wood Product Markets and Marketing Efforts................................................... 129

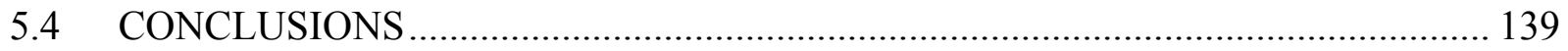

5.5 FUTURE RESEARCH RECOMMENDATIONS .................................................. 141 


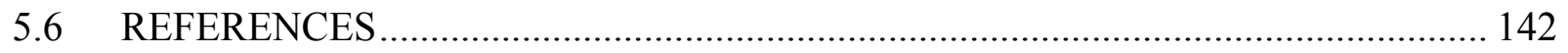

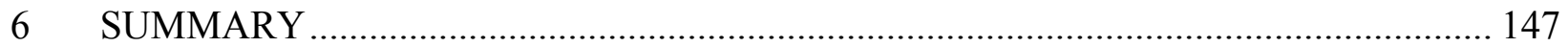

Appendix A - Survey of Wood Product Usage in Affordable Housing Construction .............. 150

Appendix B - Spatial Regression ................................................................................ 163

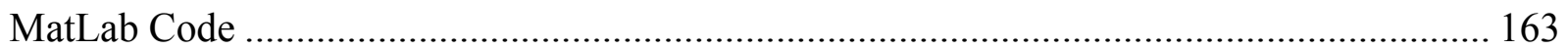

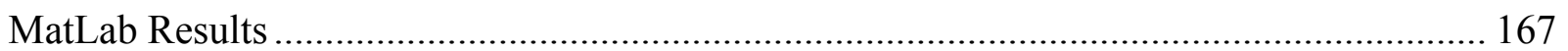

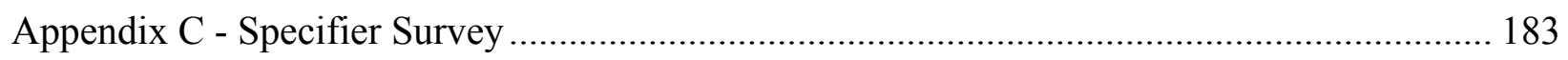

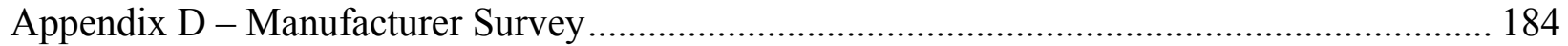

Appendix E - Specifier and Manufacturer Perceptions....................................................... 185 


\section{LIST OF TABLES}

Table 2-1. Factors related to AH builders purchasing certified wood products.

Table 2-2. Product media for marketing communications based on $\mathrm{AH}$ and Non-AH builder

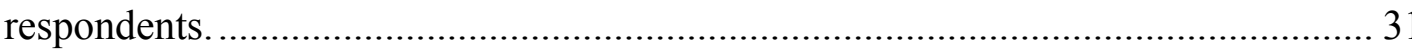

Table 3-1. Threshold distances for the five analysis regions............................................. 46

Table 3-2. Results from SDM regression analysis for all commercial LEED certified projects in the continental U.S. that obtained the certified wood credit. ................................... 57

Table 4-1 Thematic Analysis Results of Material Specifier Interviews. ................................ 81

Table 5-1. Thematic Analysis Results of Secondary Wood Product Producer Interviews ....... 112 


\section{LIST OF FIGURES}

Figure 2-1. Number of employees reported by affordable housing respondents $(n=10) \ldots \ldots \ldots \ldots .18$

Figure 2-2. Total revenue reported by affordable housing respondents $(n=10) \ldots \ldots \ldots \ldots \ldots \ldots \ldots . . . . . . . .19$

Figure 2-3. Percentage of affordable housing business reported by affordable housing builders

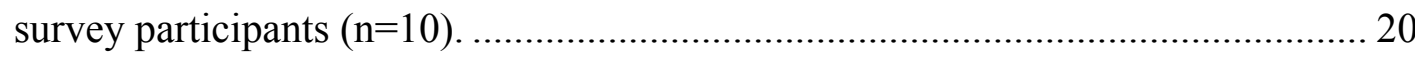

Figure 2-4. Percentage of affordable housing builder respondents who specifically looked to purchase certified wood products $(\mathrm{n}=10)$.

Figure 2-5. Affordable housing builder respondents who plan to use certified wood products in the future $(n=10)$.

Figure 2-6. Percentage of affordable housing builder respondents who followed a green building program $(n=10)$.

Figure 2-7. Willingness of affordable housing builder respondents to pay more for local and certified wood products (CWPs) $(\mathrm{n}=10)$......

Figure 2-8. Willingness of nonaffordable housing builder respondents to pay more for local and certified wood products (CWPs) $(n=50)$.

Figure 3-1. Four census regions of the United States. 45

Figure 3-2. LEED certified projects that obtained the certified wood credit, locations in sample data by year 2000, 2005, 2010, and August 2013

Figure 3-3. Moran's I for all LEED certified projects that obtained the certified wood credit in sample data throughout the U.S. and the four census regions.

Figure 3-4. Hot Spot locations of statistically significant $(p<0.05)$ clustering of counties containing LEED certified projects that obtained the certified wood credit in the continental U.S.

Figure 3-5. Hot Spot locations of statistically significant $(\mathrm{p}<0.05)$ clustering of counties containing high numbers of LEED certified projects that obtained the certified wood credit in the four major U.S. census regions.

Figure 4-1. Moran's I by year for all LEED certified projects and LEED certified projects that obtained the certified wood credit - both within the Appalachian Region. 78

Figure 4-2. Hotspot counties for commercial LEED certified projects in the Appalachian region that received the certified wood credit. 80 


\section{INTRODUCTION}

The depletion of finite energy resources that sustain suitable living conditions for a growing world population has helped drive the popularity and practice of "green" building construction. Moreover, environmental concerns continually shape the methods and materials used in building construction. As a result, an increasing focus has been placed on the use of sustainable (i.e. green) materials. Material attributes such as: sustainability, life cycle impacts, greenhouse gas emissions (GHG) and resource extraction process impact help guide industry and academia during the developments of new products and processes.

Green building is defined by the Environmental Protection Agency (EPA) as: “...the practice of creating structures and using processes that are environmentally responsible and resource-efficient throughout a building's life-cycle from siting to design, construction, operation, maintenance, renovation and deconstruction" (EPA 2011). The application of materials that incorporate conscious utilization and low environmental impacts, mitigate environmental and human health concerns such as ozone depletion, interior air quality, and have low embodied emissions/energies can be used to help achieve green building.

Purchasing initiatives such as the Federal Environmentally Preferable Purchasing Program for projects that are funded either solely or partly by federal funds have been shown to influence builder's material choices (EPA 2000). In addition to the Federal Environmentally

Preferable Purchasing Program, there are non-governmental programs that also promote the use of sustainable building and building materials, such as green building initiative programs like Leadership in Energy and Environmental Design (LEED), Green Globes, and the National 
Association of Home Builders - National Green Building Standard (NAHB-NGBS). These programs help designers and builders by providing a guideline for minimizing energy requirements and environmental impacts of a building through material selection and building construction practices. These standards reward the use of construction materials with low environmental impacts - such as wood - by achieving points toward the overall building certification. Therefore, opportunities exist for wood product producers and distributors interested in pursuing green building projects for those who are participating in the environmental certification of wood products as well as those who do not obtain an environmental certification.

The use of green building programs for single family home construction has increased in terms of market share over the past several years and is expected to continue this trend (McGraw-Hill 2012). As a significant portion (24\%) of U.S. working households face a severe housing cost burden (Williams 2012), the affordable housing sector of the U.S. represents a large section of the single family home building market. Additionally, in many green building standards, the use of CWPs and non-certified wood products can help accumulate points needed to achieve certification. When applying for government funding, affordable housing builders have increased their compliance with green building standards in an effort to increase their funding success rate (Hlady and Wells 2010). Further investigation toward the use of woodbased materials in the affordable housing market may indicate a need for new wood-based materials and specific marketing approaches to meet the perceptions of builders.

The further development of markets for green building products, may serve to grow demand for a slumping forest products sector. A recent study (McGraw Hill 2013) indicates that the green market made up $48 \%$ of all 2012 building project activity in the US. The percentage of 
respondents from this research that have $60 \%$ or more of their total job portfolios in green building projects is expected to reach $53 \%$ in 2015 , up from $40 \%$ in 2012 . New commercial buildings, retrofits of existing buildings, and new institutional buildings are the top sectors reported where respondents plan to build green projects. Consequently, there may be increased opportunities for wood products manufacturers to supply the green building market by providing products suitable to gain points towards building certification in various green building standards; particularly those manufacturers providing environmentally certified wood materials recognized by green building standards.

Current hardwood markets for Appalachian producers consist of both national and international sales. With the recent economic down turn and decrease in new housing starts in the U.S., more research has been directed at improving international markets (Naka et al. 2009; Wang et al. 2010a; and Wang et al. 2010b). However, with the emerging green building sector, new local and regional opportunities need to be explored. To further expand the use of Appalachian wood based products in green building, it is important to understand current building practices, material specifications, and market demands. Collaboration with manufacturing and design professionals may indicate applications where wood-based products can be used to meet supply and demand needs found in the green building market and the forest products industry, respectively.

Identifying geographic locations with increased use of green building construction may help to indicate spatial growth patterns and offer the location of prime sales markets for interested wood products manufacturers and distributors. Furthermore, identifying the perceptions of material specifiers who are involved in the green building industry may also help guide manufacturers' sales tactics. Promoting wood products to meet the needs and influence 
specifiers' perceptions may help to further penetrate the green building market. Additionally, understanding the current perceptions and sales tactics of manufacturers toward the green building sector may uncover perception gaps between the two groups. Identifying these gaps may help the forest products industry better market their products to specifiers involved in green building.

Demand for green buildings in the U.S. is growing and hardwood products are a potentially important material source to help meet this demand (Chapter 4). The Appalachian region of the United States offers a sustainable, renewable wood material resource capable of filling this need. Further research is needed to understand material specifiers' perceptions toward the materials they prefer for green building construction. Focusing on the Appalachian region where few studies of these kinds have been reported could provide valuable insight to hardwood material suppliers that will allow them to adapt their products to meet the current and future demand. Determining these perceptions from the demand side will indicate the marketing and promotion direction necessary for hardwood suppliers to properly position their products to have the greatest success for inclusion in future building projects.

Specifically, this project investigates: 1) affordable home builder demand for green and certified wood products, 2) spatial analysis of certified wood product use in commercial LEED green building projects, 3) specifier perception of wood product use in commercial LEED certified projects in the Appalachian region, and 4) secondary wood product manufacturer's perception and marketing efforts toward the green building market. 


\section{REFERENCES}

EPA. (2000). Federal Pioneers: Environmentally Preferable Purchasing Success Stories From the Federal Government. http://www.epa.gov/epp/pubs/case/FedPioneers.pdf. Accessed January 2, 2013.

EPA. (2011). Green Building - Basic Information. United States Environmental Protection Agency. Available at: http://www.epa.gov/greenbuilding/pubs/about.htm. Accessed 7 November 2011.

Hlady, N. and W. Wells. 2010. Green building criteria in low-income housing tax credit programs - 2010 analysis. http://www.globalgreen.org/docs/publication-164-1.pdf. Accessed June 9, 2011.

McGraw-Hill. 2012. Green home builders and remodelers survey. http://www.builtgreenpierce.com/media/pdf/2012\%20McGrawHill\%20BldrRem\%20Sum mary\%20Sheet.pdf. Accessed February 26, 2013.

McGraw Hill Construction (2013). World Green Building Trends. http://analyticsstore.construction.com/index.php/world-green-building-trendssmartmarket-report-2013.html (15 September 2014).

Naka, K., B.A. Parsons, and A.L. Hammett. (2009). Hardwood lumber industry in the Appalachian region: Focus on exports. The Forest Chronicle. 85(1):75-81.

Wang, J., J. Wu, D.B. DeVallance, and J.P. Armstrong. (2010a). Appalachian hardwood product exports-An analysis of the current Chinese market. Forest Products Journal. 60(1):94-99. 
Wang, J., J. Wu, and J.P. Armstrong. (2010b). An analysis of Appalachian hardwood products in the Chinese Market. Wood Fiber Science. 42(1):71-80.

Williams, L. 2012. An annual look at the housing affordability challenges of America's working households. http://www.nhc.org/media/files/Landscape2012.pdf . Accessed June 13, 2012. 
2 AFFORDABLE HOME BUILDER DEMAND FOR GREEN AND CERTIFIED WOOD PRODUCTS 


\section{ABstract}

Annual new housing starts in the United States decreased dramatically between 2005 and 2012. Consequently, products that are heavily tied to new housing starts, such as flooring, cabinetry, and moulding produced from Appalachian hardwoods, have suffered a corresponding decrease in demand. There may be opportunities to increase demand for these products, however, as demand in the green building sector increases. The present study evaluated the demand for certified wood products (CWPs) and green-labeled wood products in the central Appalachian affordable housing sector in 2011. The study also identified price premiums that affordable home builders were willing to pay for CWPs and green-labeled wood products. Results indicated that 50 percent of affordable housing respondents were planning future CWP purchases. Results also indicated that 62 percent of affordable housing respondents followed some type of green building standard. Additionally, more than 70 percent of affordable housing respondents suggested a willingness to pay an additional percentage for CWPs and local wood products. The use of CWPs was found to result from a combination of builder and homeowner preference. Last, of the housing builders who looked to purchase CWPs locally in 2011, only 17 percent were not able to locate the materials for purchase. The low percentage of unsuccessful procurement suggests CWPs are well distributed in areas near affordable housing projects in central Appalachia.

\subsection{INTRODUCTION}

According to 2010 National Association of Home Builder (NAHB) estimates, residential construction in the United States employs approximately 3.4 million people per year (Siniavskaia 2012). In terms of predicted lumber usage, softwoods account for 26.9 billion board feet (bf) and 
hardwood lumber for 6.5 billion bf (Howard and McKeever 2012). The large gap between softwood and hardwood usage can be explained by the relative uses of the two groups. Softwood lumber is used more in structural applications, such as framing and supporting members, while hardwood lumber is used more in aesthetic applications, such as flooring, cabinetry, and moulding (Forest Products Laboratory 2000).

Current hardwood markets for Appalachian producers consist of both national and international sales. The recent economic downturn and decrease in new housing starts in the United States has limited utilization of wood products, consequently lowering employment rates in this industry. For example, there was an 8 percent drop in forest industry employment as a percentage of total manufacturing employment between 2005 and 2010 in West Virginia alone (Woodall et al. 2011). However, it is currently unknown how reduced employment in hardwoodproducing states has impacted the availability of wood products in the Appalachian region.

Rising interest over environmental issues has resulted in an increased focus on using sustainable (i.e., "green") materials in building construction (Ortiz et al. 2009). Since 2005, green building has retained a relatively consistent market share of total single-family residential building in the United States. The stability of this market share can be partially attributed to a sales increase of US\$11 billion between 2005 and 2011 for green building, relative to the dramatic decrease of US\$217 billion for all single-family residential sales for the same period. Also, there is a projected increase for new green home construction and home renovations from 2011 to 2016 of from 17 percent to between 29 and 38 percent (McGraw-Hill 2012). This increase in popularity of green construction projects presents an opportunity for wood products to gain significant market share in the green economy. To take full advantage of these opportunities, however, more research is needed to evaluate customer demand for wood products 
labeled as sustainable in niche markets, such as the affordable housing (AH) sector of residential building. According to the US Department of Housing and Urban Development (USHUD 2013), housing costs should account for no more than 30 percent of a household's total income to be considered affordable. As of February 2012, the USHUD estimates that 12 million renters and homeowners allocate 50 percent or more of their household incomes to housing costs (USHUD 2013). Of the 45 million working households in the United States in 2010, 10.6 million (24\%) face a severe housing cost burden (Williams 2012). Therefore, the AH sector represents a large portion of the housing industry and provides both local and regional opportunities for expanding the use of wood products that have yet to be fully explored.

In addition to providing suitable living conditions for people with financial difficulties, AH provides positive impacts for both local job creation and economic growth. For example, when a new, 100-unit $\mathrm{AH}$ apartment complex is built, 80 new construction jobs are created, 42 local jobs are supported by local spending during construction, and 32 local jobs (ongoing) are supported by occupant spending post-construction (NAHB 2010). To further categorize the jobs created and later maintained by the influx of $\mathrm{AH}$ developments; approximately 70 percent are directly tied to the construction industry during development, approximately 30 percent of jobs in wholesale and retail trade are supported by the spending of locally earned wages, and approximately 32 percent of wholesale and retail trade jobs are supported by occupants postconstruction.

Identifying demand for certified wood products (CWPs) has been a popular focus in recent studies. Anderson and Hansen (2004a) showed that undergraduate respondents preferred products accompanied by environmental certification when prices were kept consistent between certified and noncertified products. Similarly, Anderson and Hansen (2004b) also found that 
plywood consumers preferred Forest Stewardship Council (FSC)-certified products to uncertified products when prices were equal. A 2 percent increase in price to FSC-certified products, however, negated the environmental preference. In western Canada, survey respondents indicated interest in future purchases of value-added CWPs as long as the quality and variety were equal to the competing noncertified products (Kozak et al. 2004). Vlosky et al. (2009) found that according to survey respondents, manufacturer sales of CWPs doubled between 2002 (10\%) and 2008 (21\%). Additionally, results from a distributor-focused survey have shown that CWPs are accepted by most retailers and that 69 percent of the respondents expect future sales volumes of CWPs to increase (Perera et al. 2008). To our knowledge, however, no study has focused on identifying demand for and availability of CWPs for use in AH projects, especially in the central Appalachian region. Therefore, the present research was undertaken to help identify existing and potential markets for wood-based products, both certified as sustainable and noncertified, in $\mathrm{AH}$ markets.

To expand the use of Appalachian wood-based products in affordable building, it is important to understand both current building practices and material specifications. By collaborating with industry professionals, potential niches can be identified for renewable, sustainable materials, such as wood-based products, in building construction and renovation. Information obtained as a result of this research may help Appalachian wood product producers further understand their local marketplace and guide them in marketing decisions aimed at increasing the use of their products. Additionally, the information obtained through the present study is intended to assist Appalachian hardwood product producers in meeting consumer demand for wood-based products. 
The goal of this project was to assess the current and future demand for and local availability of CWPs and green-labeled wood products that are used in AH construction within the central Appalachian region. A secondary goal was to identify preferential differences between builders who attribute a small portion of their business to $\mathrm{AH}$ construction and builders who attribute the majority of their business to AH construction (i.e., Federation of Appalachian Housing Enterprises [FAHE]). Specific objectives were to evaluate the demand for CWPs and green-labeled wood products in the central Appalachian AH sector as well as additional price percentages that AH builders are willing to pay for CWPs and green-labeled wood products.

\subsection{METHODS AND MATERIALS}

To reach a diverse and unbiased sampling group, a list of approximately 2,800 builders in the central Appalachian region was compiled from the NAHB, state home builder lists, county and city code departments, and building associations. These builders were identified through direct contact via telephone conversations and e-mail correspondence as well as research of online databases. The target area included all or a portion of the following states: Virginia, Kentucky, North Carolina, Ohio, Pennsylvania, South Carolina, Tennessee, and West Virginia. Builders were assembled into a database, and a random sample of prospective respondents was generated from the full data table. The sample included 700 of the initial 2,794 general builders as potential respondents of a formal mail survey. This sample of 700 builders was randomly selected to be representative of the target population as well as to lower project costs. This survey was developed to elicit responses related to business activity conducted during the calendar year of 2011. 
Initial surveys were sent to the selected mailing addresses. In the event a survey was retuned due to insufficient $(n=2)$ or incorrect $(n=39)$ address information, personal correspondence in the form of phone calls and e-mails was employed to obtain updated information. These actions resulted in the addition of updated contact information for three businesses.

Given the FAHE is primarily focused on AH construction, all 50 members were chosen, in addition to the 700 general builders, to take part in the same survey. FAHE builders were cross-referenced with the 700 randomly chosen builders to ensure no duplications in the sampled populations. The data collected from these respondents were combined with general builder respondent data. Inclusion of the FAHE helped the study gain a broader perspective of builders who specialize in the AH sector. Additionally, surveying the FAHE members allowed comparison between builders who are specifically focused on AH (i.e., FAHE members) and general builders who may only attribute a portion of their business to AH projects. Comparison between these two groups of builders could indicate preferential differences in the use of wood products. Obtaining contact information for subcontracting companies of FAHE members was pursued but relatively unsuccessful. Therefore, FAHE members were asked to distribute the surveys to their subcontracted builders in the event they did not perform the construction themselves.

Surveys (Appendix A) were designed and distributed according to suggestions of the Tailored Design Method (Dillman 2000). A notification to potential respondents was distributed followed by the actual survey for both the general builders and the FAHE members. After a 3week period, follow-up correspondence accompanied by a second questionnaire was sent to general builders to encourage survey response from nonrespondents. Also after a 3-week period, 
follow-up correspondence was sent to FAHE members to encourage additional survey response. A second questionnaire was not sent to FAHE members, however, because this group was redistributing the surveys to their builders on our behalf and did not require additional surveys. Lastly, an appreciation letter and token of appreciation were distributed to all who did respond.

The response rate for completed surveys received was calculated by dividing the total number of completed surveys by the number of contacted units less the ineligible units and the refusals:

$$
\mathrm{rr}=\frac{\mathrm{cs}}{\mathrm{cu}-\mathrm{iu}-\mathrm{rf}}
$$

where $\mathrm{rr}$ is the response rate, $\mathrm{cs}$ is the number of completed surveys, $\mathrm{cu}$ is the number of contacted units, iu is the number of ineligible units, and $\mathrm{rf}$ is the number of refusals.

The survey contained 23 multiple-choice questions that were designed to alleviate confusion and minimize the respondent's commitment and completion time. Questions were designed using information discussed with various stakeholders who assist builders within the Appalachian region with finding CWPs and to reflect our research interests. Response selections were a combination of closed-ended and partially closed-ended (i.e., including "other" and space for open-ended response), unordered categories. These surveys were peer-tested to assure these attributes and to minimize uncertainties and grammatical errors. The peer group for this survey consisted of experienced colleagues at other land grant institutions that routinely survey the wood products industry. Constructs used in the questionnaire included demographics, product purchasing preferences, competition factors (Wagner and Hansen 2004), and willingness to pay (Ozanne and Vlosky 1997). Types of questions asked included company demographics (i.e., number of employees, revenue, and percentage of business from AH construction), current and 
future demands for CWPs, factors that influence the use of CWPs, use of green building standards, and pricing of local wood products and CWPs. To further investigate the relationship among builder characteristics and their product consumption relationships, $\chi 2$ tests of independence were performed. These tests were used to examine the relationship between observed and expected data (Dowdy et al. 2004).

When categorical response counts are low or expected counts are less than five, combining adjacent categories has been suggested as one method to increase frequency counts for more robust analysis (Linacre 2002, Dowdy et al. 2004, Robichaud et al. 2012). Therefore, due to the relatively low number of categorical responses, data from both $\mathrm{AH}$ and non- $\mathrm{AH}$ builders were grouped into two "number of employees" groups ( 1 to 5 and $\geq 6$ ). Similarly, respondent data were also divided into groups by willingness to pay an additional amount for CWPs and also for locally sourced wood products ( $0 \%$ more and $\geq 1 \%$ more). Separating the data into these groups resulted in a sufficient number of responses to perform a $\chi^{2}$ test to determine if 2011 business characteristics as given by survey respondents, such as number of employees or amount of revenue, were factors indicative of the willingness to pay additional percentages for CWPs and local wood materials. However, Fisher's exact test was used in the few instances when predicted cell sizes were fewer than five responses.

All survey respondents were initially segregated by whether or not they participated in AH projects in 2011. Because this group was the main focus of the present study, many of the results are based on their responses. In some instances, however, both groups of respondents (AH and non-AH builders) were combined to reflect the perceptions of builders in the central Appalachian region. 


\subsection{RESULTS AND DISCUSSION}

\subsubsection{Response rate}

General builders.-For the 700 surveys sent throughout the central Appalachian region to general builders, 60 completed surveys were received, and 41 were returned as nondeliverable. Three returned surveys were omitted from the sample set due to lack of questions answered $(\mathrm{n}=$ 1) or inconsistency in answering $(n=2$; i.e., answering questions related to $\mathrm{AH}$ while previously answering there was no involvement with $\mathrm{AH}$ ). Therefore, the adjusted response rate calculated for general builders was 9.1 percent. Further analysis of the 60 received surveys from the general builder group indicated that $10(16.7 \%)$ of the respondents were involved in $\mathrm{AH}$ construction in 2011.

FAHE members.-Five surveys were sent to each of the 50 FAHE members. Completed surveys were received from 12 different FAHE members, one per member, and resulted in a response rate of 24 percent. For the purpose of calculating response rate for this group, the total number of contacted units used was 50. As expected, all 12 FAHE member respondents indicated they were involved in AH construction in 2011. The number of subcontractors that had been employed by the FAHE members in 2011 was unknown. FAHE members were asked to distribute additional surveys to their subcontracted builders. FAHE members were not asked or responsible for implementing Dillman's method to ensure maximum survey response. Direct contact with this potential group of subcontracted companies might have resulted in a higher response rate, as second mailings and follow-up correspondence could have influenced potential respondents to complete the survey. A total number of 22 subcontractor survey respondents ( $\sim 31 \%$ of all survey respondents) indicated they were involved in AH projects in 2011. 


\subsubsection{Survey responses}

Results from demographic analysis indicate that 50 percent of the $\mathrm{AH}$ respondents employed an average of one to five people in 2011 (Figure 2-1). Additionally, 27, 18, and 27 percent of the $\mathrm{AH}$ respondents indicated that their total revenue for 2011 was between US\$100,000 and US\$500,000, between US\$500,000 and US\$1,000,000, and between US $\$ 1,000,000$ and US\$5,000,000, respectively (Figure 2-2). Of the AH respondents, 82 percent reported that more than 50 percent of their total 2011 construction business was attributed to $\mathrm{AH}$ projects (Figure 2-3). 


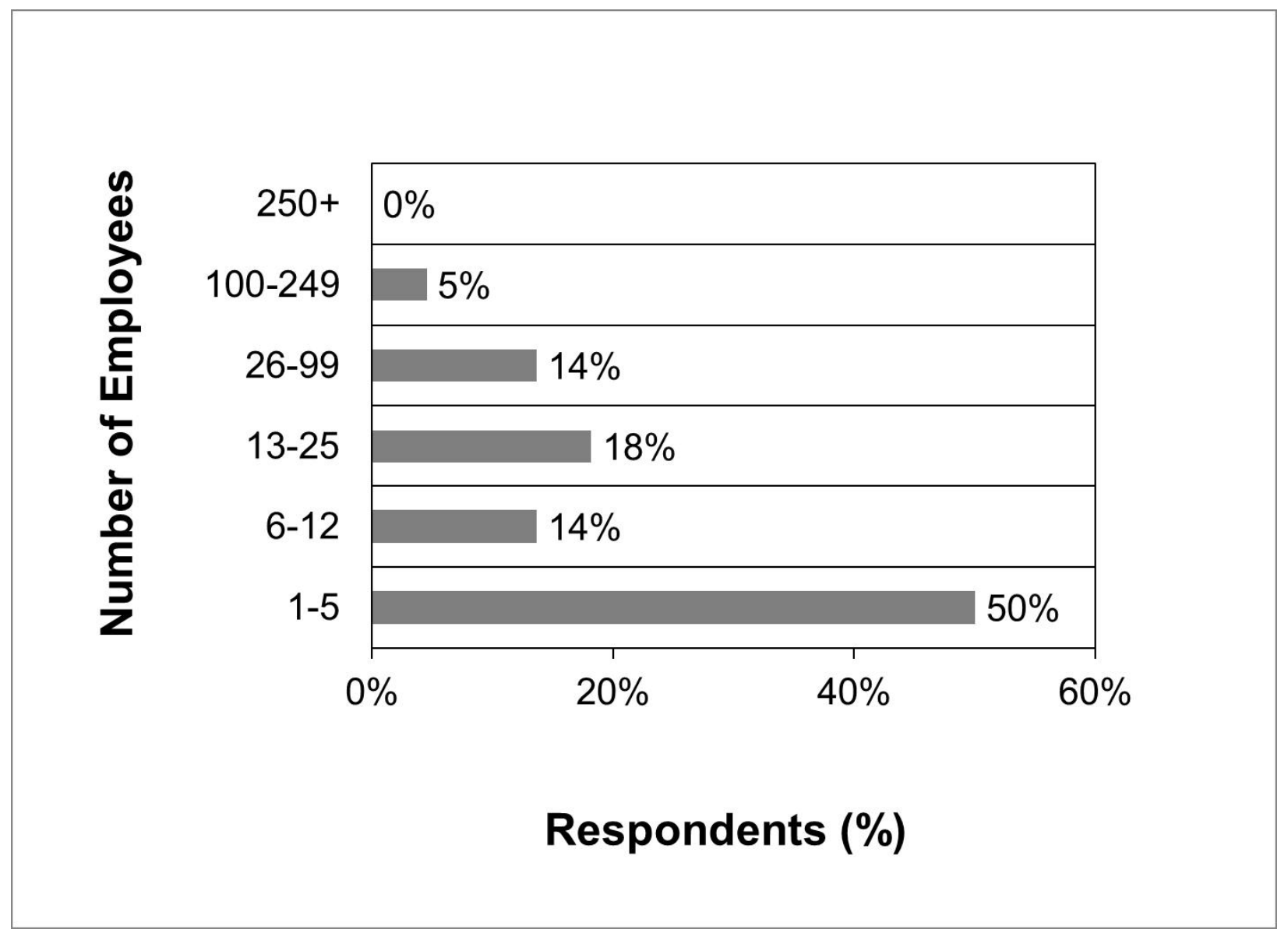

Figure 2-1. Number of employees reported by affordable housing respondents $(n=10)$. 


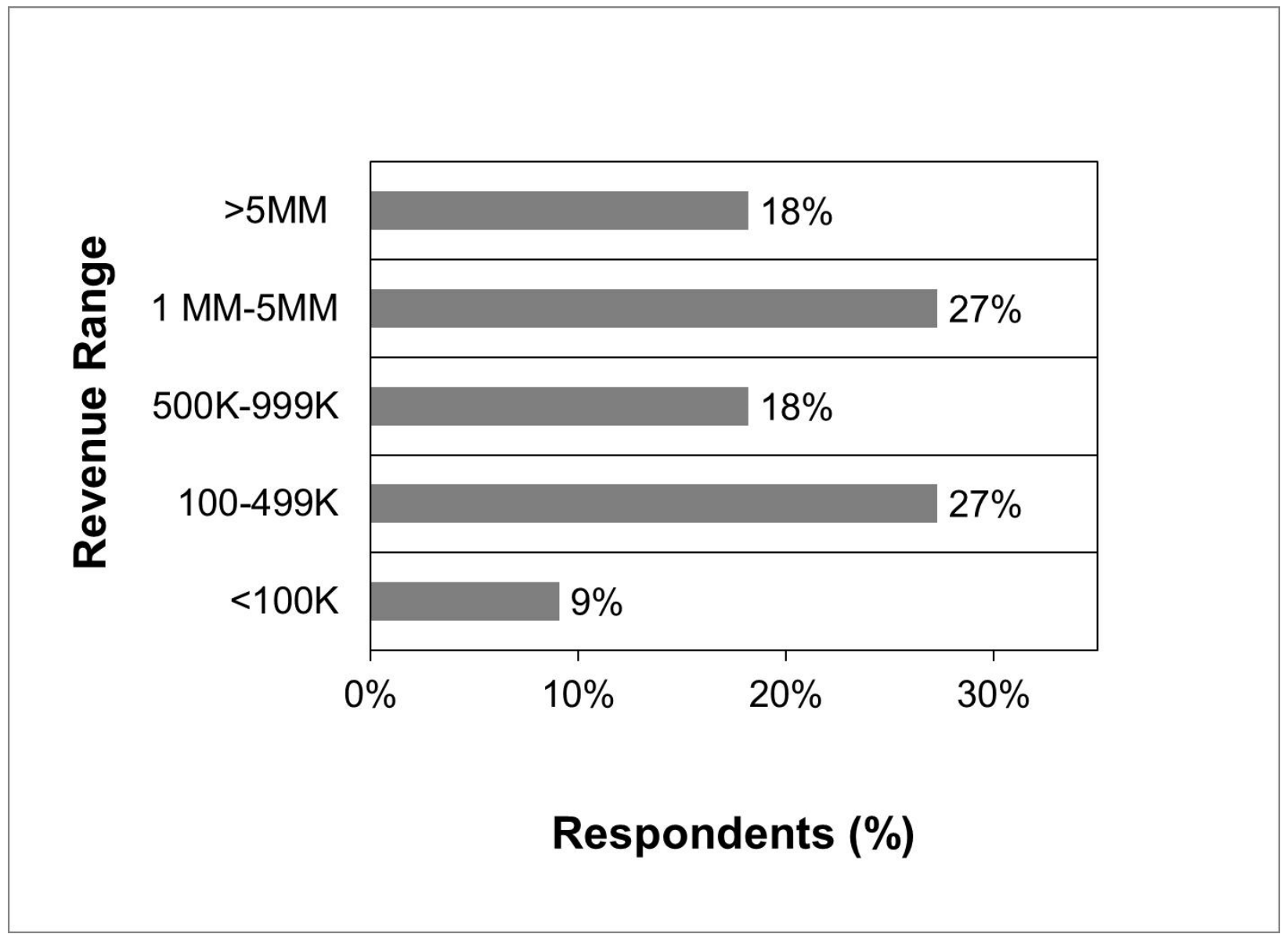

Figure 2-2. Total revenue reported by affordable housing respondents $(n=10)$. 


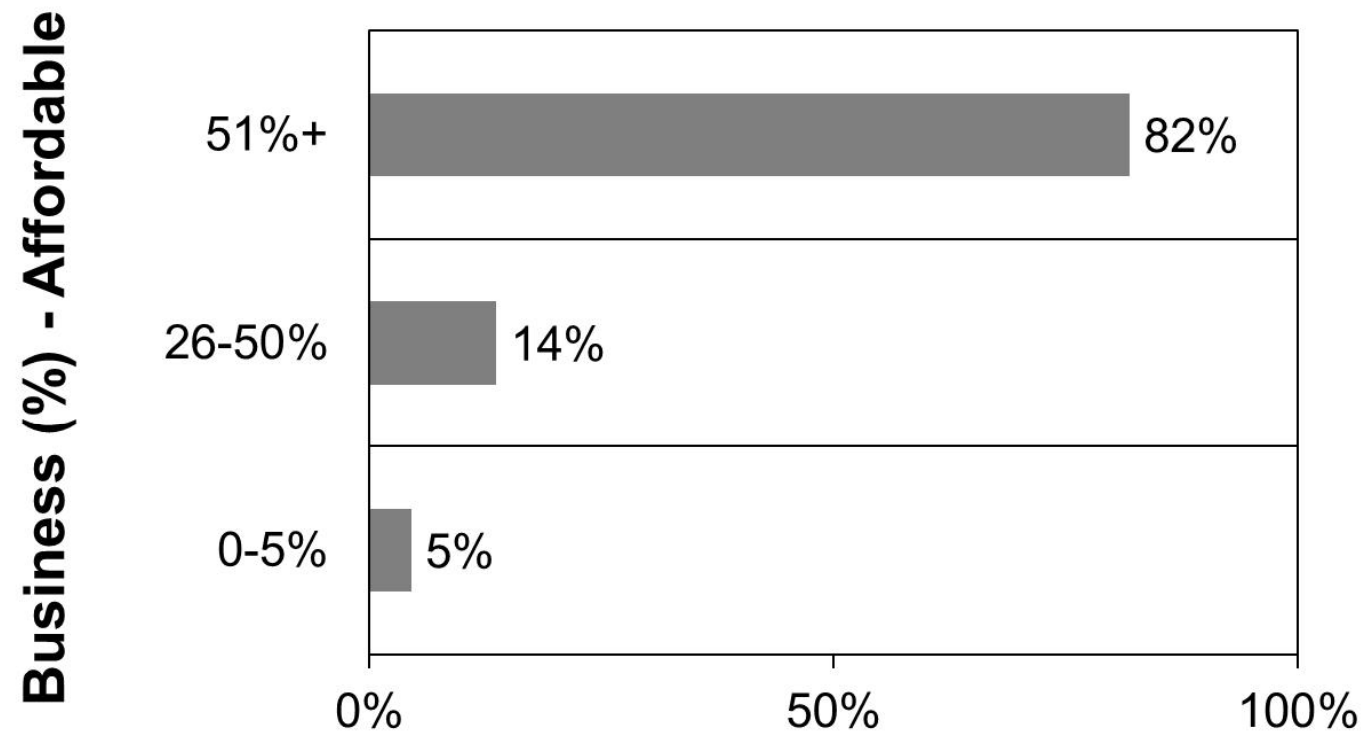

\section{Respondents (\%)}

Figure 2-3. Percentage of affordable housing business reported by affordable housing builders survey participants $(n=10)$.

According to AH respondents, only 14 percent specifically sought out CWPs for building construction projects (Fig. 4). However, 50 percent planned to use CWPs in the future (Fig. 5). The use of CWPs has been anticipated in other studies (Vlosky et al. 2009), in which 97 percent of respondents indicated continuing the sales of CWPs in the future. Additionally, results from a study conducted by Perera et al. (2008) show that 69 percent of survey respondents predicted some degree of increase in CWP sales volume over the 5 years following the study. A 27 percent difference was noted for AH respondents who weren't sure if they will specifically looking to 
purchase CWP between the time of this study and future intentions. This difference in past and future CWP purchasing may have resulted from clients requiring the use of CWPs in past projects instead of CWPs being the builder's own initiative. In many green building standards, the use of CWPs can help accumulate points needed to achieve certification. Annual increases of compliance with green building technologies between 2005 and 2010 have been seen by AH builders (Hlady and Wells 2010) as a way to maximize their success rate when applying for government funding, such as Low Income Housing Tax Credits.

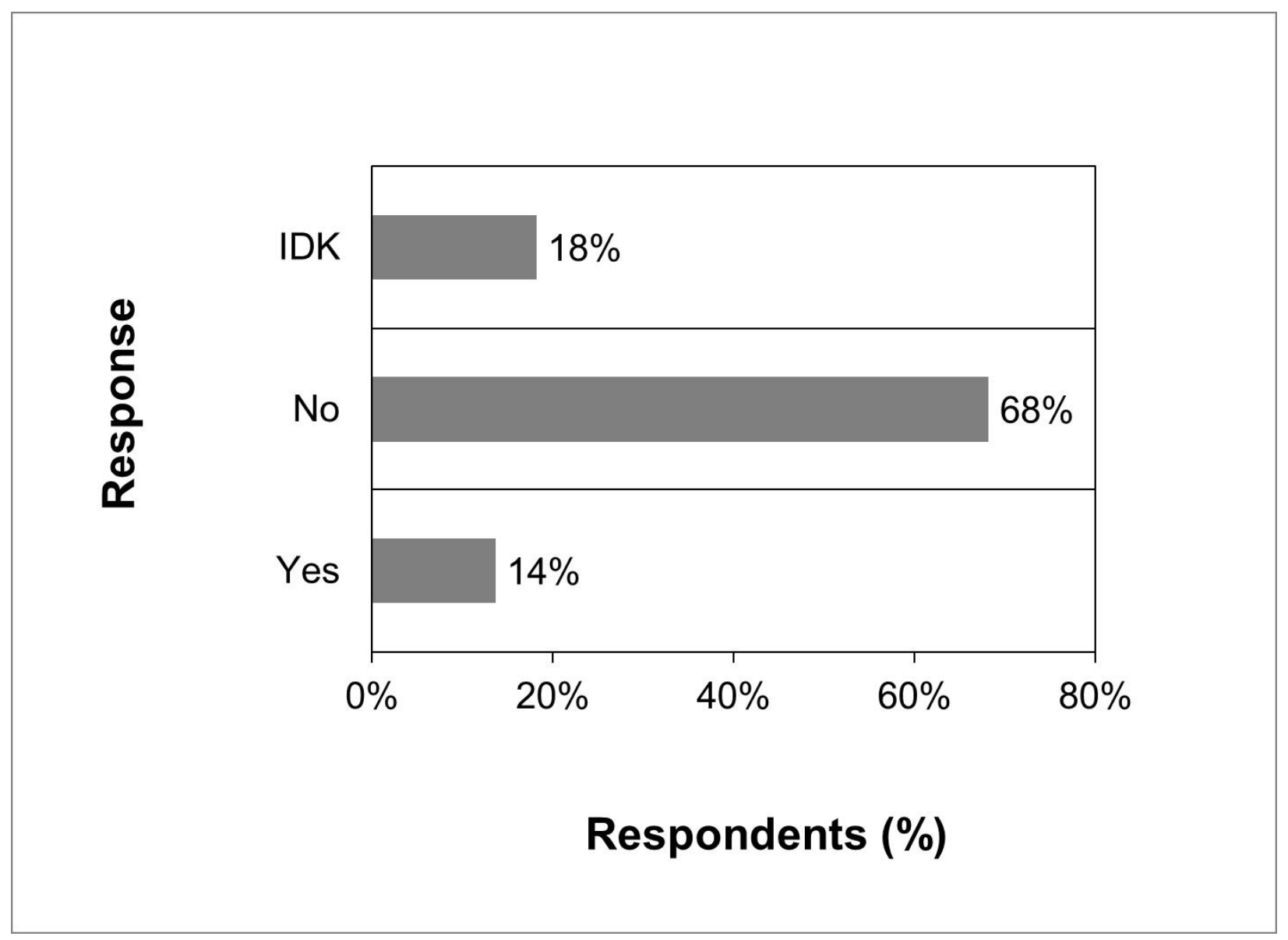

Figure 2-4. Percentage of affordable housing builder respondents who specifically looked to purchase certified wood products $(\mathrm{n}=10)$. 


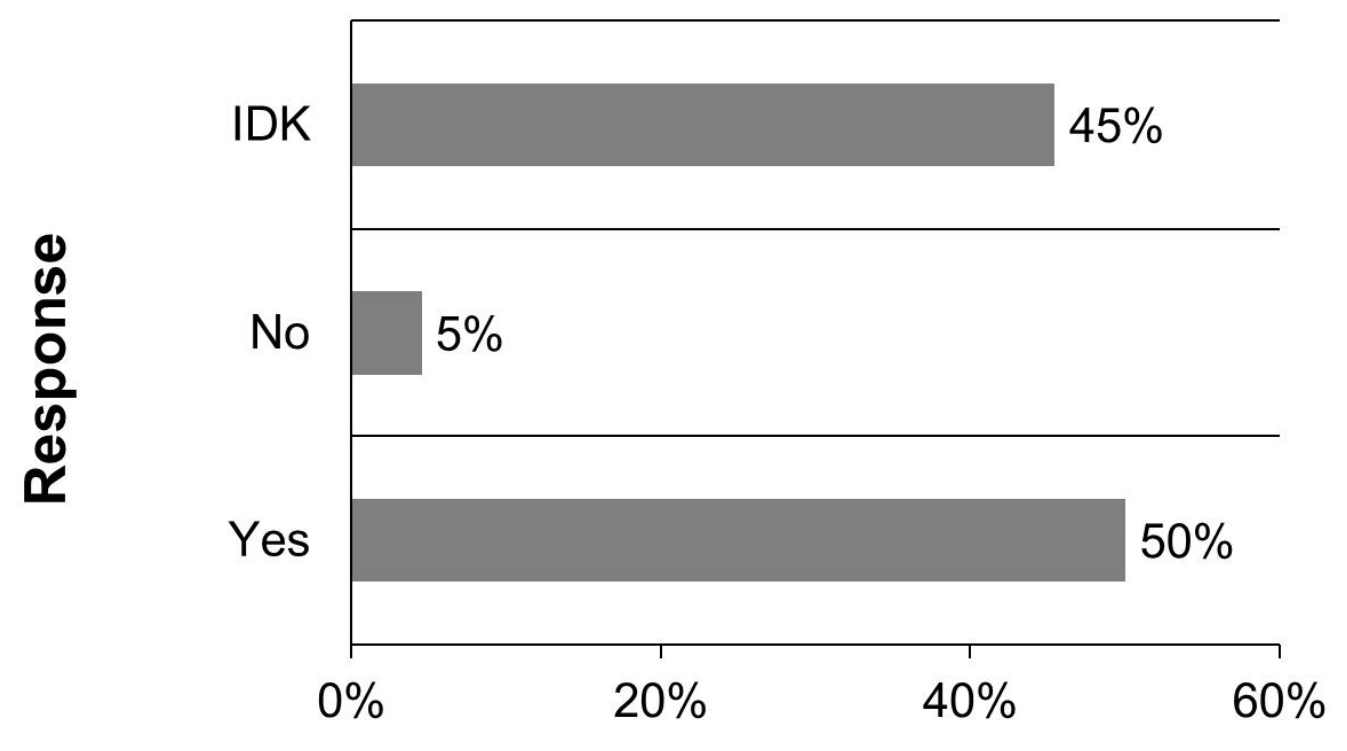

\section{Respondents (\%)}

Figure 2-5. Affordable housing builder respondents who plan to use certified wood products in the future $(\mathrm{n}=10)$.

When indicating factors influencing whether or not to purchase CWPs, respondents were asked to select all factors that applied. In addition to 14 predetermined choices, the option to choose "other" and provide individual responses was made available. AH respondents indicated that the top seven, as determined by percentage of respondents per category, influential factors regarding the purchase CWPs were environmental benefits, building programs mandating CWPs, customers requesting CWPs, cost of CWPs being too high, customers not requesting CWPs, cost of CWPs being appropriate, and increased quality of CWPs (Table 2-1). The most popular reason 
$\mathrm{AH}$ respondents chose to use CWPs was the environmental benefits of the materials. This response indicates that the distribution of environmental information concerning CWPs has reached and affected the opinions of AH builders. Results such as these are not uncommon given the overall customer understanding of CWPs has increased (Ozanne and Vlosky 2003). Additionally, given environmental benefits are of importance, wood product manufacturers should emphasize environmental marketing to increase their potential market share with these customers. Likewise, because 23 percent of the respondents indicated a lack of experience or knowledge of CWPs, there may be an opportunity to better inform AH builders about the attributes of and benefits from using CWPs in construction projects.

Table 2-1. Factors related to AH builders purchasing certified wood products.

\begin{tabular}{cc}
\hline \hline Influence & Response (\%) \\
Environmental Benefit & $64 \%$ \\
Building programs mandate CWPs & $36 \%$ \\
Customers request CWPs & $36 \%$ \\
Cost of CWPs too high & $32 \%$ \\
Customers don't request CWP & $32 \%$ \\
Cost of CWPs is appropriate & $27 \%$ \\
Increased quality of CWPs & $27 \%$ \\
\hline \hline
\end{tabular}

Sixty-two percent of AH respondents reported following some type of green building program in 2011. Of the 13 respondents who followed a green building program, five indicated 
particular programs that were followed. In three of these instances, builders followed more than one green building program. The green building programs that were used by these survey respondents were Green Advantage (two respondents), Building Performance Institute (two respondents), Energy Star (two respondents), State Housing Finance Agency's “Green” Requirements (one respondent), and Healthy Home (one respondent). Interestingly, no respondent indicated the use of the predetermined choices on the survey; instead, respondents opted to select the "other" category and write in the green building program(s) they followed. Choices provided in the survey with reference to the type of green building program used in 2011 were National Green Building Program, NAHB; Leadership in Energy and Environmental Design, US Green Building Council; Green Globes, Green Building Initiative; EarthCraft; and Enterprise Green Communities. Although these programs are widely used and well known, the AH respondents appeared to be following other programs that may not have the publicity of the larger programs specifically listed in the survey. These results may indicate that AH builders have specific motivations toward the use of green building standards. Perhaps funding agency preference, personal experience, or cost may be a factor.

Of the 62 percent of AH respondents who used a green building standard, 26 percent followed a green building program because it was required by their client (Figure 2-6). A majority of the $\mathrm{AH}$ clients represented in this survey population were not specifying their house to be built to any green building program. However, AH builders were still following green building standards even though the client was not requesting this component. These results suggest that builders may have been able, to some degree, to convince their clients about the benefits from using a green building standard. 


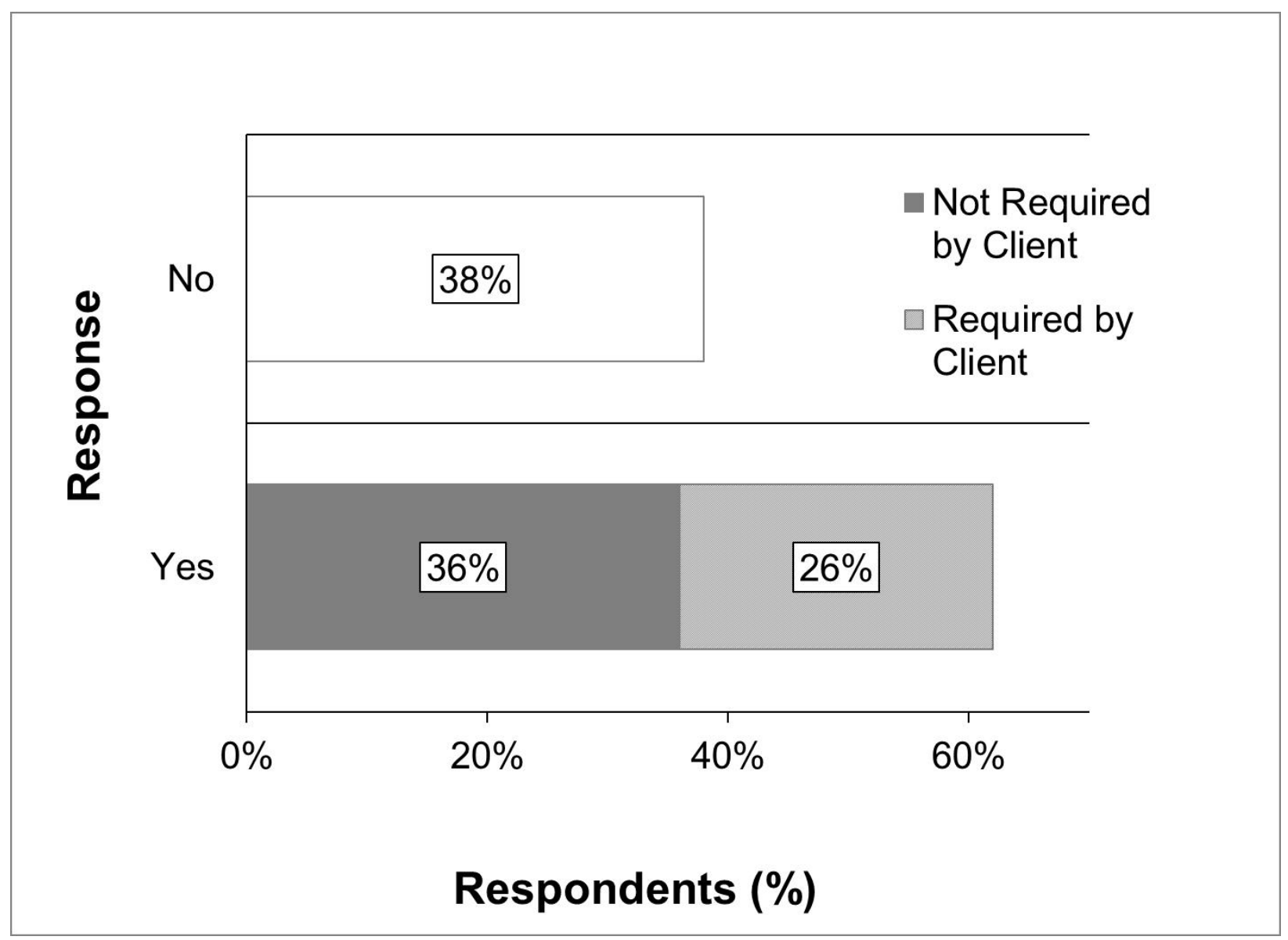

Figure 2-6. Percentage of affordable housing builder respondents who followed a green building program $(n=10)$.

Cumulatively, 77 percent of $\mathrm{AH}$ builder respondents indicated a willingness to pay some additional cost for CWPs (Figure 2-7). These results agree with previous surveys that indicated customers may be willing to pay an additional amount for CWPs. Ozanne et al. (1999) found that 75 percent of consumer respondents indicated a willingness to pay more for CWPs. Aguilar and Vlosky (2007) found that an average of 62 and 66 percent of respondents were willing to pay an additional amount for various CWP items in 1995 and 2005, respectively. Although survey respondents in the present study indicated a willingness to pay higher prices for both certified and local wood products, actual buying behaviors could be different. Previous research 
(Anderson and Hansen 2004a, 2004b) has shown that consumer buying behavior shifts toward purchasing non-CWPs when the price of comparable CWPs are higher. Consumer willingness to pay more for CWPs could inspire more raw material manufactures, such as sawmills, to start or increase their participation in certification of wood and wood fiber. However, factors such as market size and cost of entry would need to be individually addressed by businesses to properly assess the associated costs and benefits. To increase manufacturer participation in certification programs, however, would require a portion of the increased revenue from the sales of CWPs to go directly to the manufacturer through willingness for a supplier to pay more for CWPs. Survey results suggest there may be opportunities within the $\mathrm{AH}$ sector for wood products producers to offset their product certification costs through price increases and also the potential increased revenue. 


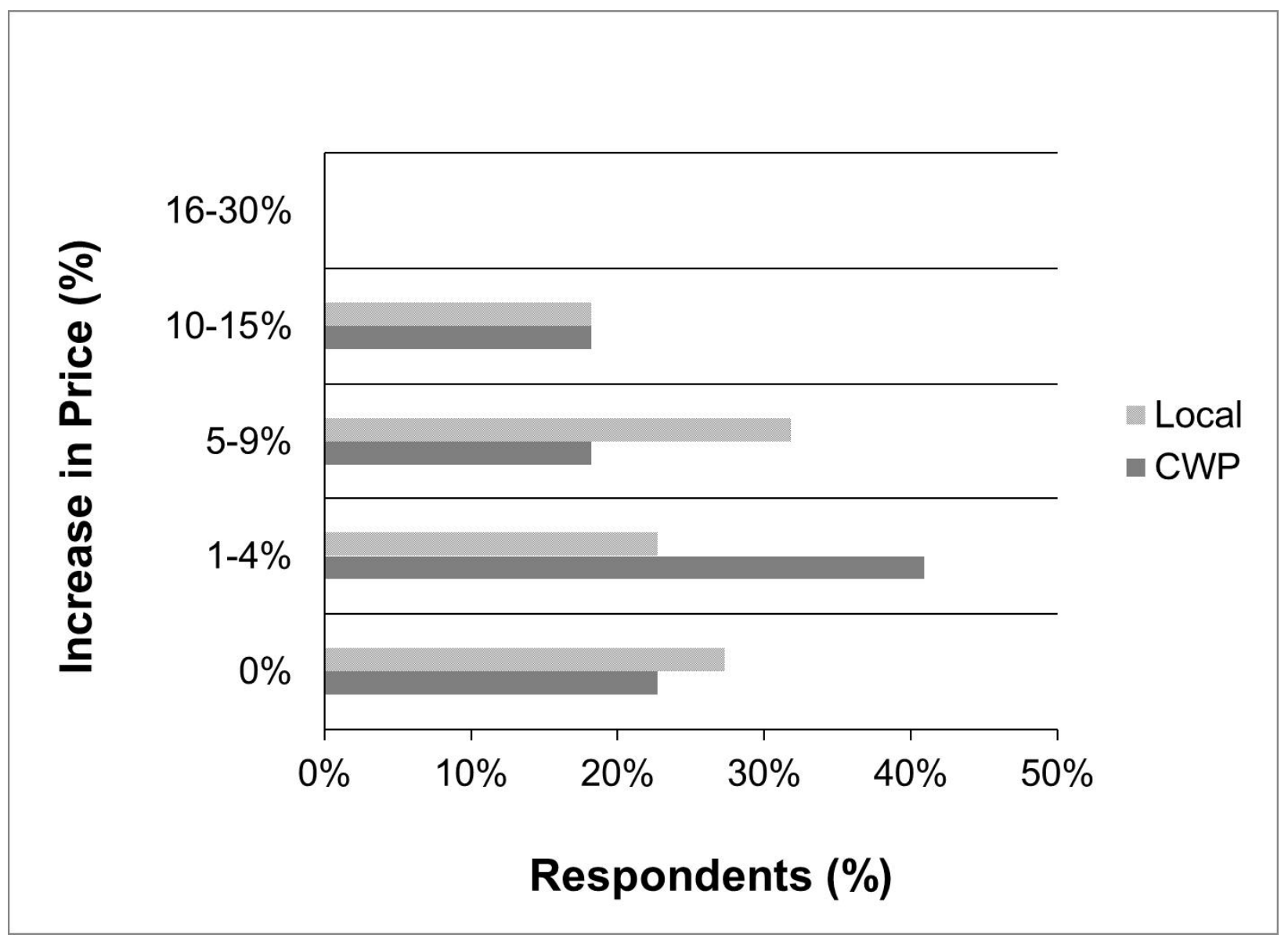

Figure 2-7. Willingness of affordable housing builder respondents to pay more for local and certified wood products (CWPs) $(\mathrm{n}=10)$.

Similar results were found for AH respondents who indicated that they would be willing to pay more for locally sourced materials. Specifically, 73 percent of AH builder respondents indicated a willingness to pay some additional cost for locally sourced materials (Figure 2-7). From the results, it appears there is interest in locally sourced materials, and AH builders would likely pay more for them. Survey results received from non-AH builders were also analyzed to determine their willingness to pay additional prices for local materials and CWPs. Of non-AH builder respondents, 74 and 78 percent indicated a willingness to pay an additional cost for 
CWPs and local materials, respectively (Figure 2-8). Both AH and non-AH builders appeared to have a similar willingness to pay more for CWPs and local materials. In terms of CWPs, the survey results indicated that AH builders (77\%) were more likely to pay a higher price for CWPs compared with non-AH builders (74\%). In terms of local materials, the survey results indicated that non-AH builders (78\%) were more likely to pay a higher price for local materials compared with AH builders (73\%). Going one step further, a potential market for local wood product and/or CWP producers to target is construction businesses with yearly revenue under US $\$ 500,000$. Survey results indicate that businesses in this demographic are more likely to pay an additional price for local wood products and/or CWPs. However, further investigation into factors such as potential market size and cost of entry would need to be addressed to fully assess if the benefits outweigh the costs for individual businesses. 


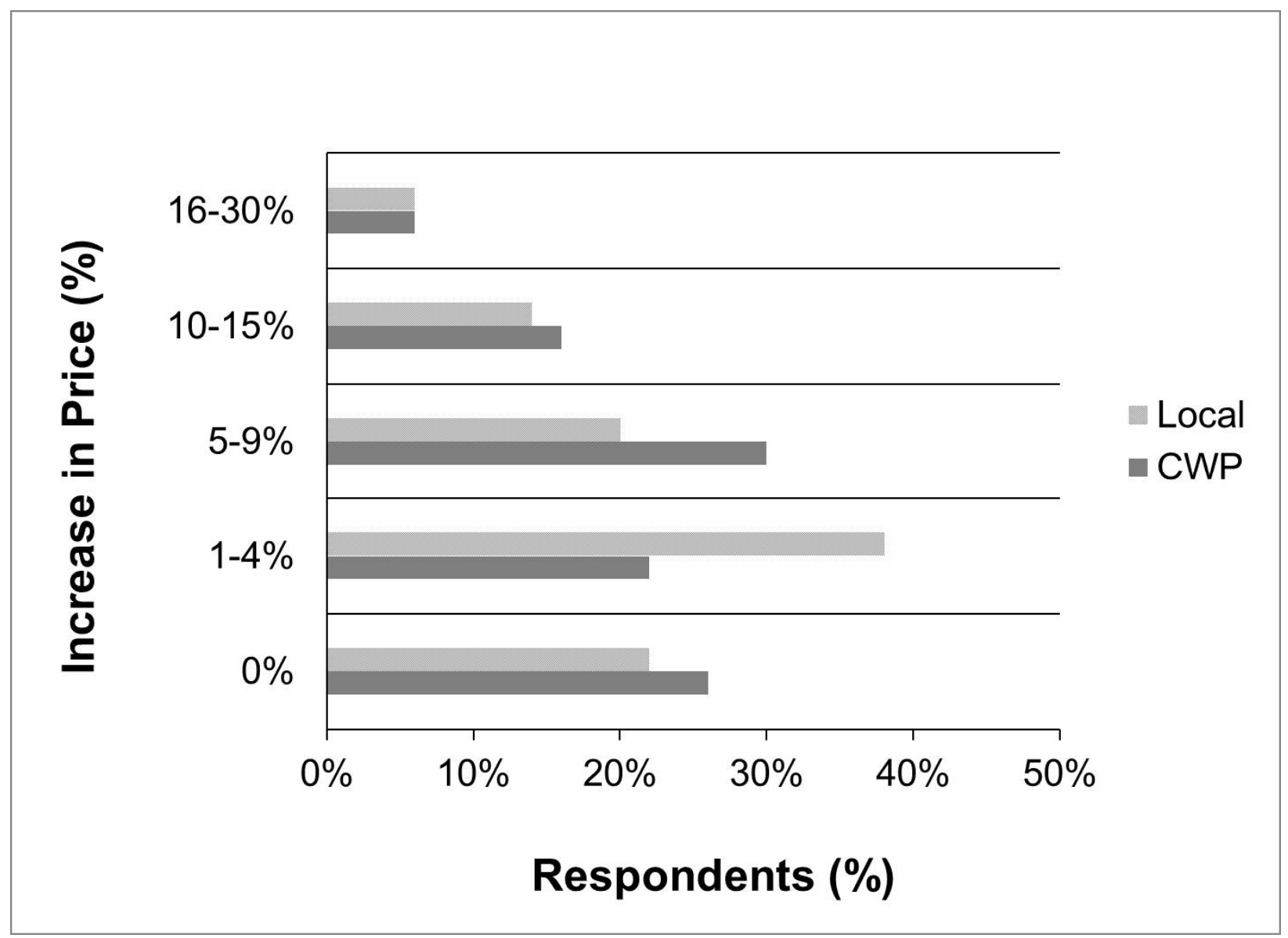

Figure 2-8. Willingness of nonaffordable housing builder respondents to pay more for local and certified wood products (CWPs) $(n=50)$.

To further determine if CWPs were available to builders locally, respondents were asked if they were looking to buy any CWPs that could not be found locally. Results indicated that 17 percent of all survey respondents were looking to purchase CWPs locally but found these products were not available. Of the respondents who could not find CWPs locally, the top five CWPs that were in demand were framing lumber (75\%), oriented strandboard (75\%), plywood (58\%), pressure-treated lumber (58\%), and doors (58\%). These results indicate that the majority of builders who wanted to use CWPs could find them locally. Also, the size of the company, in terms of both number of employees and amount of revenue, had some effect on the ability to find 
CWPs locally. For example, 20 percent of respondents from companies with five or fewer employees were unable to find CWPs in their local markets, while only 11 percent of respondents from companies with six or more employees were unable to find CWPs in their local markets. Additionally, 26 percent of respondents from companies with less than US\$500,000 in pretax revenue for 2011 were unable to find CWPs in their local markets, while only 10 percent of respondents from companies with revenue higher than US\$500,000 were unable to find CWPs in their local markets. These results suggest that larger companies have greater access to locally available CWPs. However, there remains a portion of local demand that is not currently being met. Based on the results, there appears to be some market opportunities for local retailers. Specifically, there is a demand for locally available lumber and structural panels that have been certified to a sustainable forestry practice standard.

To better represent the building industry, respondents of both AH and non-AH builders were combined and analyzed to determine how they learned about new building products. Results indicated that builders were most likely to learn about new building products through local retailers (75\%) and Web sites (72\%; Table 2-2). Builders were least likely to hear about new building products through professional societies (47\%) and advertisements (40\%). While advertisements were last, many of the other listed sources likely used some type of advertisement in introducing new products. It was apparent, however, that Web sites and local retailers are an important media for marketing communication for introducing and promoting new wood products. This suggests that wood product companies should emphasize their Internet presence and their personal contact and relationships with local retailers when developing a marketing strategy for new products. 
Table 2-2. Product media for marketing communications based on $\mathrm{AH}$ and Non-AH builder respondents.

\begin{tabular}{cc}
\hline \hline Learning Source & Response (\%) \\
\hline Local Retailers & $75 \%$ \\
Websites & $72 \%$ \\
Magazines & $69 \%$ \\
Trade Shows & $54 \%$ \\
Professional Societies & $47 \%$ \\
Advertisements & $40 \%$ \\
\hline \hline
\end{tabular}

Impact of company size and revenue.-Survey results indicate that the size of the company, in terms of number of employees, had no statistically significant relationship $\left(\chi^{2}=\right.$ $0.3692, \mathrm{p}=0.5434)$ on whether or not the company was willing to pay an additional percentage for CWPs. Similarly, the same analysis for locally sourced wood products showed no statistically significant relationship (Fisher's exact test, $p=0.0625$ ) between the company size, in terms of number of employees. These results indicate that of the survey respondents, the number of company employees may not be a significant factor in determining the willingness to pay an additional amount for locally sourced wood products. However, a relationship did exist between the revenue a company receives and whether or not that company is willing to pay additional amounts for both CWPs and locally sourced wood products. When analyzed by willingness to pay more for CWPs, there was a statistically significant relationship $\left(\chi^{2}=9.9890, p=0.0016\right)$ that indicated survey respondents with revenues less than US\$500,000 in 2011 were more likely to pay additional amounts for CWPs. Similarly, when analyzed by willingness to pay more for locally sourced wood products, there was a statistically significant relationship $\left(\chi^{2}=8.8874, \mathrm{p}=\right.$ 
0.0029 ) that suggested survey respondents with revenues less than US $\$ 500,000$ in 2011 may be more likely to pay additional amounts for locally sourced wood products.

Affordable housing builders: FAHE versus general.-A Fisher's exact test was used to determine if responses from FAHE builders varied greatly from other AH builders. Specifically of interest was whether or not general builders shared some of the same perceptions and experiences of those tied solely to the AH sector. Particular comparisons between FAHE and non-FAHE AH respondents were analyzed for the following scenarios: revenue, looking to purchase CWPs, plan to purchase CWPs in the future, following a green building program, client requirement to follow a green building program, and willingness to pay more for CWPs as well as locally sourced products. Results suggested that FAHE builders showed a statistically significant higher tendency $(\mathrm{p}=0.045)$ to follow a green building program because of the client's request compared with general AH builders. This difference could be the result of FAHE's indication to implement more green building programs in their construction (Survis 2012). The remainder of the results, however, indicated that there was no statistically significant difference between respondents who were FAHE builders and general builders involved in AH construction in 2011 .

\subsection{SUMMARY AND CONCLUSIONS}

The present research focused on local and CWP demand in the AH sector within central Appalachia. Specifically, the study looked at the attributes related to green building and perceptions and to use of local and CWP materials. While the number of AH builders is small in relation to all builders, our survey population was representative of those in the central 
Appalachian region. The addition of information from non-AH builders allowed a larger comparison of the local availability and market potential of CWPs in Appalachia.

The major conclusion was that AH builders tended to favor the use of CWPs. In general, results indicated that in 2011, 50 percent of AH respondents planned on purchasing CWPs in the future. Also, 74 and 77 percent of all non-AH builder and $\mathrm{AH}$ builder respondents, respectively, were willing to pay more for CWPs. Furthermore, 73 and 78 percent of all AH builder and nonAH builder respondents, respectively, were willing to pay more for locally sourced materials, indicating a possible niche market for wood products manufacturers. However, only the respondents with annual company revenues of less than US\$500,000 showed a statistically significant relationship toward paying additional amounts for CWPs and local wood products. Manufacturers may also gain local market share by providing CWPs, because 17 percent of all survey respondents were unable to purchase CWPs locally.

The results of the present study also indicated that wood product manufacturers should focus on environmental marketing to improve the demand of CWPs. This result is similar to findings of Kozak et al. (2004), who reported an increased interest in CWPs after potential customers were informed of the environmental benefits related to using this type of product. Also, when introducing new products, results suggest that wood product manufacturers should focus their efforts on Internet marketing and providing information to local retailers. Papadopoulos et al. (2010) also found the Internet to be a highly effective means by which to promote CWPs. It appears that the use of CWPs and green building standards is gaining more attention in the AH sector. With increased interest in energy efficiency, it is expected that in the future, builders will construct more homes that meet one or more of the green building standards. An increase in green building construction could position the wood products industry for 
significant growth by providing the only current environmentally certified structural building material (Bowyer 2008).

The present research indicated that non-AH builders in the central Appalachian region also showed interest in CWPs and locally sourced wood products. Future work should look more closely at non-AH builders and their preferences regarding use of CWPs, use of green building standards, and current and future purchasing decisions for different types of wood products.

\section{Acknowledgments}

This report resulted from a collaborative effort between Rural Action and the FAHE, West Virginia University Division of Forestry and Natural Resources, and the Appalachian Hardwood Center. Funding for this research was provided by the Ford Foundation through RUPRI Center for Rural Entrepreneurship (Wealth Creation in Rural Communities) and Rural Action. The primary function of the funding is to improve economic development in rural Appalachian regions.

\subsection{REFERENCES}

Aguilar, F. X. and R. P. Vlosky. 2007. Consumer willingness to pay price premiums for environmentally certified wood products in the US. Forest Policy Econ. 9:1100-1112.

Anderson, R. and E. Hansen. 2004a. The impact of environmental certification on preferences for wood furniture: A conjoint analysis. Forest Prod. J. 54(3):42-50.

Anderson, R. and E. Hansen. 2004b. Determining consumer preferences for ecolabeled forest products: An experimental approach. J. Forestry 102(4):28-32. 
Bowyer, J. L. 2008. The green movement and the forest products industry. Forest Prod. J. 58(7/8):6-13.

Dillman D. 2000. Mail and Internet Surveys. The Tailored Design Method. John Wiley \& Sons, New York. 464 pp.

Dowdy S., S. Weardon, and D. Chilko. 2004. Statistics for Research. John Wiley \& Sons, Hoboken, New Jersey. 627 pp.

Forest Products Laboratory. 2000. Wood Handbook: Wood as an Engineering Material. University Press of the Pacific, Honolulu, Hawaii.

Hlady, N. and W. Wells. 2010. Green building criteria in low-income housing tax credit programs—2010 analysis. http://www.globalgreen.org/docs/publication-164-1.pdf. Accessed June 9, 2011.

Howard, J. L. and D. B. McKeever. 2012. US forest products annual market review and prospects, 2008-2012. Research Note FPL-RN-0328. USDA Forest Service, Forest Products Laboratory, Madison, Wisconsin.

Kozak, R., D. Cohen, J. Lerner, and G. Bull. 2004. Western Canadian consumer attitudes towards certified value-added wood products: An exploratory analysis. Forest Prod. J. 54(9):21-24.

Linacre J. 2002. Optimizing rating scale category effectiveness. J Appl. Meas. 3(1):85-106.

McGraw-Hill. 2012. Green home builders and remodelers survey. http://www.builtgreenpierce.com/media/pdf/2012\%20McGrawHill\%20BldrRem\%20Sum mary\%20Sheet.pdf. Accessed February 26, 2013. 
National Association of Home Builders (NAHB). 2010. The local economic impact of typical housing tax credit developments. http://www.nahb.org/fileUpload_details.aspx?contentTypeID=3\&contentID=35601\&sub ContentID=265044. Accessed June 10, 2011.

Ortiz, O., F. Castells, and G. Sonnemann. 2009. Sustainability in the construction industry: A review of recent developments based on LCA. Constr. Build Mater. 23:28-39.

Ozanne, L., H. Bigsby, and R. P. Vlosky. 1999. New Zealand consumer perceptions and willingness to pay for environmentally certified forest products. N. Z. J. Forestry 43(4):17-23.

Ozanne, L. and R. Vlosky. 1997. Willingness to pay for environmentally certified wood products: A consumer perspective. Forest Prod. J. 47(6):39-48.

Ozanne, L. and R. Vlosky. 2003. Certification from the US consumer perspective: A comparison of 1995 and 2000. Forest Prod. J. 53(3):13-21.

Papadopoulos, I., G. Karagouni, M. Trigkas, and E. Platogianni. 2010. Green marketing-The case of Greece in certified and sustainably managed timber products. EuroMed J. Bus.. 5(2):166-190.

Perera, P., R. P. Vlosky, M. A. Dunn, and G. Hughes. 2008. US home-center retailer attitudes, perceptions and behaviors regarding forest certification. Forest Prod. J. 58(3):21-25.

Robichaud F., A. Richelieu, and R. Kozak. 2012. Wood use in nonresidential construction: An exploratory research of the roles of media and content in direct marketing. Wood Fiber Sci. 44(4):394-411. 
Siniavskaia, N. 2012. Residential construction employment across states and congressional districts. http://www.nahb.org/generic.aspx?genericContentID=178434. Accessed December 12, 2012.

Survis, E. 2012. A brighter path forward: The intersection of green construction and affordability. http://www.fahe.org/wp-content/uploads/ABrighterPath.pdf. Accessed November 2, 2012.

US Department of Housing and Urban Development (USHUD). 2013. Affordable housing. http://portal.hud.gov/hudportal/HUD?src=/program_offices/comm_planning/affordableho using. Accessed February 14, 2013.

Vlosky, R., R. Gazo, D. Cassens, and P. Perera. 2009. Changes in value-added wood product manufacturer perceptions about certification in the United States from 2002-2008. Drvna Industrija 60(2):89-94.

Wagner, E. and E. Hansen. 2004. A method for identifying and assessing key customer group needs. Indust. Mark. Manag. 33(7):643-655.

Williams, L. 2012. An annual look at the housing affordability challenges of America's working households. http://www.nhc.org/media/files/Landscape2012.pdf . Accessed June 13, 2012.

Woodall, C. W., R. J. Piva, K. E. Skog, P. J. Ince, and W. G. Luppold. 2011. An assessment of the downturn in the forest products sector in the northern region of the United States. Forest Prod. J. 61(8):604-613. 


\section{SPATIAL ANAL YSIS OF CERTIFIED WOOD PRODUCT USE IN COMMERCIAL LEED GREEN BUILDING PROJECTS}




\section{ABSTRACT}

There is a growing demand for green building products within the United States. Because of this increased demand and interest in green products, there exists potential for wood products manufacturers to gain additional market share opportunities within the green building sector. The overall objective of this research was to use spatial analysis techniques to evaluate the growth of green building projects and the use of certified, wood products within these projects. The focus of this research was on green building projects certified as part of the U.S. Green Building Council's (USGBC) Leadership in Energy and Environmental Design (LEED) that obtained the certified wood credit. Using spatial analysis techniques, the research was able to identify geographic areas where wood products are used and awarded points towards green building certification. Results indicated a trend of commercial LEED certified projects that obtained the certified wood credit to be more geographically concentrated over time. The research also identified various "Hot Spot" county clusters throughout the U.S. for commercial LEED certified projects that obtained certified wood materials. A spatial econometric regression analysis resulted in significant explanatory variables such as population of a county; obtaining LEED credits in material reuse, recycled material content, composite wood and agrifiber products and regional material; and the density of FSC certified product manufacturers within 100 miles. The results of the research are expected to help improve the availability of wood products by indicating potential green building marketing regions for wood products producers.

\subsection{INTRODUCTION}

The recent and forecasted growth of green building projects in the United States (U.S.) has identified the green building industry as a viable and increasing market for construction 
materials. A study published by McGraw Hill (2013) indicates that the green market made up $48 \%$ of all 2012 building project activity in the US. Additionally, respondents that have $60 \%$ or more of their jobs in green building projects expect that over one-half of their projects (53\%) will be green oriented in 2015, up from $40 \%$ in 2012 . The top-reported sectors where respondents plan to have green projects are new commercial buildings, retrofits of existing buildings, and new institutional buildings. Wood products manufacturers, particularly those providing environmentally certified wood materials, may have additional opportunities to include their products in various green building standards for specific point accumulations. The most recognized green building standard in the U.S. is the Leadership in Energy and Environmental Design (LEED) program developed by the United States Green Building Council (USGBC) (USGBC 2013.a) and currently lists 62,525 registered and certified projects (USGBC 2013b) in the U.S. alone. As a significantly popular standard in the green building industry, building projects pursuing LEED certification represent a large potential market for manufacturers of environmentally low-impact construction materials.

Wood products have low environmental impacts as compared to other construction materials such as steel or concrete (Gustavsson et al. 2006a, Gustavsson et al. 2006b, Lippke et al. 2004, Buchanan A. H. and Levine S. B. 1999, Peterson A.K and Solburg B. 2002, Peterson A.K and Solburg B. 2003, Upton et. al. 2008, Puettmann and Wilson 2005) and are rewarded by LEED through point generating categories used to obtain building certification. LEED specifically encourages the use of certified wood products (CWP) by granting one point for the use of Forest Stewardship Council (FSC) certified wood - provided that at least 50\% (cost based) of all wood based materials used in the project are FSC certified. Other opportunities for credit accumulation exist, in LEED versions 2009 and earlier, for uncertified wood products in 
categories such as recycled content, indoor environment quality, locally sourced materials, and rapidly renewable materials. The sales opportunities for wood product producers interested in pursuing green building projects under LEED, therefore, are not limited to those participating in FSC wood product certification.

The inclusion of certified wood products in the green building sector has been a recent topic of research interest. One study suggests that non-wood products may have an unfair advantage in that green building programs require wood to be accompanied by an environmental certification to comply with particular point generating categories (Bowyer 2007). However, the singling-out of wood products may also provide an opportunity to educate others on the environmentally friendliness of the material (Falk 2009). Recommendations have been made to manufacturers who may be interested in diversifying their current market with the green building sector by becoming certified to produce FSC labeled products and to track new marketplace developments (Tardif et. al. 2009). A different study focused in the western U.S., however, has suggested that design professionals have little incentive to include the use of wood products in the structural material selection of green buildings, even though wood was viewed as a more environmentally-friendly material when compared to steel and concrete (Knowles et al. 2011).

Spatial trends in LEED certified structures have also been a topic of recent studies. Kahn and Vaughn (2009) investigated the spatial distribution of LEED certified projects on a state level across the U. S. They further investigated zip code level data for the state of California and determined that the explanatory variable "environmental factor" (a combination of a zip code area's percentage of voters registered with the Green Party, votes in favor of Proposition 12, and votes in favor of Proposition 13) was significant for both the dependent variables "All” LEED ownership types and "Commercial” LEED ownership types with in a given zip code. A different 
study (Johansson 2011) determined the temporal and spatial growth of LEED projects in the U.S. and indicated an expansion diffusion pattern of growth at the regional level. This study also identified the Pacific coast region as the primary epicenter of green building in the U.S. followed by a secondary epicenter, New England. Cidell (2009) suggested that after the initial dispersion of LEED certified projects throughout the U.S., few new areas had obtained LEED certification of projects.

Although the general use of certified wood products in green building projects has been explored, there is no known research that explores the spatial and temporal growth of certified wood product utilization in the largest green building certifying standard in the U.S. (LEED). Research in this area could help FSC certified product manufacturers understand the geographic trends associated with the use of FSC certified products in the green building sector. Therefore, this research was undertaken to indicate the spatial growth trend of FSC certified wood product use in the LEED green building program as well as to identify specific geographic regions where the use is more prominent.

To identify geographic trends of FSC use in the LEED rating system, it is important to explore certified project locations as well as influencing factors that may be associated with that region. By collaborating with the USGBC and the FSC, the spatial growth of LEED projects utilizing FSC certified wood to gain points towards building certification may indicate specific areas of market potential for FSC manufacturers. Information obtained through this research may help identifying specific market areas for FSC product manufacturers and help to indicate geographic market conditions for future growth trends.

The goal of this project was to assess the spatial growth trends of LEED certified projects that were awarded the certified wood credit throughout the entire U.S. Specific objectives of this 
research were to: identify geographical distribution of LEED certified projects that were awarded the certified wood credit and to identify particular areas of concentrated use of CWPs in certified LEED projects.

\subsection{METHODS AND MATERIALS}

\subsubsection{Spatial Analysis}

The United States Green Building Council (USGBC), the governing entity for the LEED certification program, was contacted to obtain the most accurate and updated list of LEED certified projects. This dataset contained all non-confidential projects up to August 13th, 2013 that received LEED certification and were located in the U.S. LEED for Homes projects were not included in this dataset due to confidentiality restrictions. The dataset initially included 13,436 projects that were spread across 6 different LEED rating program types: LEED for Commercial Interiors (CI), LEED Core and Shell (CS), LEED Existing Building Operation and Maintenance (EBOM), LEED for Schools, LEED for Healthcare, and LEED for New Construction (NC). The interest of this project is to identify possible markets for wood product producers. As the two states Alaska and Hawaii are located outside of typical sales markets for most wood product producers in the continental U.S., the projects located in these states (105) were removed from the list of data as well as further analysis. Additionally, 2,007 of the projects listed as EBOM were removed from this study due to the lack of a certified wood credit available in the rating program. Therefore the remaining dataset contained 11,324 LEED certified projects. Of these certified projects, 3,456 projects obtained the certified wood credit and were defined as the working data set for this research. 
The following attributes specific to each project were also obtained: gross square footage of project, owner type, certification date, certification level, latitude and longitude coordinates of the project, industry type, space use type, rating program, and whether the project achieved the certified wood credit. Additionally, specific category achievements were obtained from the USGBC for material reuse recycled content, composite wood and agrifiber products, and regional materials. Although these categories may not be limited to the use of wood products specifically, there are opportunities for non-certified wood product use to satisfy these categories. Therefore, this data was acquired to explore possible relationships between the achievement of these category credits and that of the certified wood credit.

The individual projects located in the continental U.S. were geocoded and projected (USA Contiguous Equidistant Conic) and uploaded to Geographic Information Systems (GIS) software for spatial analysis. Individual project locations were grouped for analysis by joining the LEED data with the respective county centroid. It is understood that uniform areas (unlike county borders) are preferred when spatially analyzing data; however, county level analysis was applied due to the availability of complementary data such as electricity rates, income, population, and other census-based data obtainable on the same geographic level.

Spatial analysis was performed on the continental U.S. as a whole to indicate countrywide growth trends for LEED certified projects. Additionally, spatial analysis was individually performed on the four major census regions of the U.S., to provide greater detail of FSC certified wood product use in LEED certified projects for manufacturers and suppliers in these areas. Spatial analysis is inherently tied to the areas of observation. By dividing the continental U.S. into the four census regions (Figure 1), higher levels of detail are achieved in these regions as compared to results obtained when analyzing the entire U.S. Therefore, the following five areas 
were spatially analyzed: Continental U.S., Northeast U.S., South U.S., Midwest U.S., and West U.S.

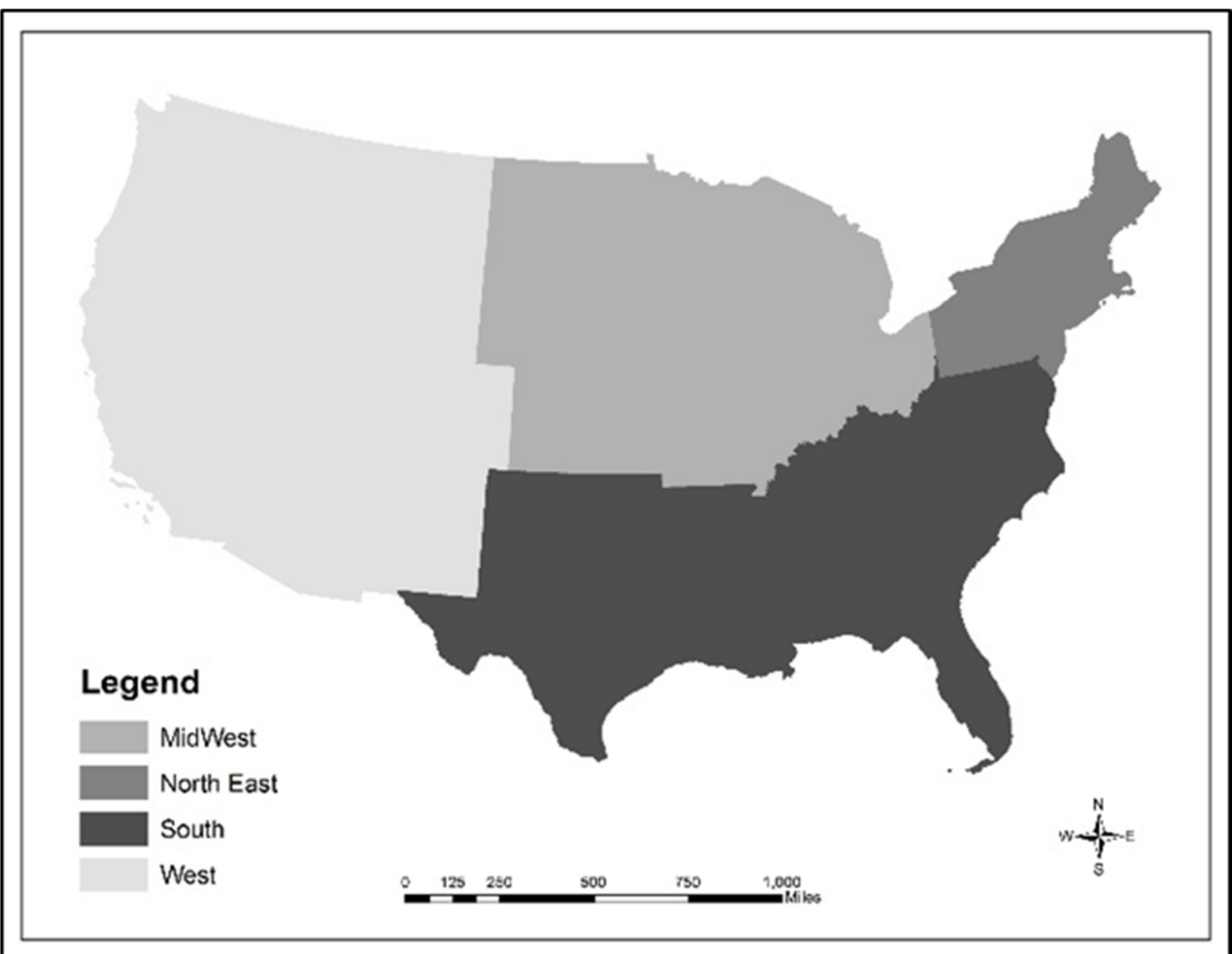

Figure 3-1. Four census regions of the United States.

As a precursor to the Getis-Ord Gi* test (Hot Spot Analysis) for cluster locations, a Moran's I test was initially conducted on the data in all five areas to determine if spatial autocorrelation existed. Results from the Moran's I test indicated that a statistically significant (p $<0.05)$ clustered pattern results for all five areas. Hotspot analysis was then performed on county-level data to indicate the location of statistically significant clustering and/or dispersion of data points within a determined threshold distance (or neighborhood). Distance thresholds were initially determined by measuring the distance needed to encompass the centroids of the 
eight largest neighboring counties within each of the five areas of analysis; eight data points have been suggested as a rule of thumb to maintain the reliability of the resulting z-score (ESRI 2014a). Each distance was then input to an incremental spatial autocorrelation analysis tool to determine the highest ranked distance threshold, relative to the input distance and based on significance level. The threshold distance calculated for West U.S. was the largest between the four census regions due to the relatively large size of the counties found in this region. This threshold distance, 121,856 meters, was also used to analyze data for the Continental U.S. as well in order to provide county-level precision throughout the country while still encompassing approximately 8 neighboring data points for each county centroid. Table 1 shows the resulting threshold distance used for each of the 5 different areas in the Hotspot analysis. As county size increased in an area, the threshold distance also increased to encompass neighboring county centroids.

Table 3-1. Threshold distances for the five analysis regions.

\begin{tabular}{|c|c|}
\hline \hline Area of Analysis & Threshold Distance (m) \\
\hline (1) Continental U.S. & 121,856 \\
(2) Northeast U.S. & 45,411 \\
(3) South U.S. & 84,888 \\
(4) Midwest U.S. & 56,723 \\
(5) West U.S. & 121,856 \\
\hline
\end{tabular}

Spatial analysis was performed on county level data to indicate geographic trends in certified project locations. Certified LEED projects obtaining the certified wood credit experienced significant spatial growth throughout the country between the years 2000 and 2013 
(Figure 2). Moran's I testing was used to indicate the spatial autocorrelation of county centroids based on location and the number of certified LEED projects in that county. In general, results from this test indicate whether the spatial distribution of the data is significantly $(p<0.05)$ different from random distribution. Moreover, if the test results in a significant p-value, the zvalue associated with the test indicates whether the pattern of the data is significantly clustered (z-score is positive) or significantly dispersed (z-score is negative) compared to random distribution of the data (ESRI 2014b). When comparing the Moran's I statistic, negative values indicate a dispersed pattern, zero values indicate a random pattern, and positive values indicate a clustered pattern. To determine growth trends of LEED certified projects, Moran's I was calculated for each year $(2000$ - 2013) in each of the five analysis regions. Increasing Moran's I results indicate higher levels of clustering patterns. Therefore, by comparing the results for each year within each geographic region, building patterns for LEED projects were determined.

\subsubsection{Regression}

Spatial regression techniques were used to determine the statistical significance of explanatory variables and their influence on the use of FSC certified wood in LEED projects. Identifying statistically significant explanatory variables may help determine future FSC market areas based on the presence of the significant variables in other geographic locations. Additionally, the use of FSC certified wood in a LEED project may be affected by its proximity to a FSC certified product producer. Therefore, a list of all FSC certified wood product producers and their locations were acquired from the Forest Stewardship Council - United States (FSC US). The list contained 40,092 companies, along with the respective product types, and locations. In many cases, a singular company was listed multiple times at the same location - 
each listing containing a different product type. This list was narrowed, however, to only contain those company locations that offered products relative to the building construction market. The following general product categories were selected and determined the final list of FSC product providers for use in the regression analysis: wood for construction, houses and building elements, roofing and trusses, stairs and flooring, cabinetry, boards/planks/beams, plywood/OSB, engineered wood products, and wood plastic composites. Companies with multiple products available at the same location were reduced to one listing for analysis. The resulting list included 1,261 company locations for use in the spatial econometric analysis. These locations were geocoded, projected and added to the GIS map. The density of FSC product producers was then determined within 100 miles, between 101-200 miles, and between 201-500 miles of the county centroids containing LEED certified projects that obtained the certified wood credit.

The analysis (Appendix B) for spatial regression was performed on the county data points through the use of MatLab software (2014) and included the following independent factors:

- latitude,

- longitude,

- percentage of population that has obtained a four-year degree or higher (Cidell 2009) (USDA 2012a);

- average electricity rate (EIA. 2012);

- population (USDA 2012b);

- payroll per building (USCB 2012);

- median income (USDA 2012c);

- the number of projects that obtained the material reuse credit, the recycled content credit, the wood composite and agrifiber credit, and the regional material credit;

- and the density of FSC certified product providers within 100 miles, between 101 and 200 miles, and between 201 and 500 miles. 
The dependent factor analyzed was the number of LEED certified projects that obtained the certified wood product credit in a county. A procedure determined by Florax et.al. (2003) and another determined by Elhorst (2010) were used to determine which regression model was suitable to best describe the data found in the analysis regions.

The results of the spatial regression model analysis indicated the regression model that was most suited for the analysis region. For the U.S. region, the Spatial Durbin Model (SDM) was indicated as the best model to use for the data obtained (Equation 1). The Spatial Durbin Model (SDM) is unique in that it incorporates the impacts that explanatory variables have not only on the local dependent variable, but also on the neighborhood dependent variables as well. Moreover, the SDM includes feedback loop effects where neighborhood impacts also affect the local observations (LeSage \& Pace 2008).

$$
y=\rho W y+x \beta+W x \theta+\varepsilon
$$

Where:

$\mathrm{y}=$ vector dependent variable

$\mathrm{x}=$ matrix of explanatory variables

$\mathrm{Wx}=$ matrix of spatially weighted explanatory variables

$\mathrm{Wy}=$ vector of spatially weighted dependent variable

$\beta=$ vector regression coefficients

$\theta=$ vector regression coefficients on spatially weighted variables

$\rho=$ scalar spatial autocorrelation parameter

$\varepsilon=$ error 


\subsection{RESULTS AND DISCUSSION}

\subsubsection{Spatial Analysis}

Results for the LEED certified project data indicate this growth pattern as becoming generally more clustered from one year to the next (Figure 3) when looking at the U.S. as a whole. When the U.S. is segmented into the four major census regions, growth patterns generally trend towards increased cluster patterns between 2000 and 2013. Both the Midwest (MW) and West (W) regions have experienced only clustered patterns of LEED projects during this time period. In the North East (NE), project locations initially indicate a random distribution with no presence of statistically significant clustering or dispersion. In 2007 however, increased growth in LEED projects in this region led to significantly clustered project locations, with this growth pattern continued since. In the South (S), growth patterns have shifted steadily over the 13-year span from neither clustered or dispersed in 2002 to significantly clustered since 2003 . Results from the Moran's I test indicate LEED project locations throughout the U.S. and that growth in the four census regions has been generally in a clustered pattern. This means that areas that have experienced high volumes of LEED certified project placement may likely continue to see growth of LEED certified projects and FSC certified wood use in the future. 


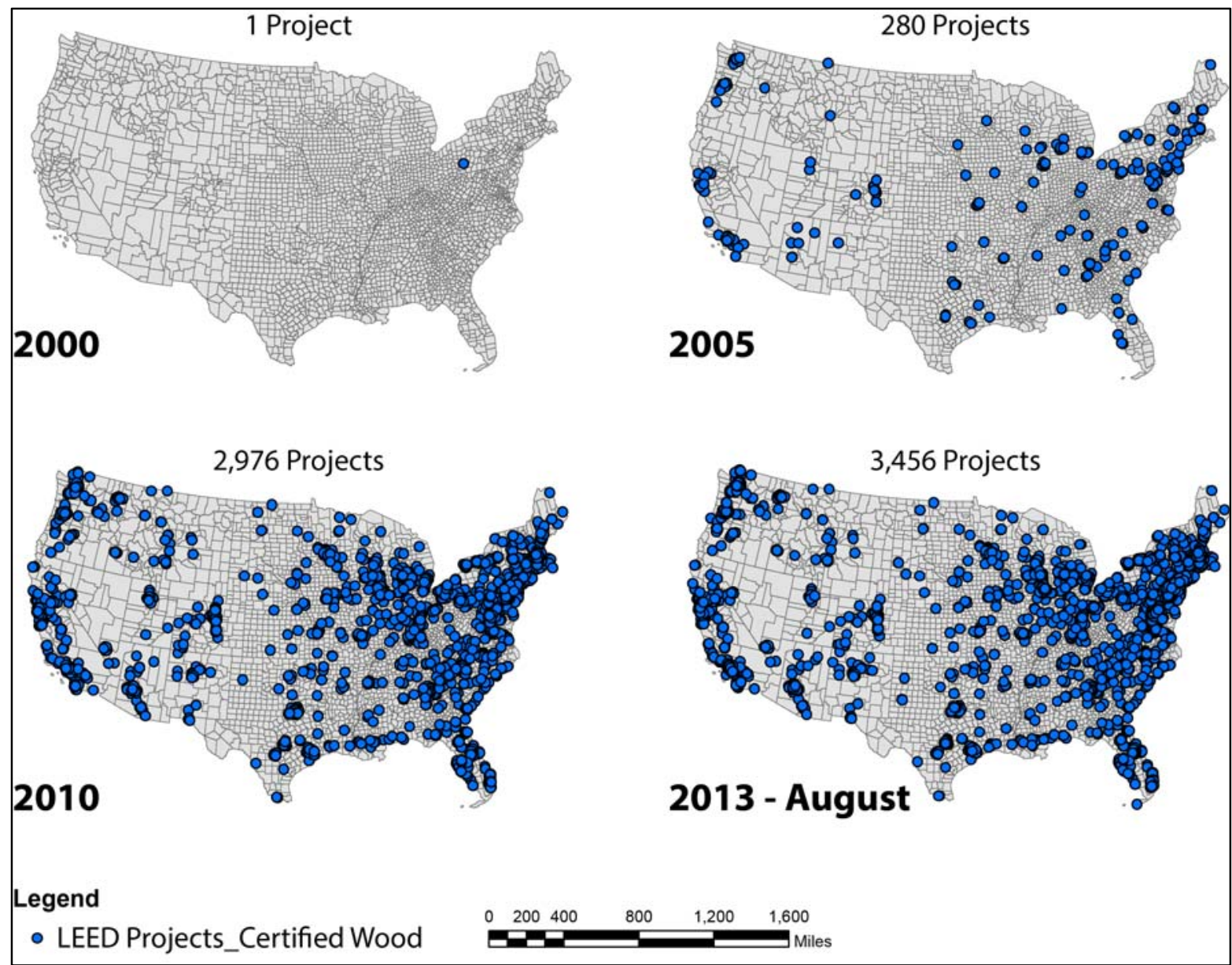

Figure 3-2. LEED certified projects that obtained the certified wood credit, locations in sample data by year 2000, 2005, 2010, and August 2013. 


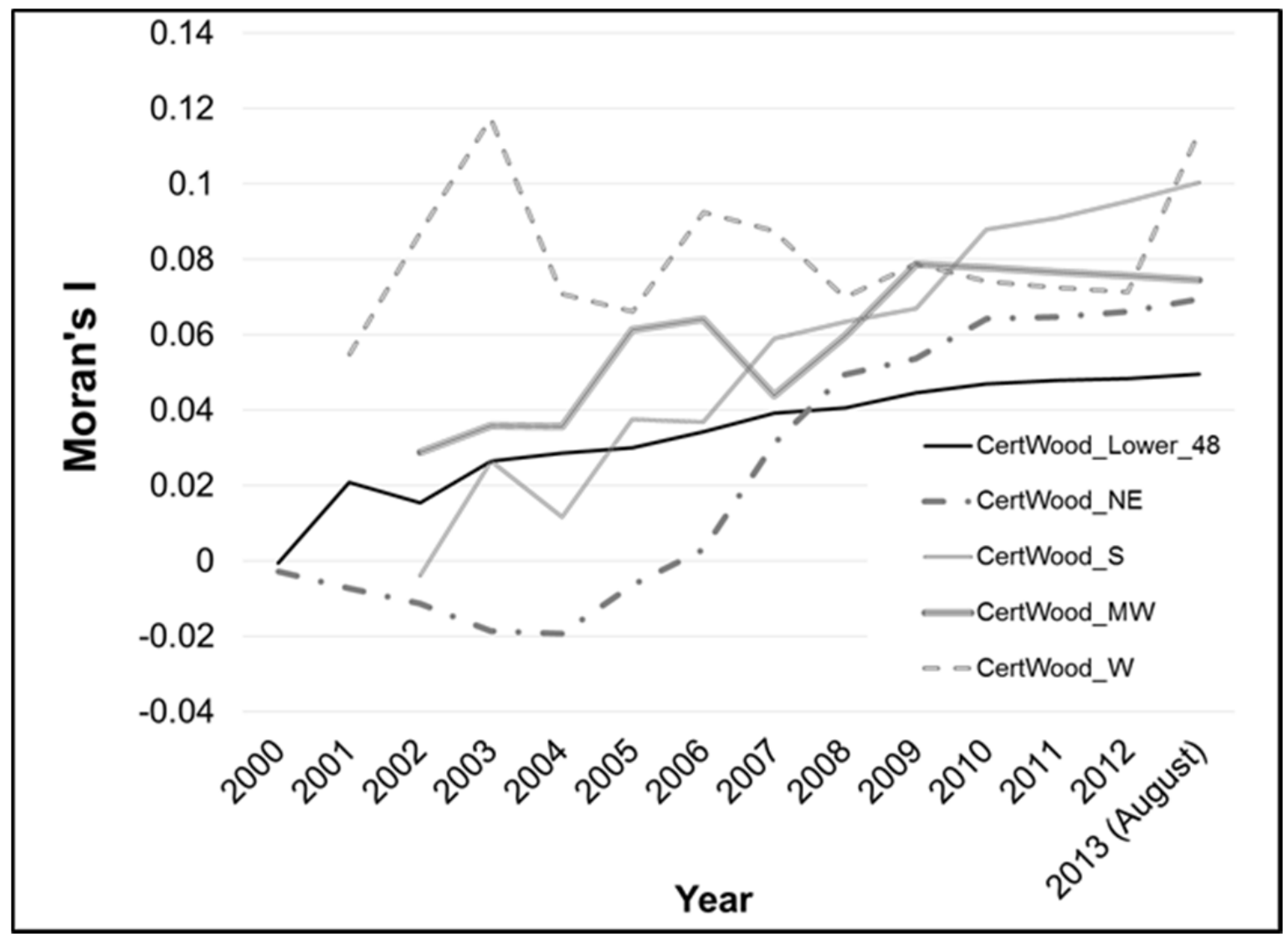

Figure 3-3. Moran's I for all LEED certified projects that obtained the certified wood credit in sample data throughout the U.S. and the four census regions.

Hot Spot Analysis was performed on the certified LEED projects throughout the continental U.S. that obtained the certified wood credit. Of the 3,109 counties, 718 (23\%) contained at least one LEED certified project that obtained the certified wood credit. The Hot Spot Analysis identified statistically significant clustering of counties that contained a high number of certified projects. Several Hot Spot areas were identified throughout the U.S. (Figure 4). Groups of adjacent Hot Spot counties were observed near the large metropolitan areas of Seattle, WA; Portland, OR; San Francisco, CA; Los Angeles, CA; Denver, CO; Houston, TX; Chicago, IL; Washington, D.C.; Baltimore, MD; Philadelphia, PA; New York, NY; Boston, MA; 
and Miami, FL. In all of the Hot Spot counties there was a significantly high concentration of LEED certified projects that obtained the certified wood credit within the neighborhood analysis distance (121,856 meters). Based on the significantly clustered growth pattern of these projects, these geographic areas may be high potential locations for future development for FSC certified wood material providers.

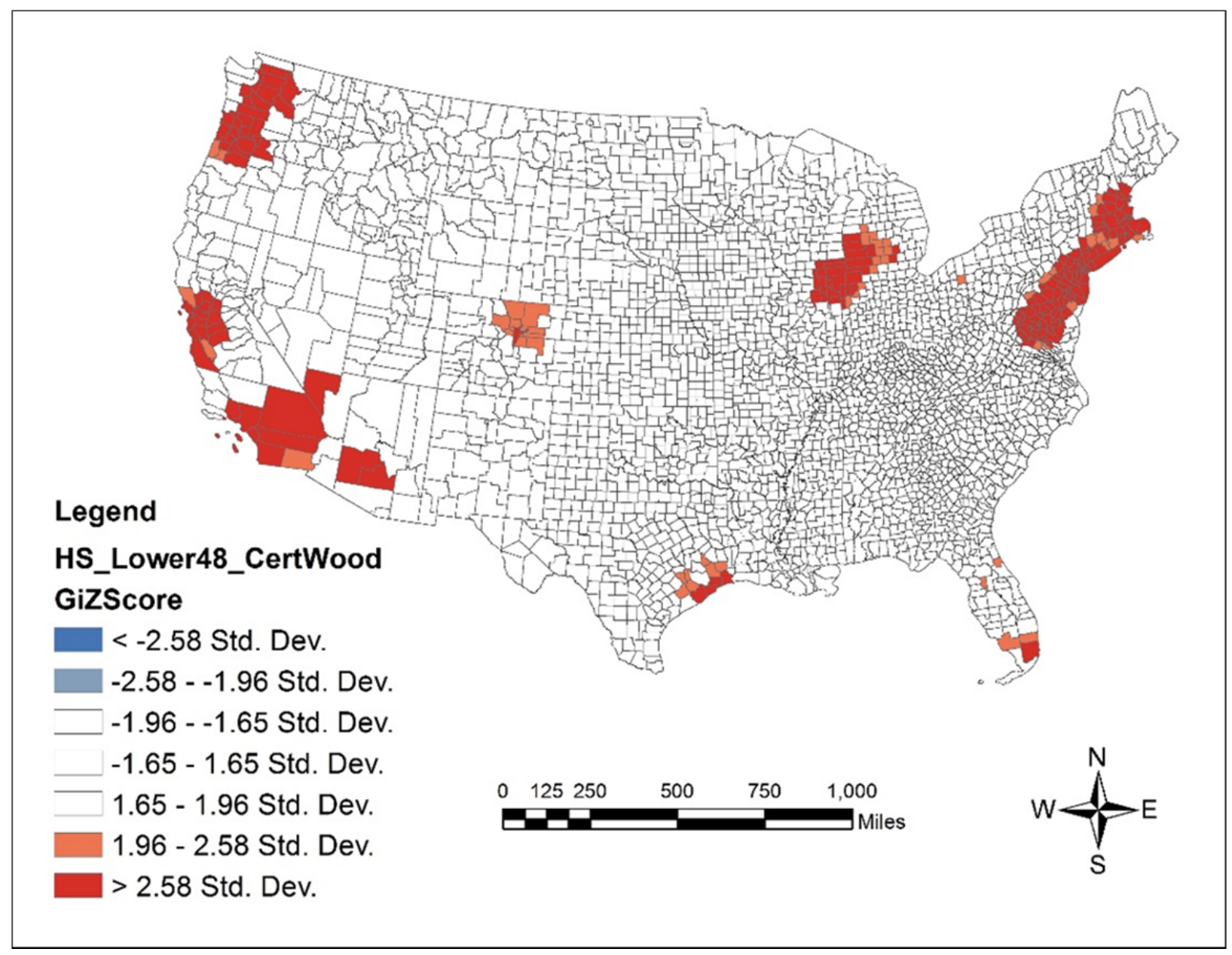

Figure 3-4. Hot Spot locations of statistically significant $(\mathrm{p}<0.05)$ clustering of counties containing LEED certified projects that obtained the certified wood credit in the continental U.S. 
Hot Spot Analysis was performed on the four census regions to determine areas of concentrated LEED certified projects utilizing and obtaining credit for use of certified wood products. Results from census region analyses differ from those on the national level due to decreased neighborhood analysis areas and the total area included in the analysis. By decreasing the threshold distances for the Hot Spot analysis as well as the total area analyzed, results indicate smaller, more precise areas of clustered projects. For each of the four regions, a smaller neighborhood analysis distance (except the West region) coupled with a smaller area analyzed resulted in more geographically specific Hot Spot counties.

Results from the Hot Spot analysis (Figure 5) indicate counties containing significantly high numbers of LEED certified projects that have obtained the certified wood credit included the following regions/cities:

- $\quad$ Midwest - Minneapolis, MN; Chicago, IL; Grand Rapids, MI; Detroit, MI; Cleveland, $\mathrm{OH}$; Cincinnati, OH; and Saint Louis, MO

- $\quad$ Northeast - Pittsburgh, PA; Philadelphia, PA; New York, NY; and Boston, MA;

- South - Washington D.C. and surrounding cites; Raleigh, NC; Lexington, NC; Rock Hill, NC; Atlanta, SC; Orlando, FL; Tampa FL; Miami, FL; Dallas, TX; Houston, TX; and Austin, TX;

- West - Seattle, WA; San Francisco, CA; Los Angeles, CA; and Phoenix, AZ, and Portland, OR. 


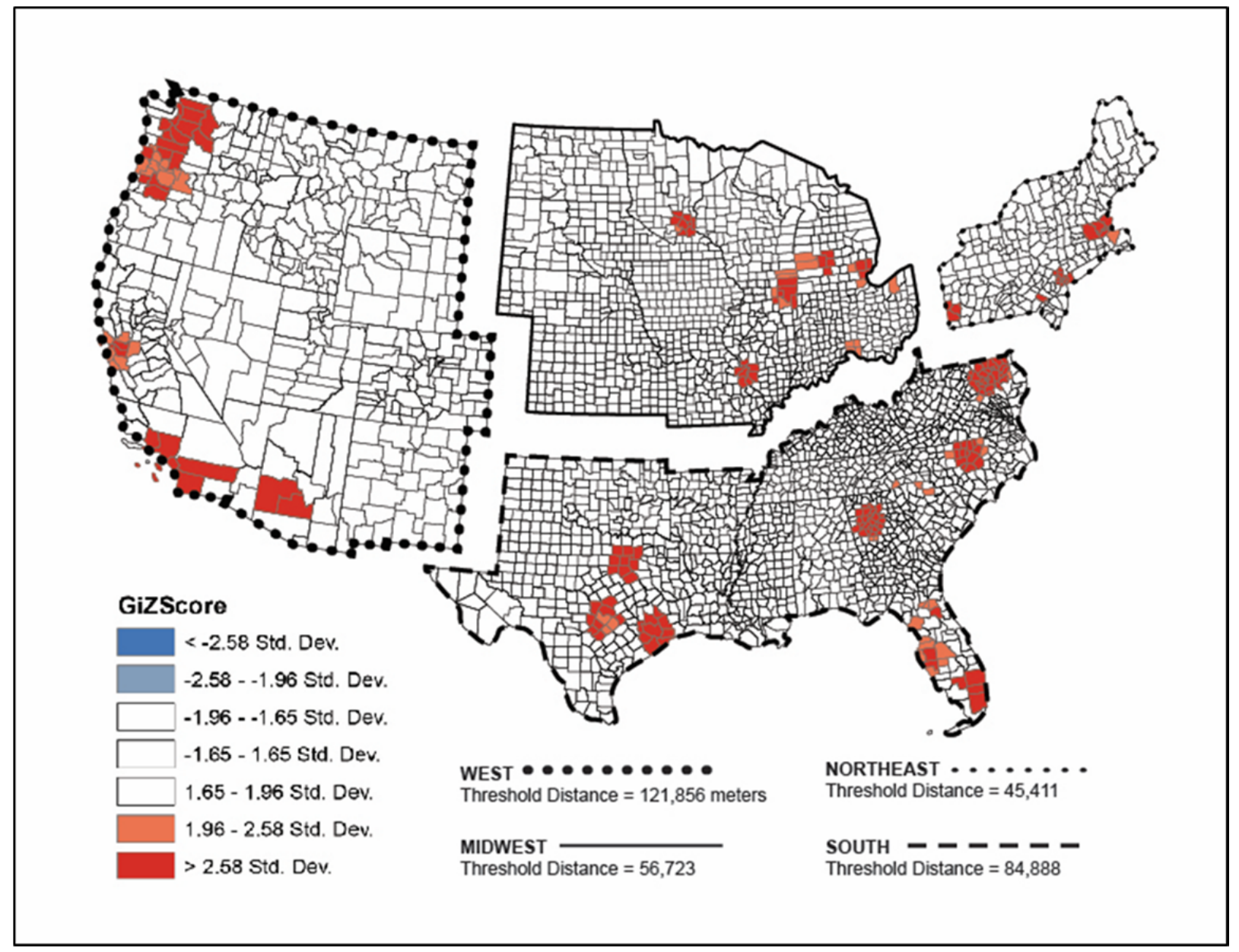

Figure 3-5. Hot Spot locations of statistically significant $(p<0.05)$ clustering of counties containing high numbers of LEED certified projects that obtained the certified wood credit in the four major U.S. census regions.

Finding based on these neighborhood analysis distances reveal more specific areas of interest for green building product manufacturers as well as FSC certified product suppliers. A more focused target market is indicated than in the county-wide analysis that could help to further minimize manufacturer's efforts in determining potential sales areas. For example, large consecutive areas of Hot Spot counties were found around the Washington D.C., New York, Philadelphia, Boston, and Chicago areas in the country-wide analysis. In the regional analysis, 
however, these hot spot areas are dissipated to indicate more geographically specific areas of significant certified wood product use in LEED commercial projects. The areas indicated by the regional analysis may better serve the FSC certified product manufacturers in pinpointing potential counties to direct.

A caution is in order, however, in that introducing arbitrary boundaries into the geographically connected data set can have misleading results. Specifically, the analyzed data points near the boundary will not include the influence of other data points within the neighborhood analysis region, but outside the boundary between the census regions. Not accounting for this influential data reduced the significance of Hot Spot counties near boundaries. For example, the cluster of significant Hot Spot counties around the Washington D.C. area (in the South region) has an effect on the neighboring counties in the Northeast region, but would not be taken into account when separated by census region boundaries. Because of this factor, future research is suggested to determine the Hot Spot significance of county locations by including an additional buffer equal to the neighborhood analysis distance to each of the census regions. By adding these buffers, the bordering counties within the analysis region would incorporate influential effects produced by neighboring counties outside of the analysis region.

\subsubsection{Regression}

Results for the SDM country-wide regression analysis indicate direct, indirect and total effects. In our regression we utilized a contiguity based spatial weight matrix, W. The direct effects provide an indication of the impact a dependent variable will have based on the changes of the explanatory variables at that location. The indirect effects are an estimate of the impact that the dependent variables of neighboring data points will have based on the changes of 
explanatory variables of the central data point. The total effects are a summation of the direct and indirect effects. According to the results of the SDM regression analysis (Table 2) for all counties in the Continental U.S. containing LEED certified projects that obtained the certified wood credit $(\mathrm{n}=718)$, significant $(\mathrm{p} \leq 0.05)$ explanatory variables for direct effects are: population and obtaining the materials re-use credit, recycled material credit, composite wood and agrifiber products credit, and the regional material credit. The significant explanatory variable for indirect effects is electricity rate. Significant variables for the total effects for this region include: electricity rates, population, obtaining the regional material credit, and the density of FSC material producers within 100 miles of the county centroid.

Table 3-2. Results from SDM regression analysis for all commercial LEED certified projects in the continental U.S. that obtained the certified wood credit.

\begin{tabular}{|c|c|c|c|c|c|c|c|c|c|}
\hline \multirow{2}{*}{$\begin{array}{c}\text { Explanatory } \\
\text { Variables } \\
\end{array}$} & \multicolumn{3}{|c|}{ Direct } & \multicolumn{3}{|c|}{ Indirect } & \multicolumn{3}{|c|}{ Total } \\
\hline & Coefficient & t-stat & $p$-value & Coefficient & t-stat & p-value & Coefficient & t-stat & $p$-value \\
\hline $\begin{array}{l}\% \text { population with } 4 \\
\text { year degree or more }\end{array}$ & 0.0336 & 2.2534 & 0.0245 * & -0.0232 & -0.6460 & 0.5185 & 0.0104 & 0.2919 & 0.7704 \\
\hline electric rate & 14.3845 & 1.5147 & 0.1303 & -46.7683 & -3.8763 & 0.0001 * & -32.3838 & -4.4007 & 0.0000 * \\
\hline $\begin{array}{l}\text { payroll by number of } \\
\text { establishments }\end{array}$ & 0.0009 & 1.7932 & 0.0734 & -0.0016 & -1.4516 & 0.1471 & -0.0007 & -0.5732 & 0.5667 \\
\hline population & 0.0031 & 10.3492 & 0.0000 * & -0.0007 & -1.1481 & 0.2513 & 0.0024 & 4.0874 & 0.0000 * \\
\hline reuse & 1.3989 & 3.2049 & 0.0014 * & 0.1580 & 0.1325 & 0.8946 & 1.5569 & 1.1991 & 0.2309 \\
\hline recycled material & 0.2633 & 4.1926 & $0.0000^{*}$ & 0.0045 & 0.0252 & 0.9799 & 0.2678 & 1.2765 & 0.2022 \\
\hline composite wood & 0.3164 & 4.8661 & 0.0000 * & 0.0861 & 0.4499 & 0.6529 & 0.4025 & 1.8291 & 0.0678 \\
\hline regional material & 2.6323 & 36.2355 & 0.0000 * & 0.1918 & 0.9458 & 0.3446 & 2.8241 & 12.9743 & 0.0000 * \\
\hline FSC 100 miles & -0.0036 & -0.1848 & 0.8535 & 0.0383 & 1.6914 & 0.0912 & 0.0347 & 3.0213 & 0.0026 * \\
\hline FSC 101 - 200 miles & 0.0129 & 0.8295 & 0.4071 & -0.0178 & -0.9333 & 0.3510 & -0.0049 & -0.6426 & 0.5207 \\
\hline FSC 201 - 500 miles & 0.0058 & 0.8143 & 0.4158 & -0.0082 & -1.0894 & 0.2763 & -0.0024 & -1.3612 & 0.1739 \\
\hline income & -0.0165 & -1.4128 & 0.1581 & 0.0293 & 1.2604 & 0.2079 & 0.0128 & 0.5430 & 0.5873 \\
\hline
\end{tabular}

* - statistically significant at $\mathrm{p}<0.05$.

$\mathrm{R}^{2}=0.9216$ 
Results show that the percentage of population with a four-year degree or higher had a direct, positive effect on the number of commercial LEED certified projects that obtained the certified wood credit. Increased population in a county also had a direct, positive effect supporting the results of the spatial analysis where many of the Hot Spot counties contained population dense cities. Furthermore, the presence of each additionally obtained LEED credit (e.g., material reuse, recycled material content, composite wood and agrifiber products and regional material) had a direct, positive influence on the number of projects that obtained the certified wood credit in that county. An explanation for this result could be that the material specifiers of projects in these areas favored the use of wood products. The additionally-obtained LEED credits could utilize a wood product to gain the respective credit; however, since it was unknown if wood-based materials were used to gain these credits, further research would be needed to determine if a relationship existed between obtaining these credits and the building material used. Another explanation could be that the use of a certified wood product may have also gained points for one or more of these four credits. In this case, the variables could be confounding and artificially increasing the effects of the explanatory variables.

The electricity rate was determined to be a significant, indirect explanatory variable. Furthermore, this variable has a negative coefficient that indicates high electricity rates to be correlated with a reduction in the number of certified projects in the surrounding neighborhood data points. An explanation for this result could be that higher electricity rates may be found in population dense areas with high commercial building density. As the distance from these counties increase to their surrounding county neighbors, the likelihood of certified LEED project placement decreases. 
Electricity rate, population, obtaining the regional material credit, and the density of FSC certified material manufacturers within 100 miles had significant total effects on the number of commercial LEED projects that obtained the certified wood credit. The electricity rate had a significant total effect on the number of commercial LEED certified buildings that were located in an analyzed county. The direct effect of this variable on the number of projects located in the county of analysis was insignificant but the indirect effect (e.g., the effect this variable has on the number of projects located in counties that neighbor the analyzed county) was significant. Additionally, the magnitude of the coefficient for indirect effects (-46.77) weighted the total effects to maintain the negative coefficient (-32.38) for the total effects of electricity rates. Results indicate that increasing electricity rates in the analyzed county may result in a lower number of commercial LEED certified projects that receive the certified wood credit found in neighboring counties. These results indicate that more commercial LEED projects are likely to be located in areas of higher electricity rates and less likely to be located in neighboring counties of lower electricity rates. The total effects for the population and obtaining the regional material credit explanatory variables indicate that an increase in either one may increase the total number of commercial LEED certified projects that obtain the certified wood credit in that county.

The results indicated that a shorter distance to a FSC product provider may be an influential factor in the number of commercial LEED projects that obtained the certified wood credit. The total effects, determined by the SDM regression model, indicated that increased density of FSC manufacturers located within 100 miles of the analyzed county centroid may increase the number of commercial LEED projects that obtain the certified wood credit in the neighboring counties. 
As in the spatial analysis section, introducing arbitrary boundaries into a geographically connected data for spatially weighted regression analysis can have misleading results. However, unlike the Hot Spot analysis where only the counties near the border of the region are affected, the regression analysis returned a singular result indicative of the entire region being analyzed. Consequently, the influential data points that exist outside the analyzed region are not taken into account and ultimately affect the regression results for the entire analysis region, not just the counties near the border. Therefore, regression analysis on each of the four census regions was determined to be inaccurate and omitted as part of this research.

Additionally, the results and implications of this research are based on projects certified or applying for LEED certification via versions 2009 or earlier. Changes in LEED version 4 (v4) certification, particularly in the "Material and Resources" category, continue to reward the use of FSC certified wood but only as one of six different ways to gain the singular credit point through "Responsible Sourcing Criteria" (LEED 2015). Therefore, specifiers may choose to meet any of the other five responsible sourcing criteria types in place of FSC certified wood to gain this point. Changes in LEED v4 may influence the use of wood products for point accumulation and should be considered when applying the results of this study to include projects applying for LEED v4 certification.

\subsection{CONCLUSIONS}

This research focused on determining high use areas for certified wood products in commercial LEED certified projects within the continental U.S. Specifically, the results of this study have indicated county-level Hot Spots for certified wood product use in LEED certified projects. The projects have high levels of spatial autocorrelation and continue to be constructed 
near existing LEED certified projects throughout the country. Given the trend of spatial growth, the Hot Spot counties may indicate regions of continued growth for both environmentally certified and non-certified wood products in future LEED projects.

Results indicate approximately nine statistically significant areas of clustered LEED certified projects that obtained the certified wood credit throughout the U.S. (Figure 4). These areas indicate a holistic view of the increased use of FSC certified wood products for LEED projects and may indicate potential markets for providers of such products. These areas may also indicate target markets' non-FSC-certified wood products. Additional points are available in the LEED standards, version 2009 and earlier, for non-FSC-certified wood products in categories such as: Regional Material, Indoor Environmental Quality, Recycled Content, and Material Reuse. Therefore, certified and non-certified wood product manufacturers searching to supply the LEED green building industry may increase their chances of success by focusing on these areas of concentrated project locations.

Regression results indicate significant explanatory variables that may influence the number of certified LEED projects that obtain the certified wood credit in a county. Significant explanatory variables include those with direct, indirect and total effects on the dependent variable. Significant variables with a direct effect include: the percentage of population with a four year degree or higher, population in a county, and the presence of each of the additionally obtained LEED credits: material reuse, recycled material content, composite wood and agrifiber products and regional material. Only one significant variable, electricity rate, was identified to have an indirect effect. Lastly, the significant variables that had an overall, total effect on the dependent variable were: electricity rates, population in a county, obtaining the regional material credit, and the density of FSC certified product providers within 100 miles. 
In general, the spatial econometric regression results indicate that areas of increased population and a higher percentage of individuals with a four year degree or higher are a likely candidate for the location of commercial LEED certified projects that obtain the certified wood credit. Additionally, obtaining the LEED credits material reuse, recycled material content, composite wood and agrifiber products and regional material positively influenced the number of commercial LEED projects that obtained the certified wood credit in a county. Lastly, the density of FSC certified product manufacturers within 100 miles had a positive effect on the number of commercial LEED projects that obtained the certified wood credit. This result could be of interest to FSC certified manufacturers who are looking to locate near high population areas and market to the green building industry. However, further research is needed to determine if the location of the existing FSC manufacturers is due to a demand driven market such as commercial LEED certified projects that obtain the certified wood credit or if the location of these manufacturers have helped to drive the market for the location of commercial LEED certified projects to obtain the certified wood credit.

While the results of this research are limited to the use of commercial LEED certified green building projects, certified under LEED version 2009 or earlier, that obtained the certified wood product credit, they provide a framework for investigating hot spots for other types of green building projects. Future spatial analysis research is needed to identify additional regions of high wood product use in various green building standards as well as the newest version of LEED, v4. This type of spatial analysis on a variety of green building programs would assist wood products manufacturers in identifying key green building markets and growth trends for wood product use. 


\subsection{REFERENCES}

Bowyer J (2007) Green Building Programs - Are They Really Green? Forest Prod J 57(9):6-17.

Buchanan AH, SB Levine (1999) Wood-based building materials and atmospheric carbon emissions. Environ Sci \& Policy 2:427-437.

Cidell J (2009) Building green: the emerging geography of LEED-certified buildings and professionals. Prof Geogr 61(2):200-215.

EIA (2012) Energy Information Administration - Electricity power sales, revenue, and energy efficiency Form EIA 861 detailed data files. http://www.eia.gov/electricity/data/eia861/. (15 September 2014).

Elhorst JP (2010) Applied spatial econometrics: raising the bar. Spat Econ Anal 5(1):9-28.

ESRI (2014a) Hot Spot Analysis (Getis-Ord Gi*) (Spatial Statistics) Usage tips. http://resources.esri.com/help/9.3/arcgisengine/java/gp_toolref/spatial_statistics_tools/hot _spot_analysis_getis_ord_gi_star_spatial_statistics_.htm. (15 September 2014).

ESRI (2014b) How Spatial Autocorrelation (Global Moran’s I) Works. http://help.arcgis.com/en/arcgisdesktop/10.0/help/index.html\#//005p0000000t000000 (15 September 2014).

Falk B (2009) Wood as a Sustainable Building Material. Forest Prod J 59(9):6-12.

Florax RJ, Folmer H, Rey SJ (2003) Specification searches in spatial econometrics: the relevance of Hendry's methodology. Reg Sci Urban Econ 33(5):557-579. 
Gustavsson L, Madlener R, Hoen HF, Jungmeier G, Karjalainen T, Klohn S, Mahapatra K, Pohjola J, Solberg B, and Spelter H (2006b) The Role Of Wood Material For Greenhouse Gas Mitigation. Mitig Adapt Strategies Glob Chang 11:1097-1127.

Gustavsson L, Pingoud K, Sathre R (2006a) Carbon Dioxide Balance Of Wood Substitution: Comparing Concrete- and Wood-Framed Buildings. Mitig Adapt Strategies Glob Chang 11: 667-691.

Johansson O (2011) The spatial diffusion of green building technologies: The case of Leadership in Energy and Environmental Design (LEED) in the United States. Int J Technology Management Sust Dev 10(3):251-266.

Kahn ME, Vaughn RK (2009) Green Market Geography. The Spatial Clustering of Hybrid Vehicles and LEED Registered Buildings. BE J Econ Anal Poli 9(2):1-22.

Knowles C, Theodoropoulos C, Griffin C, Allen J. (2011) Oregon design professionals views on structural building products in green buildings: implications for wood. Can J For Res 41:390-400.

LeSage J, Pace RK (2008). Introduction to spatial econometrics. CRC press.

Lippke B, Wilson J, Perez-Garcia J, Bowyer J, and Meil J (2004) Corrim: Life Cycle Environmental Performance of Renewable Building Materials. Forest Prod J 54(6):8-19.

MATLAB and Statistics R2014a, The MathWorks, Inc., Natick, Massachusetts, United States.

McGraw Hill Construction (2013). World Green Building Trends. http://analyticsstore.construction.com/index.php/world-green-building-trendssmartmarket-report-2013.html (15 September 2014). 
Petersen AK, Solberg B (2002) Greenhouse gas emissions, life-cycle inventory and costefficiency of using laminated wood instead of steel construction. Case: beams at Gardermoen airport. Environ Sci Policy 5:169-182.

Petersen AK and Solberg B (2003) Substitution between floor constructions in wood and natural stone: comparison of energy consumption, greenhouse gas emissions, and costs over the life cycle. Can J For Res 33:1061-1075.

Puettmann ME and Wilson JB (2005) Life-Cycle Analysis Of Wood Products: Cradle-To-Gate Lci Of Residential Wood Building Materials. Wood Fiber Sci - Corrim Special Issue $37: 18-29$.

Tardif P, O'Conner J (2009) Selling Wood Products to the Green Building Market. FPInnovations Forintek. Version 1.0 - February 2009.

Upton B, Miner R, Spinney M, Heath L (2008) The green House Gas and Energy Impacts of Using Wood Instead of Alternatives in Residential Construction in the United States. Biomass Bioenergy 32:1-10.

USCB (2012) County Business Patterns: 2012. http://www.census.gov/econ/cbp/download/. (15 September 2014)

USDA (2012a) Economic Research Service. Education attainment for the U.S., States and counties, 1970-2012. http://www.ers.usda.gov/data-products/county-level-datasets/download-data.aspx\#.UxX78vldWZ8. (15 September 2014) 
USDA (2012b) Economic Research Service. Population estimates for the U.S., States and counties, 2010-13. http://www.ers.usda.gov/data-products/county-level-datasets/download-data.aspx\#.UxX78vldWZ8. (15 September 2014)

USDA (2012c) Economic Research Service. Unemployment and median household income for the U.S., States and counties, 2000-12. http://www.ers.usda.gov/data-products/countylevel-data-sets/download-data.aspx\#.UxX78vldWZ8. (15 September 2014)

USGBC (2013a) USGBC History. http://www.usgbc.org/about/history. (15 September 2014)

USGBC (2013b) USGBC Profile. http://www.usgbc.org/profile. (15 September 2014) 


\section{SPECIFIER PERCEPTIONS OF WOOD PRODUCT}

\section{USE IN COMMERCIAL LEED CERTIFIED PROJECTS}

\section{IN THE APPALACHIAN REGION}




\section{ABSTRACT}

A growth in green building projects within the Appalachian Region of the United States has increased the potential for wood product use. The overall objective of this research was to identify factors that influenced the use of wood products in commercial LEED projects within the Appalachian Region. Through purposeful sampling methods, the study determined material specifiers' perceptions of wood-based products in the context of using them for use in LEED commercial projects. Using spatial analysis techniques, two major geographic areas in the Appalachian Region (surrounding Pittsburgh, PA and Greenville, SC) were identified where wood products have been awarded points towards LEED building certification. Results indicated that material specifiers generally had a positive perception towards wood-based building materials and felt wood offers the environmental and physical attributes needed in green building practices. Specifiers also felt that the main barrier to wood use in commercial green building projects lie in the building type as well as fire and structural building code restrictions. However, optimism exists for specifiers in the form of building code acceptance to new and innovative wood-based materials like Cross Laminated Timbers (CLTs). Based on the results of this study, wood products manufacturers have the potential to increase their market share in the green building industry by promoting the environmental benefits of their products through media for marketing communications such as websites or print advertisement. Wood product manufacturers should also consider future CLT demand growth and assess opportunities to manufacture these products. 


\subsection{INTRODUCTION}

The green building industry has been identified as a viable and growing market for construction materials given the recent and forecasted growth it has experienced. A recent study (McGraw Hill 2013) indicates that the green market made up 48\% of all 2012 building project activity in the US. The percentage of respondents from that study that have $60 \%$ or more of their total job portfolios in green building projects is expected to reach 53\% in 2015, up from $40 \%$ in 2012. New commercial buildings, retrofits of existing buildings, and new institutional buildings are the top sectors reported where respondents plan to build green projects. Consequently, there may be increased opportunities for wood products manufacturers to supply this market by providing products suitable to gain points towards building certification in various green building standards. In particular, there are increased opportunities for those manufacturers providing environmentally certified wood materials recognized by green building standards. The Leadership in Energy and Environmental Design (LEED) program was designed by the U.S. Green Building Council (USGBC) in 1998 (USGBC 2013b). With 74,981 currently registered and certified projects (USGBC 2014a), LEED is currently the largest green building standard in the United States. As a significantly popular standard in the green building industry, building projects pursuing LEED certification represent a large potential market for manufacturers of an environmentally low-impact construction material like wood.

The use of some specific wood products in LEED certified building projects is rewarded through the achievement of points that are tallied to reach one of the four levels of LEED building certification. Opportunities for credit accumulation exist for uncertified wood products in categories such as recycled content, indoor environment quality, locally sourced materials, and rapidly renewable materials. However, LEED specifically encourages the use of certified wood 
products (CWP) by granting one point for the use of Forest Stewardship Council (FSC) certified wood, given that at least 50\% (cost based) of all wood-based materials used in the project are FSC certified. An additional point through the innovative design category may be earned for projects that incorporate more than 95\% (cost basis) of FSC certified wood (LEED 2014). The sales opportunities for wood product producers interested in pursuing green building projects under LEED, therefore, are open to manufacturers and distributers participating in FSC wood product certification as well as those who do not carry the certification. Understanding the perceptions of those specifying the use of materials in these projects is important to develop strategic marketing plans aimed at meeting their needs and preferences.

Perceptions of material specifiers and other professionals in the construction industry towards wood products has been a recent topic of research interest. Wang et al. (2014) found that the environmental performance of wood was a major driver for use in the United Kingdom's (UK) green building industry. Similarly, a study by Wagner and Hansen (2004) found that environmental certification of wood products, by a third-party certification standard, was more effective at positively influencing the perceptions of architects when compared to other environmental actions taken by a company such as: 1) lumber coming from plantations instead or natural forests and 2) the reputation of the company. A different study focused in the western U.S., however, has suggested that design professionals have little incentive to include the use of wood products in the structural material selection of green buildings, even though wood was viewed as a more environmentally-friendly material when compared to steel and concrete (Knowles et al. 2011). O'Conner et al. (2004) indicated that the primary barrier to wood use as a structural material in nonresidential construction is related to building code issues, particularly in regard to fire safety. An area where the increased use of certified wood products is anticipated is 
in the Appalachian affordable housing sector. Estep et al. (2013) found that 50\% of material specifier respondents plan to use CWPs in future affordable housing projects, up from the $14 \%$ that specifically looked to purchase CWPs in the previous year.

The spatial distribution and trends of LEED certified projects have also been a topic of recent studies. Kahn and Vaughn (2009) indicated the spatial distribution of LEED certified projects on a state level across the United States. They further investigated zip code level data for the state of California and determined that the explanatory variable "environmental factor" is significant for both the dependent variables "All” LEED ownership types and "Commercial" LEED ownership types within a given zip code. A different study (Johansson 2011) determined the temporal and spatial growth of LEED projects in the U.S. and indicates an expansion diffusion pattern of growth at the regional level. Results from this study also indicated the Pacific coast region as the primary epicenter of green building in the U.S. followed by a secondary epicenter, New England. Also, studies (Cidell 2009) suggested that after the initial dispersion of LEED certified projects throughout the U.S., few new areas had obtained LEED certified projects. More recently, Estep et al. (2015) used a Hotspot spatial analysis method to determine counties within the U.S. that contained statistically significant clusters of commercial LEED certified projects. By determining Moran's I for subsequent years, the research indicated that the dispersion of commercial LEED projects in the continental U.S. were growing in a clustered pattern (Chapter 3.3.1 Spatial Analysis).

Although perceptions of wood product use in green building projects have been explored, there is no known research that explores wood product utilization in commercial LEED certified projects in the Appalachian region. Additionally, there is no known research that identifies the perceptions of material specifiers purposefully chosen by location of high potential sales markets 
for LEED certified projects. Research in this area could help wood product manufacturers understand the geographic trends and material specifier perceptions associated with the use of wood products in the Appalachian region's green building sector. Therefore, this research was developed to indicate the spatial growth trend of FSC certified wood product use in the LEED green building program as well as to identify the perceptions of wood use for purposefullychosen material specifiers within the Appalachian region.

The spatial growth of LEED projects utilizing FSC certified wood to gain points towards building certification may indicate specific areas within the Appalachian region of market potential for wood product manufacturers. Information obtained through this research may help identify specific market areas for FSC product manufacturers and help to indicate geographic market conditions for future growth trends. The goal of this project was to identify factors influencing the use of wood products in high-potential markets of commercial LEED projects certified in the Appalachian region. Specific objectives of this research were to: identify what factors motivated specifiers to include wood products in their building design; identify specifiers' perceptions of future growth/contraction in green building; and identify specifiers perceptions of future growth/contraction in wood product use in green building projects.

\subsection{METHODS AND MATERIALS}

\subsubsection{Method}

A qualitative survey method was used to elicit perceptions that material specifiers had towards wood product use in commercial green building projects. Using a qualitative survey method allowed the researchers to perform in-depth interviews with follow-up questions for response clarification and to allow respondents freedom to elaborate on their perspectives 
without being bound by a closed-ended question format (Patton 2002, Grushecky et al. 2006, Roos et.al. 2010, Wang et al. 2014). Also, employing this method allowed for additional, improvisational questions to further understand the perspectives of the respondents.

\subsubsection{Purposeful Sampling}

In building construction projects, the task of material specification may fall on an engineer, architect, general contractor, owner or others. Therefore, to identify the perceptions of the actual material specifiers of projects in the Appalachian Region, a purposeful sampling approach was chosen. The goal of selecting sample groups was to identify specific material specifiers of commercial LEED certified projects that obtained, and those that did not obtain, the certified wood credit. An additional goal was to obtain information from areas within the Appalachian region where a large number of commercial LEED projects were located. Therefore, stratified purposeful sampling, a form of purposeful sampling that can be used to facilitate comparison of sub-groups, was used to choose the potential material specifiers (Patton 2002).

\subsubsection{Spatial Analysis}

The first level of stratified purposeful sampling was based on using spatial analysis to identify county-level areas within the Appalachian region that were statistically significant in high clustering of existing commercial LEED certified projects. A list of commercial LEED certified projects located in the Appalachian region between 2000 and August of 2013 was obtained from the United States Green Building Council (USGBC), the governing entity for the LEED certification program. LEED for Homes projects were not included in this dataset due to confidentiality restrictions. The dataset contained 612 total commercial LEED certified projects that spread across four different rating programs: LEED for Commercial Interiors (CI), LEED 
Core and Shell (CS), LEED for Schools, and LEED for New Construction (NC). Of these commercial certified projects, 210 projects (34\%) obtained the certified wood credit. The following attributes specific to each project were also obtained: gross square footage of project, owner type, certification date, certification level, latitude and longitude coordinates of the project, industry type, space use type, rating program, and if the project obtained the certified wood credit. The individual project locations were geocoded, projected (USA Contiguous Equidistant Conic) and uploaded to Geographic Information Systems (GIS) software for spatial analysis. Individual project locations were grouped for analysis by joining the LEED data with the respective county centroid.

LEED projects located outside of the Appalachian region were not included in this analysis. Including data outside of the Appalachian region may have influenced the identification of additional Hotspot counties inside this region. As part of the purposeful sampling procedure, our aim was to identify only the perceptions of material specifiers for projects located in Appalachian Hotspot counties.

As a precursor to the Getis-Ord Gi* test (Hot Spot Analysis) for cluster locations, a Moran's I test was initially conducted on the county level data to determine if spatial autocorrelation existed. Results from the Moran's I test indicated statistically significant $(\mathrm{P}<$ 0.05) clustered pattern for commercial LEED certified projects in the Appalachian region. Additionally, growth trends of these projects were determined by calculating Moran's I for county-level data of each individual year (2000 - 2013). The resulting Moran's I value signifies if the data is significantly clustered, significantly dispersed, or simply of random arrangement. Increasing Moran's I results indicate higher levels of clustering patterns. Therefore, by 
comparing the results for each year in the Appalachian region, building patterns for commercial LEED projects were determined.

Hotspot analysis was then performed on county level data to indicate the location of statistically significant clustering and/or dispersion of data points within a determined threshold distance (or neighborhood). Distance threshold was initially determined by measuring the distance needed to encompass the centroids of the eight largest neighboring counties within the region. Eight data points have been suggested as a rule of thumb to maintain the reliability of the resulting z-score (ESRI 2014). The distance was then input to an incremental spatial autocorrelation analysis tool to determine the highest ranked distance threshold, relative to the input distance and based on significance level. The threshold distance calculated for the Appalachian Region was 53,298 meters. Results from the Hotspot analysis identified two separate county clusters as containing statistically significant clusters of projects in areas around: Pittsburgh, PA and Greenville, SC.

Of the 612 total projects located in the Appalachian region, 199 projects were located in the Hotspot counties. To understand the perceptions of material specifiers of recently certified LEED projects in the two Hotspot areas, all 199 projects were filtered by those that received certification since 2012. In total, 57 projects were located within the Hotspot counties and were certified since January 1,2012. Of these 57 projects, only 5 projects obtained the certified wood credit. In an effort to compare perceptions between material specifiers that obtained the certified wood credit with those that did not for similar projects, the list of 57 projects was again filtered by the ownership type of the 5 certified wood credit obtaining projects from 2012 and 2013 . These 5 projects had the ownership type of "Federal Government" and "Non-Profit". The second stage of filtering performed on the 57 projects produced a total of 14 projects ( 9 that did not use 
certified wood and 5 that did) between the two Hot Spot areas. The material specifiers of these 14 projects were the targeted potential respondents for the survey.

\subsubsection{Data Collection}

Each of the 14 commercial projects was directly contacted to determine the material specifier for each project. In one instance, an architect was the material specifier for two of the 14 projects. Additionally, although both material specifiers were determined for two of the 14 projects, no direct contact was made despite multiple attempts. Therefore, 12 of the 14 projects were represented by 11 individual material specifiers. Each material specifier from the twelve projects was briefed on the study as well as the types of discussion points that were included in the survey. Upon willingness of the individual to participate in the survey, contact information was then obtained and a time and date to hold the phone survey was scheduled. A follow-up email was sent to all potential respondents that included a short introduction to the study, contact information, and Internal Review Board (IRB) recognition. Additionally, an interview guide that outlined the major discussion topics was attached in the email.

An interview guide (Appendix C) was prepared to ensure that the same basic topics were facilitated to each respondent and to help systematically use the limited time availabilities of the respondents (Patton 2002). The interview guide was reviewed by construction and architectural industry professionals for content validity and revised as needed. The final interview guide consisted of six major topics and was distributed to the respondents several days prior to the interview. Interviews were conducted via telephone and Skype (Skype 2014a). The duration of the Skype/telephone interviews was between nine and forty minutes. The interviews were recorded using the MP3 Skype recorder (Skype 2014b) and promptly transcribed verbatim for later analysis. Theoretical saturation was achieved by the 11 respondents. Theoretical saturation 
was determined by repetitive data submittal by different respondents and the lack of new data being presented by subsequent respondents.

\subsubsection{Data Analysis}

Thematic analysis was used to analyze the data obtained from the respondents. Thematic analysis is a method commonly used in qualitative research to identify patterns or themes that exist within the data (Bruan and Clarke 2006). To aid in the analysis, the transcribed interview data was uploaded to NVivo (NVivo 10 2014). Themes were determined, through an inductive approach, by grouping respondent information that represented patterns throughout the research topics. This approach identifies themes based on exploration of the data itself (Bruan and Clarke 2006, Guest et al. 2011). The six phases of thematic analysis used were: 1) familiarizing yourself with the data, 2) generating the initial codes, 3) searching for themes, 4) reviewing the themes, 5) defining and naming the themes, and 6) producing the report (Braun and Clarke 2006). Individual responses from each of the respondents were evaluated and grouped into codes by topic similarity.

\subsection{RESULTS AND DISCUSSION}

\subsubsection{Spatial Analysis}

Results indicate that the 612 LEED certified projects located in the Appalachian region are spatially clustered. Likewise, Moran's I was determined for the 210 LEED certified projects in this region that obtained the certified wood credit. Results indicate that these 210 projects also demonstrate a spatially clustered pattern. Furthermore, by determining the Moran's I for both sets of data on a yearly basis (Figure 4-1); we can see the trend of spatial clustering that these 
projects have followed. These results indicate that, given the current trend continues, it is likely additional LEED certified projects will be located near existing LEED certified projects and that new LEED certified projects that obtain the certified wood credit.

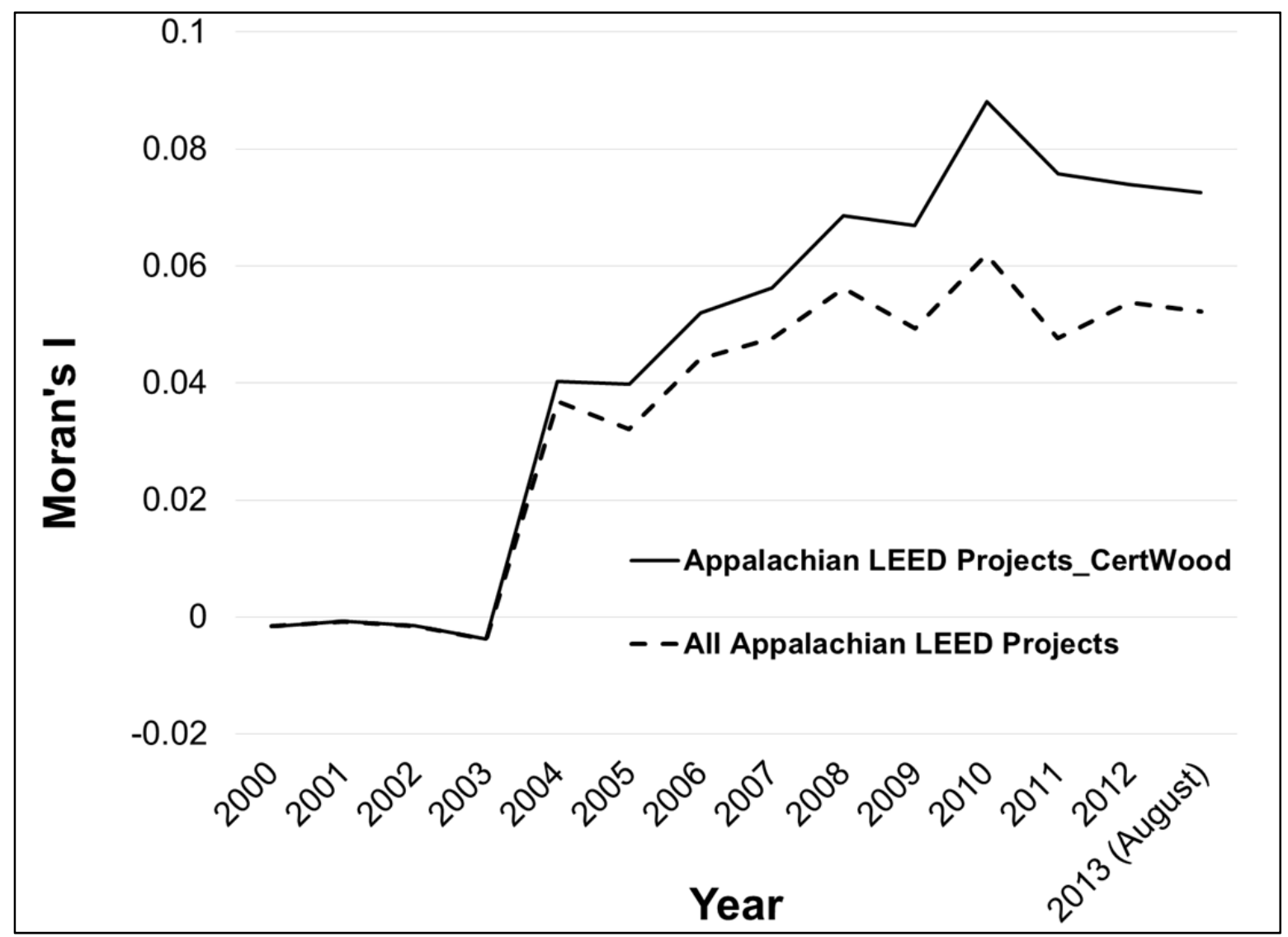

Figure 4-1. Moran's I by year for all LEED certified projects and LEED certified projects that obtained the certified wood credit - both within the Appalachian Region.

Statistically significant Hotspots of clustering all 612 LEED projects, as well as the 210 LEED projects that obtained the certified wood credit, were found in two areas: Pittsburgh, PA and Greenville, SC (Figure 4-2). At a p-value $<0.05$, the significant Hotspot counties indicated for both groups were identical. These two geographic areas have offered significant construction 
markets for previous LEED projects in a region that has shown increasing clustered growth of LEED projects. Therefore these areas are considered to be potential growth areas for future LEED certified buildings as well as LEED certified buildings that obtain the certified wood credit. Within the Hot Spot counties indicated by the analysis, 199 LEED certified projects have been constructed since 2000. Of these 199 projects, 87 (approximately 44\%) obtained the certified wood credit. will likely be located near existing LEED certified that have obtained the certified wood credit. Wood product manufacturers interested in pursuing the commercial green building market, therefore, should consider marketing in the Pittsburgh, PA and Greenville, SC areas where large numbers of commercial LEED certified projects have been located and new projects will likely be constructed. 


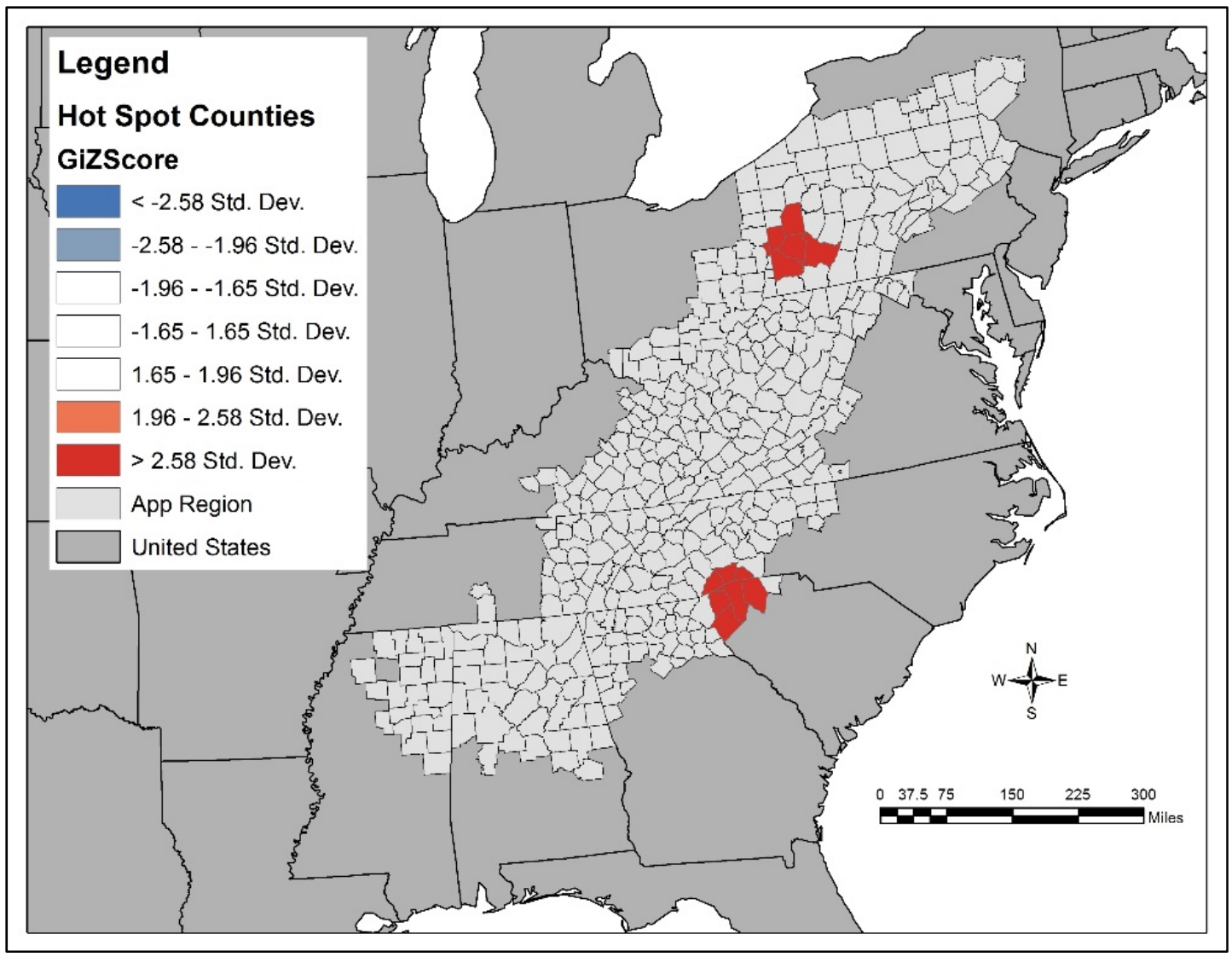

Figure 4-2. Hotspot counties for commercial LEED certified projects in the Appalachian region that received the certified wood credit.

\subsubsection{Thematic Analysis}

Initially, 395 separate references were extracted from the respondent data. Of those 395 references, two major categories and four prominent themes were identified (Table 4-1). Two themes in the "Wood Product Use in Green Building" category were: 1) "Supports for Wood Use" and 2) "Barriers for Wood Use". Additionally, two themes in "The Green Building Market" category were: 1) "Motivations for Building Green" and 2) "Changes in the Green Building Market”. 
Table 4-1 Thematic Analysis Results of Material Specifier Interviews.

\begin{tabular}{|c|c|c|}
\hline Major Categories & Themes & Dimensions \\
\hline \multirow{9}{*}{$\begin{array}{l}\text { Wood Product } \\
\text { Use in GB }\end{array}$} & \multirow{4}{*}{ Supports for Wood Use } & Availability \\
\hline & & Physical Attributes \\
\hline & & $\begin{array}{l}\text { Environmental } \\
\text { Attributes }\end{array}$ \\
\hline & & $\begin{array}{l}\text { Structural Wood } \\
\text { Products }\end{array}$ \\
\hline & \multirow{5}{*}{ Barriers for Wood Use } & Building Type/Code \\
\hline & & Cost \\
\hline & & Inferior Properties \\
\hline & & Availability \\
\hline & & Environmental Impact \\
\hline \multirow{6}{*}{$\begin{array}{l}\text { The Green } \\
\text { Building Market }\end{array}$} & \multirow{2}{*}{ Motivations for Building Green } & Existing Motivations \\
\hline & & Suggested Motivations \\
\hline & \multirow{4}{*}{$\begin{array}{c}\text { Changes in the Green Building } \\
\text { Market }\end{array}$} & GB Standard Use \\
\hline & & Barriers to LEED Use \\
\hline & & $\begin{array}{l}\text { Code Growth Driving } \\
\text { Standard Growth }\end{array}$ \\
\hline & & $\begin{array}{l}\text { Market Segment } \\
\text { Growth }\end{array}$ \\
\hline
\end{tabular}

\subsubsection{Wood Product Use in Green Building}

\subsubsection{Supports for Wood Use}

Similar to Wang et al. (2014), the results of this study identified a positive perception towards the use of wood-based products in building projects. The support for wood use in commercial green building projects were based on specifiers' perceptions surrounding various material aspects such as the physical and environmental attributes, availability of environmentally certified wood products, and the optimism associated with new structural woodbased composite products. The physical attributes of wood products were highly praised by respondents, especially for the aesthetic contrast wood provides when paired with metal or concrete. Many respondents commented that they used wood materials in projects because of its 
warm and natural feel as well as its ability to add a "more stately feel" by using a "more refined product selection".

“...it's [wood] warm...there's a real aesthetic value for the use of wood. We love contrasting it with other materials, white drywall walls, other materials like metals...”

In addition to the aesthetic warmth of wood, specifiers also commented on the tactile qualities and often placed the material in strategic locations such as doors and handrails to provide touch points for the building's inhabitants.

“There were mahogany handrails that were used in special places that had a tactile feel. It was at the main stairs were you went up so that people could grasp onto something that was alive and warm comparatively."

Specifers were comfortable using wood materials because of the familiarity they and contractors had with wood and that it was an easy material to work with in various applications. The ability of contractors to easily manipulate the shape and size of the material provides flexibility and adaptation for its use. Additionally, the durability of specific wood species such as mahogany was indicated as a support for wood use in exposed applications.

"In using the right products I think it has a perfect relationship in the green building environment because it is a green product. It doesn't just do one thing, there so many different things you can do with it."

The environmental benefits of wood materials were often cited as an obvious choice to use the material in green building projects. For many respondents, the use of FSC certified products was one way to prove the sustainability of the material. Additionally, the added benefit 
of point accumulation toward building certification for the use of FSC certified products increased the incentive for its use. For most respondents, obtaining the certified wood credit towards building certification was attractive given the relatively small amounts of wood materials used in commercial building projects.

"We know that wood that is harvested properly and sustainably, that has the certification throughout the process is actually being, again, harvested and produced in a sustainable manner."

Although much of the conversations surrounded wood use as a finished material for interior applications, several respondents were optimistic toward the use of wood-based composites for structural application in commercial buildings. Currently, the use of wood for structural applications is limited to a maximum of 4 stories ( 5 stories in the case of heavy timber construction) depending on the area of the building, intended occupancy, and fire ratings (IBC 2012). However, novel wood-based composites called cross-laminated timbers (CLTs) that have been used in other parts of the world as the supporting structure for mid-rise buildings up to 8 stories in height (Crespell and Gagnon 2010) may be one avenue for future structural wood use in multistory buildings in the U.S. Respondents indicated interest in this technology and feel there would be a growing market opportunity for the product.

“That's [CLTs] something we would definitely be all over looking at for a midrise alternative to structural metal studs or traditional steel frame.”

"I know that there have been some mid-rise buildings that have been done using structural engineered wood. I do think that that's interesting and I do think that market will increase.” 
Generally, respondents felt that the future use of interior as well as structural wood products in commercial building applications would remain constant given the current products available. Similar to results found by Knowles (2011), many respondents stated that structural material selection was primarily based on the building type and intended use before considering its environmental impact. Introducing a wood-based composite such as CLTs that could be considered as a direct alternative to steel or concrete products may impact the order in which specifiers evaluate material attributes, giving more preference to less environmentally impactful materials like wood (Gustavsson et al. 2006a, Gustavsson et al. 2006b, Lippke et al. 2004, Buchanan A. H. and Levine S. B. 1999, Peterson A.K and Solburg B. 2002, Peterson A.K and Solburg B. 2003, Upton et al. 2008, Puettmann and Wilson 2005). Optimism for the use of CLTs was shared by respondents; however, increased education towards material specifiers for CLTs and other novel wood products is needed. Although some specifiers were aware of CLT products and their use in other countries for commercial projects, greater market education is needed to introduce the product and its capabilities. Although there is no current manufacturing of CLTs in this region to promote education for the product, inclusion in the 2015 International Building Code (AWC 2012) will likely spur further interest in its use and, consequently, its market opportunity.

Through follow-up conversations, respondents also indicated that their preferential education sources for wood products were through two main avenues: 1) peer learning opportunities such as product representative "lunch-and-learns", conferences, and other designers and 2) through personal research such as magazines, company websites, and case studies. This information provides an excellent opportunity for wood product manufacturers and 
distributors to reassess the use of their current media for marketing communications, and adjusting if necessary, to most effectively reach material specifiers.

\subsubsection{Barriers for Wood Use}

Respondents indicated that building code restrictions, building type restrictions, cost of environmentally certified wood products, inferior properties, availability of specialty wood products, and environmental impact of certain wood products imposed barriers for material use in commercial green building projects. Almost all respondents suggested building code and type restrictions as the main barriers to structural wood product use in commercial building projects. Respondents specifically indicated building height, pre-engineered steel buildings, combustible material restrictions, and open floor space requirements as reasons they didn't use wood in structural applications. Novel wood products such as CLTs, however, may be able to overcome these issues. CLTs are pre-engineered and pre-constructed prior delivery to the job site and may be an appealing alternative given some specifiers preference for wood materials. Additionally, CLTs provide the structural capacity for high- and mid-rise buildings along with long floor and ceiling spans (Gagnon and Pirvu 2011). Additionally, many felt that the environmental impact of the material was not a concern so much as specifying a material that properly addressed the particular needs of the project as well as the building codes.

"I don't see the selection of the structural material been based on whether it's a green building or not. I see the structural system being based more on what the building is designed to do. If it's a spec office building I don't see it being wood just because of the required open floor spaces.” 
Moreover, respondents indicated code-based barriers associated with noncombustible construction projects such as higher education and laboratories. In situations like these as well as multi-story buildings, wood products for structural use are not currently an approved option and were not considered.

“...we don’t use any wood products in non-combustible construction. That's the way we typically go for our higher education work...non-com. So that limits our use of wood use to case work and trim and paneling..."

Cost of materials is of high importance when specifying products for use in green or typically designed buildings. Some specifiers indicated that the cost of FSC certified wood products was a deciding factor in whether or not it was included during construction. One tipping point mentioned was whether the additional credit-point associated with receiving the certified wood credit towards building certification made the difference in the project becoming certified or moving the certification to a higher level (i.e. from Silver to Gold). If so, the owner may be persuaded to pursue the certified wood credit as long as other avenues to gain the needed point were more expensive.

Inferior properties such as durability in exposed applications were indicated as shortcomings of wood-based materials. Many respondents would look to alternative materials such as aluminum or plastic for use in windows, doors, decking and siding. Although most respondents preferred the look and feel of wood-based materials, they could not justify the additional maintenance required to keep the wood looking and performing well. Specifiers were asked if chemically treated wood products provided the material stability they were looking for in exposed applications. Specifiers didn't consider the treated wood as an option due to poor aesthetics associated with the discoloring due to chemical treatment. 
"The main thing that would discourage it would be the location of use. If it was an area that was likely to get wet we would shy away from it because wood is a good food for mold. Sometimes it just doesn't deal with water very well.”

Durability issues were also noted for wood products in high use areas indoors. Again, the continued maintenance of the wood products was a disadvantage when compared to substitute materials such as vinyl or porcelain.

"The durability of wood as a long-term finish like for flooring...we could use it... but there are other products available that simulate the look of wood that have a lot less maintenance associated with them and are not combustible. So we end up using products like, a luxury vinyl tile, there are some nice new porcelain tiles that simulate the look of wood...but they are very durable products that require no maintenance."

The current availability of specialty wood products such as those carrying the FSC certification was indicated by a few respondents as being difficult to procure. Although the availability of FSC products was noted by most respondents to be low several years ago, the majority felt they were readily available nowadays. Perhaps the low availability mentioned by a few respondents, indicates a restricted market penetration by FSC product suppliers in the two Hotspot regions. Other specialty wood products such as reclaimed teak, redwood, and cedar were also mentioned to have low availabilities. Although reclaimed materials only represent a small niche in the wood products industry, these responses could indicate a potential need for increased material sources. 
The environmental impact of adhesives used in the production of wood composites, specifically bamboo flooring, was indicated by one respondent as a barrier for product use. Volatile organic compounds (VOCs) associated with the adhesives used in wood products was a concern of a different respondent. Additionally, the location of the wood material source was also an environmental concern. Bamboo was noted specifically as a material that was closely researched for product origin and adhesive content before specification. This remark indicates that although Bamboo is considered a rapidly renewable material and is therefore eligible to pursue the LEED rapidly renewable material credit, specifiers may determine the environmental impact of material transportation distances (i.e. imported from other countries) higher than that of utilizing a rapidly renewable material. Additionally, the specifier who noted this concern may consider adhesives used in manufacturing plants outside of the U.S. more harmful since only bamboo flooring was mentioned. Particular adhesive types were not mentioned by the respondents, but including low VOC certifications achieved by manufacturers of wood composites may be beneficial in overcoming these perceptions.

Barriers to wood use in the commercial green building market lie mainly in building type and design; code restrictions such as building height and fire resistance; and durability issues with products placed in high-traffic and/or weather exposed applications. These barriers may provide an opportunity for wood product manufacturers by isolating perceived shortcomings of the product therefore indicating specific issues that need addressed. The development and use of CLTs may be a way to overcome building and fire code restrictions for multi-story structural wood use. Durability issues with wood products were discussed for both exterior and interior applications. Issues regarding the effects of direct sunlight and moisture exposure to exterior wood products were major concerns as well as interior wood products placed in high-use areas. 
Respondents looked for ways to use wood products but were often driven to use alternative materials due to the lack of existing wood products suitable for the application, or due to the lack of knowledge of existing wood products that were suitable. Responses indicate that material preference is often given to wood-based materials. Therefore, to capitalize on material specifier preferences that already exist, wood product manufacturers must find ways to supply woodbased products capable of meeting these demands or further educate specifiers of the products that currently exist to meet their needs.

\subsubsection{The Green Building Market}

\subsubsection{Motivations for Building Green}

Motivations for designing and constructing green buildings were driven by a combination of professional philosophy and various requirements. All respondents felt they had a professional responsibility to design their projects to be of low environmental impact. It was often mentioned that the design of a building would meet green building certification standards - even when pursuing a standard was not the initial goal.

“...we actually did a project where we got all the way through the drawings and that client decided to do LEED - so we had to go back to right when construction started and we only had to change one thing to get it. And we ended up getting LEED gold. The basic things that they were doing we're already doing for green" Additionally, specifiers felt that the evolution of green building standards is positive and that it can help guide good, sustainable design practices. Although a green-minded designer's practices may not be different than some of the green building standards, achieving the standard gives 
third-party verification to their efforts. These verifications quantify achievements of the design and may act as confirmation of the achievements in the minds of others related to the project.

“...even before the existence of LEED or even the green building dialog, really good designers were incorporating sustainable strategies in their projects. Light quality, daylighting, fresh air and all of that...orienting a building properly...all of that is about sustainable design. Ideally, designers don't need a green building checklist to work off of...but certainly there's no question - it helps...it can help.”

Owner-driven requirements were also indicated by many respondents as a current motivation for building green projects. Government-owned projects discussed during the survey were required to be designed and built to the LEED green building standard. Additionally, respondents noted most higher education facilities were also required to achieve green building certification. University and college projects sometimes took this path as part of a campus-wide initiative to show their commitment to the sustainability of the environment. Also, owners found benefit in marketing the building certification for positive public relations growth as well as elevating the organization's stature in their industry.

Owner-driven requirements to build green would sometimes include achieving building certifications. Often, however, owners would require that a project meet the requirements of a green building standard, but not pursue the actual certification. The additional cost of certification was noted as being the main reason for this approach. From these owners' perspective, a benefit in green building design lies in the cost savings associated with energy and resource use over a long period of time. 
"What we're starting to see though, is that the cost of actual certification, many owners are now choosing not to pursue actual certification, but to try to go ahead and kind of calculate what the points might be...”

“We have a couple of projects where people come back and say well, we don't really want to pay for LEED to review and for a LEED plaque and things like that. But we still want you to design it to the LEED standard."

One other primary motivation to pursue a green building standard is driven by funding source. In several instances, respondents indicated that funding for projects was tied to achieving a green building standard. Alternatively, project owners could also use their proposal for achieving green building certification in an upcoming project as a way to entice would-be funding sources.

“...non-profits we are working with...really like to make their buildings as sustainable as possible because it's a good way to go out for capital funding campaigns to ask funders...once funders see this project is going that sustainable design path they are more likely so send them money... and then it becomes another tool that - alright so-and-so is donating towards the auditorium, so-andso is donating towards the photovoltaic array, or the zero-scaping or something."

Government initiative has driven part of the green building growth and development by requiring third party certified green building standards for their buildings. Results from this study suggest other sectors such as non-profit, higher education, and private companies are growing the green building demand further. Respondents indicated that benefits driving these additional sectors were centered on the long-term cost savings, proven sustainable accomplishments, 
favorable public image, and supplying a niche market product for environmentally conscious building occupants. Economic growth has also been shown as a driver for the number of green building projects in an area (Prum and Kobayashi 2014). These factors should also be of consideration for manufacturers targeting specific industry sectors as well as geographic locations.

Motivations for building green indicated by respondents, in turn, indicate opportunities for wood products manufacturers. Specifiers suggested that professional philosophy was one reason to build low environmental impact structures. These remarks indicate that manufacturers should include the low-environmental impacts of wood products in their marketing materials and could quantify the impacts of their products through life cycle analysis (LCA) data. Providing the LCA data could also help differentiate the environmental benefits of wood materials over substitute materials like concrete or steel. Additionally, owner directives and funding source were a major driver in building green structures. In some cases the structures were built to a green building standard but never submitted for actual certification. Since building owners and funding sources can contribute significantly to deciding the types of materials used in a building, manufactures should consider promoting the attributes of wood products to this end-user target market.

\subsubsection{Changes in the Green Building Market}

Respondent perceptions of changes in the green building market were primarily based on industry growth as well as fluctuations in the demand of various green building standards. In general, respondents feel the green building market is expanding and will continue to expand in 
their respective regions. These remarks help support the results of the Moran's I analysis previously mentioned. The Moran's I analysis was performed only on commercial LEED certified projects, whereas the respondent's perceptions were based on the green building market as a whole.

“Overtime I think it [the green building market] will continue to increase. I think the demand is certainly here to stay; it's not a fad that is going to go away."

Although respondents felt the green building industry is growing as a whole, many indicated discontent with the LEED standard specifically. Complaints toward the use of the standard included both the current version as well as LEED version four. Comments revolved around the cost of certification, increased design and administrative costs, frequency of new LEED versions, inconsistent LEED reviewers, and interaction with the LEED website. These remarks led to discussions on other green building standards that were becoming popular in the two geographic areas. Standards such as Passive House, Living Building Challenge, and EarthCraft were mentioned, but the most popular green building standard indicated for use other than LEED - was Green Globes. The Green Globes standard was used by some respondents as an alternative to the LEED standard and is approved for use as a green building standard for the Federal green building requirement by the General Services Administration (GSA) (Tangherlini 2013).

“...the [client] said that they really don't want to do a LEED project but we have to... are there any alternatives out there? And we brought them Green Globes."

The purpose of choosing specifiers from projects that did obtain the certified wood credit in their LEED certified project, as well as those that did not, was to see if there were perception 
differences between these two groups. Respondents from both groups indicated similar perceptions towards wood product use in green building and the green building market in general. The reasons noted for the specifiers that did not obtain the certified wood credit were primarily a reflection of the building type (institutional, laboratories, pre-engineered metal design) and building code restrictions (building height restrictions and fire code restrictions) and was not associated with their personal or professional preferences.

Additionally, respondent data pertaining to the four themes were compared based on the geographic region of the LEED certified project selected via purposeful sampling - Pittsburgh, PA or Greenville, SC. Respondents showed no major differences in perceptions based on any of the four themes except for "Changes in the Green Building Market". Respondents from both regions agreed that the green building market will increase. However, respondents from the Greenville, SC area more often indicated Green Globes as a green building standard growing in popularity, particularly as an alternative to the LEED standard. This result could be the influence of a 2013 SC state law that prohibits the pursuit of building certification points that discriminate against products harvested from Sustainable Forestry Initiative (SFI) and American Trees Farm System (ATFS) certified tracts (South Carolina 2013). While the LEED certification only recognizes the Forest Stewardship Council (FSC) certification, Green Globes recognizes products harvested from FSC, SFI, ATFS, and Canadian Standards Association (CSA) certified forests (Green Globes 2014). Increased use of the Green Globes certification standard would therefore be a benefit to manufacturers carrying a forest product certification like SFI and may increase the opportunity to have their products incorporated for CWP specific points towards building certification. 


\subsection{CONCLUSIONS AND SUMMARY}

This research focused on determining wood-based product use perceptions of material specifiers in high use areas for certified wood products in commercial LEED certified projects within the U.S. Appalachian region. Specifically, the results of this study have indicated countylevel Hot Spots areas around Pittsburgh, PA and Greenville, SC. The projects in the Appalachian region have high levels of spatial autocorrelation and continue to be constructed near existing LEED certified projects throughout this region. Given this trend of spatial growth, the Hotspot counties may indicate regions of future market growth for both environmentally certified and non-certified wood products in future commercial LEED projects. Identifying these areas will not only provide wood product manufacturers a geographic target market, but will, in turn, provide increased opportunity for material specifiers to have access to wood-based products.

Results indicate that the respondents, in general, have a strong personal and professional responsibility toward sustainable building design and believe wood products offer environmental and physical attributes needed to help achieve this goal. Certified wood products were typically available for most respondents although the use of these materials was sometimes curbed by owner discretion based on budget considerations. These findings suggest that manufacturers should include the environmental benefits of wood in their marketing materials when targeting material specifiers. Additionally, manufactures will need to overcome the cost/value perception of CWPs for end-users in order to unify demand between material specifiers and building owners. Including information such as the certification process of CWPs may help to justify their value.

The major barriers to structural wood product use in commercial green building projects were fire code, multi-story restrictions, and open span requirements. Meeting the optimism of 
material specifiers by providing CLTs for construction may help overcome these barriers while providing a structural material type that specifiers indicated preference in using.

Although respondent perceptions indicate some constriction in the use of the LEED certification standard, all respondents indicated that the green building market as a whole continues to expand through professional philosophy, owner directives, funding source requirements, and building code advancements. As the trend for green building continues to grow, the opportunity for wood products to gain additional markets also increases.

Manufacturers should continually increase their marketing efforts towards the green building industry by strategically identifying geographic areas of high green building standard use as well as marketing to meet the preferences and needs of the material specifiers in that area. Material specifiers play a key role in material inclusion for many of these projects and providing readily available wood products to meet or exceed their expectations may not only gain their business through material preference but also through supply convenience.

This study employed a purposeful sampling technique where respondents were selected based on their experience with a LEED certified project. Although respondents were involved in designing projects for multiple green building standards, perceptions of LEED certified project experience may not be applicable to experiences with other green building projects and therefore a limitation of this study. Inclusion of respondents chosen due to their affiliation with a project certified by a different green building standard may have resulted in different perceptions.

\subsection{FUTURE RESEARCH RECOMMENDATIONS}

Future research recommendations are to expand this research to include the perceptions of other material specifiers specifically involved in green building standards other than LEED. 
The opportunities for material use and point generation toward building certification are different in each green building standard. Therefore, specifiers that are partial to a particular green building standard, may have alternative perceptions towards the use of wood products than those indicated in this study.

\subsection{REFERENCES}

AWC (2012). American Wood Council - Cross Laminated Timber (CLT) Gains Code Approval - New Opportunities for Wood in Non-Residential Structures

November 12, 2012. http://www.awc.org/NewsReleases/2012/newsreleases2012.php

Braun V and Clarke V (2006). Using thematic analysis in psychology. Qual Res Psycho. 3(2):77101.

Buchanan AH, SB Levine (1999) Wood-based building materials and atmospheric carbon emissions. Environ Sci \& Policy 2:427-437.

Cidell J (2009) Building green: the emerging geography of LEED-certified buildings and professionals. Prof Geogr 61(2):200-215.

Gagnon, S., \& Pirvu, C. (Eds.). (2011). CLT handbook: cross-laminated timber. FPInnovations.

Crespell P. and Gagnon S. (2010). Cross laminated timber: A primer. FPInnovations, PointeClarie, Quebec, Canada.

ESRI (2014) Hot Spot Analysis (Getis-Ord Gi*) (Spatial Statistics) Usage tips. http://resources.esri.com/help/9.3/arcgisengine/java/gp_toolref/spatial_statistics_tools/hot _spot_analysis_getis_ord_gi_star_spatial_statistics_.htm. (15 September 2014). 
Estep GD, DeVallance DB, Grushecky S (2013) Affordable Home Builder Demand for Green and Certified Wood Products. Forest Prod J 63(1):4-11.

Guest G, MacQueen KM, Namey EE (2011). Applied thematic analysis. Sage.

Green Globes (2014) Green Globes - About. http://www.greenglobes.com/about.asp

Grushecky ST, Buehlmann U, Schuler A, Luppold W, Cesa E. (2006). Decline in the US furniture industry: A case study of the impacts to the hardwood lumber supply chain. Wood Fiber Sci. 38(2):365-376.

Gustavsson L, Madlener R, Hoen HF, Jungmeier G, Karjalainen T, Klohn S, Mahapatra K, Pohjola J, Solberg B, and Spelter H (2006b) The Role Of Wood Material For Greenhouse Gas Mitigation. Mitig Adapt Strategies Glob Chang 11:1097-1127.

Gustavsson L, Pingoud K, Sathre R (2006a) Carbon Dioxide Balance Of Wood Substitution: Comparing Concrete- and Wood-Framed Buildings. Mitig Adapt Strategies Glob Chang 11: 667-691.

IBC (2012). International Building Code - SECTION 503 GENERAL BUILDING HEIGHT AND AREA LIMITATIONS. http://publicecodes.cyberregs.com/icod/ibc/2012/icod_ibc_2012_5_sec003.htm

Johansson O (2011) The spatial diffusion of green building technologies: The case of Leadership in Energy and Environmental Design (LEED) in the United States. Int J Technology Management Sust Dev 10(3):251-266.

Kahn ME, Vaughn RK (2009) Green Market Geography. The Spatial Clustering of Hybrid Vehicles and LEED Registered Buildings. BE J Econ Anal Poli 9(2):1-22. 
Knowles C, Theodoropoulos C, Griffin C, Allen J. (2011) Oregon design professionals views on structural building products in green buildings: implications for wood. Can J For Res 41:390-400.

LEED (2014). LEED user - NC-2009 MRc7:Certified Wood. http://www.leeduser.com/credit/NC-2009/MRc7

Lippke B, Wilson J, Perez-Garcia J, Bowyer J, and Meil J (2004). Corrim: Life Cycle Environmental Performance of Renewable Building Materials. Forest Prod J 54(6):8-19.

McGraw Hill Construction (2013). World Green Building Trends. http://analyticsstore.construction.com/index.php/world-green-building-trendssmartmarket-report-2013.html (15 September 2014).

NVivo (2014). QSR Iternational. NVIVO 10 for Windows. http://www.qsrinternational.com/products_nvivo.aspx

O'CONNOR J., Kozak R., Gaston C., Fell D. 2004. Wood use in nonresidential buildings: Opportunities and barriers. Forest prod J. 54(3):19-28.

Patton MQ (2005). Qualitative research. John Wiley \& Sons, Ltd.

Petersen AK, Solberg B (2002) Greenhouse gas emissions, life-cycle inventory and costefficiency of using laminated wood instead of steel construction. Case: beams at Gardermoen airport. Environ Sci Policy 5:169-182.

Petersen AK and Solberg B (2003) Substitution between floor constructions in wood and natural stone: comparison of energy consumption, greenhouse gas emissions, and costs over the life cycle. Can J For Res 33:1061-1075. 
Prum, DA and Kobayashi, T (2014). Green Building Geography Across the United States: Does Governmental Incentives or Economic Growth Stimulate Construction? Real Estate Law Journal.

Puettmann ME and Wilson JB (2005) Life-Cycle Analysis Of Wood Products: Cradle-To-Gate Lci Of Residential Wood Building Materials. Wood Fiber Sci - Corrim Special Issue $37: 18-29$.

Roos A, Woxblom L, McCluskey D (2010). The influence of architects and structural engineers on timber in construction-perceptions and roles. Silva Fennica, 44(5):871-884.

Skype (2014a) http://www.skype.com/en/.

Skype (2014b). MP3 Skype recorder. http://voipcallrecording.com/MP3_Skype_Recorder.

South Carolina (2013). South Carolina General Assembly. http://www.scstatehouse.gov/sess120_2013-2014/bills/635.htm

Tangherlini D. (2013) U.S. General Services Administration - Office of Federal HighPerformance Green Buildings. http://www.gsa.gov/portal/mediaId/180467/fileName/GSA_Green_Building_Certificatio n_Systems_Review_Letter_to_Sec_Energy.action

Upton B, Miner R, Spinney M, Heath L (2008) The green House Gas and Energy Impacts of Using Wood Instead of Alternatives in Residential Construction in the United States. Biomass Bioenergy 32:1-10.

Wagner ER and Hansen EN 2004. Environmental attributes of wood products: Context and relevance for US architects. Forest Prod J. 54(1):19-25. 
Wang L, Toppinen, A, Juslin, H. 2014. Use of wood in green building: a study of expert perspectives from the UK. J Clean Prod. 65:350-361.

USGBC (2013a) USGBC Profile. http://www.usgbc.org/profile. (12 November 2014)

USGBC (2013b) USGBC History. http://www.usgbc.org/about/history. (15 September 2014) 


\section{SECONDARY WOOD PRODUCT MANUFACTURERS PERCEPTION AND MARKETING EFFORTS TOWARD THE GREEN BUILDING MARKET}




\section{ABSTRACT}

Results from a recent study (in Chapter 4) have indicated material specifiers' demand for and perceptions of wood-based materials for use in the commercial LEED green building sector of the Appalachian Region. The demand and preference for wood products by specifier respondents could increase the potential for wood product use in this market. The objective of this research was to determine the perceptions of wood product manufacturers on the green building market and the role of wood products in this market differ from that of material specifiers. Through purposeful sampling methods, this study determined that manufacturers are aware of the green building market and, in general, expect it to grow in the future. However, respondents were not focusing marketing efforts specifically toward the commercial green building market and felt that limited volumes of wood were used in this market. Additionally, respondents indicated low marketing efforts overall and relied heavily on existing relationships and word-of-mouth to facilitate sales. Some indications by respondents towards low marketing efforts is because they are not interested in growing their business or are waiting to see a demand before pursuing a market. Specific gaps were identified between manufacturers and specifiers related to the use of certified wood products (CWPs). Specifically, manufactures, in general, felt the certification was not necessary and that specifiers (in Chapter 4) indicated there were benefits (e.g., point generation toward building certification and proof of sustainable building materials) to the certifications and encouraged their use. Lastly, low value was placed on marketing tactics such as websites, ads in trade magazines, and other passive efforts by manufacturers. Contrarily, specifiers (in Chapter 4) indicated that resources such websites and magazine ads were favored as media for marketing communications for sources of new product education. Manufactures should therefore consider marketing the environmental qualities of wood materials and promote 
their products in specifier-valued media for marketing communications such as websites and trade magazines. Promoting wood products by including the attributes important to specifers and in the media for marketing communications specifiers use to learn about new wood products may help drive sales growth for manufacturers in the green building market.

\subsection{INTRODUCTION}

The green commercial building sector in the United States (U.S.) offers a growing market (McGraw Hill 2013) for low environmental impact construction materials. Research indicates that the number of environmentally-conscious consumers is increasing and that they are more likely to purchase from companies with high environmental character and that actively avoid environmental impacts (Fraj and Martinez 2006). The use of wood as a construction material has been shown to have many environmental benefits over other building materials such as concrete and metals (Gustavsson et al. 2006a; Gustavsson et al. 2006b, Lippke et al. 2004; Buchanan and Levine 1999; Peterson A.K and Solburg B. 2002; Peterson A.K and Solburg B. 2003) and can be rewarded for its use in green building standards by gaining points towards building certification.

Environmental concerns along with competition from alternative material use have grown and evolved advertising efforts by the forest product industry to increase focus on environmental benefits of wood materials (Tokarczyk and Hansen 2006). Research shows that magazine advertisements by the forest product industry have increased the promotion of environmental attributes of wood and that companies preferred advertising in magazines targeted towards architects (Wagner and Hansen 2002). Grillo et al. (2008) indicate that some wood products companies have segregated their audiences as environmentally conscious and those that are driven more by product and service needs. They also suggested that wood product manufacturers 
could improve environmental messaging by connecting on a moral or emotional level as well as indicating benefits towards personal health and planet preservation. Furthermore, research (Bigsby and Ozanne 2002; Wagner and Hansen 2004) has indicated that consumers of wood products prefer specific environmental attributes such as local sourcing along with sustainable and environmental certifications such as FSC or SFI.

Research on the green building industry suggested that manufacturers carrying CWPs had improved access to green building markets but that low marketing efforts resulted in a lack of general consumer awareness (Kraxner 2008). Additionally, studies have indicated that material specifiers such as architects, engineers, and general contractors have a positive perception of wood, especially CWPs and want to increase their use in projects (Knowels et al. 2011, Estep et al. 2013, Chapter 4). Tardiff and O'Connor (2009) suggest that the trend for green design is not going away and that manufacturers should consider increasing and promoting their environmental efforts or risk losing market share to competition that are moving in this direction.

Research in Chapter 4 identified material specifiers' perceptions toward wood product use in commercial LEED certified projects. One result from that study suggested that manufacturers should include the environmental attributes of wood products and that specifiers use media for marketing communications like websites and magazine advertisements to learn about new products. A different study (Robichaud et al. 2009) reported similar findings and further suggested that forest product manufacturers who entered the commercial building market, be aware of the perceived attributes of wood and market their products accordingly.

An additional motivation for material specifiers to include wood product use in green buildings is to generate points towards building certification. Opportunities for point accumulation toward green building certifications like LEED exist for uncertified wood products 
as well as environmentally-certified wood products such as those certified by the Forest Stewardship Council (FSC) (FSC 2015). Offering environmentally certified wood products has been suggested not only to retain customers and indicate the company's responsibility toward environmental issues (Owari 2006), but also to meet demands of using the material to help obtain certification for green residential construction projects (Ganguly et al. 2013). In general, the availability of these certified products to material specifiers was lacking in the past but has become more readily available in recent years (Chapter 4). Targeted communications toward material specifiers promoting the availability and environmental benefits of wood products will likely need to continue in order to compete with alternative products such as steel, concrete, tile, etc.

A recent study (Robichaud et al. 2012) explored the role of marketing communications on architects' perceptions of the identity of wood. Through three direct marketing communication pieces: 1) a technical brochure, (2) an advertisement, and 3) a case study, results indicated no noticeable impact was achieved when presented to the architects. Although the technical brochure was determined to be the one most kept by architects, authors suggested that long-term communication strategies between secondary wood products manufacturers and architects may be needed to influence their perceived identity of wood. A different study by Buehlmann et al. (2013) looked at secondary manufacturers and found that respondents indicated "marketing and sales" was the most frequently mentioned area for needed improvement. This area was also indicated to be one of the top areas for significant investments within the next five years. Additionally, these firms often relied on conversations with customers to identify industry trends. 
The studies previously mentioned have suggested options for wood product manufacturers when marketing toward material specifiers. Primarily, the types of wood products specified in commercial projects are construction-ready or finished and supplied by secondary wood product manufacturers. Therefore, it is important to evaluate the perceptions of those individuals directly supplying materials to specifiers in the green building market. Additionally, secondary wood product manufacturers realize and plan to overcome deficiencies in sales and marketing by making significant investments towards this area (Buehlmann et al. 2013). Given the opportunity of a growing market in the green building industry, identifying the current perceptions and marketing methods of secondary wood product manufacturers towards the green building industry may uncover perception gaps between wood product demand (material specifiers) and wood product supply (wood product manufacturers). However, there have not been published qualitative studies that focus directly on Appalachian-based secondary wood product manufacturers' perspectives toward the commercial green building market and how they are promoting their products to meet the particular needs of this industry. By determining the current perceptions of secondary wood product manufacturers in the Appalachian Region and comparing them with the needs of materials specifiers determined in Chapter 4, the wood products industry can gain valuable insight for untapped education, communication, and marketing tactics that are specific to the green building industry.

The goal of this study was to explore marketing efforts by secondary hardwood producers in the Appalachian Region toward the commercial green building industry. Specific objectives of this research were to understand: what factors marketing managers feel motivate the use of wood products; what perceptions marketing managers have towards the growth/contraction (and driving influences) of the commercial green building market; and what approach tactics 
marketing managers use to promote their products in general as well as to the green building industry.

\subsection{METHODS AND MATERIALS}

\subsubsection{Method}

The qualitative survey method used in chapter four was also used for this study. Using this type of survey method allowed for in-depth interviews as well as improvisational questions for response clarification. More specific details regarding the qualitative survey methodology can be found in section 4.2.1.

\subsubsection{Purposeful Sampling}

For this project, secondary wood product manufacturers located in the Appalachian Region (ARC 2015) were targeted as potential response sources from which to gather data. Furthermore, perceptions of those manufacturers that produced products applicable to the construction industry were of specific interest. A similar purposeful sampling approach as in Chapter 4.2.2 was used in order to select manufacturers of secondary wood products. In this study, like in Chapter 4, criterion sampling (Patton 2002) was used to form the initial list of potential respondents. In particular, potential respondents were those secondary wood product manufacturers that were located in the Appalachian Region and produced products that were used in the construction industry (i.e., flooring, cabinetry, millworks, mouldings, etc.). Alternative to the purposeful sampling method in Chapter 4, an additional purposeful sampling method was also used in this study. Purposeful random sampling (Patton 2002) was used to randomly select potential respondent businesses from the list of manufacturers built using the criterion sampling method. The purpose of this method was to use a systematic approach of 
selecting individual manufacturers and increase the credibility of the study (Miles and Huberman 1994, Patton 2002).

A list of secondary wood manufacturers producing building products was compiled using information from the following, up-to-date sources: Appalachian Hardwood Manufacturers Incorporated - Producers, Appalachian Hardwood Manufacturers Incorporated - Consumers, Pennsylvania Forest Products Association, Ohio Wood Products, Kentucky Forest Industry Association, Primary Forest Products Network, Southeastern Lumber Manufacturers Association, Sustainable Forestry Initiative, Wood Products Manufacturers Association, Architectural Woodwork Institute, Appalachian Hardwood Center, National Hardwood Lumber Association, Forest Stewardship Council, and the Virginia Forest Products Association. These lists were filtered by product type and, when applicable, location, to minimize unwanted data. The location of each business was determined, geocoded and uploaded to Geographic Information Systems (GIS) software (ESRI 2012). Businesses located within the Appalachian Region were separated for use as the target population. Duplicates of businesses were deleted, leaving 582 businesses to serve as the target population.

Each business in the target population list was assigned a random number. The list was then ascendingly sorted by this number. Businesses were contacted in the order they appeared on the randomized list. The goal of contacting the businesses directly was to gain access to the sales manager or the business owner. These individuals were likely to have the most insight when asked about marketing methods used for their products as well as their perception towards the green building industry as a potential sales market. In the event contact was not possible or was declined by the sales manager or owner, the following business on the target population list was contacted. Although there is no specific number of participants required for qualitative surveys 
(Patton 2002), a goal of $12-15$ respondents was established based on the number of respondents needed to reach theoretical saturation in Chapter 4's study. Ultimately, thirteen respondents were reached that agreed to be part of the study.

\subsubsection{Question Development}

Topic questions for the interview guide were developed based on questions and responses from the Chapter 4 study in an effort to obtain comparable data between material specifiers and secondary wood product manufacturers. The interview guide (Appendix D) was prepared to ensure that the same basic topics were facilitated to each respondent and to help systematically use the limited time availabilities of the respondents (Patton 2002). The interview guide was reviewed for content validity and revised as needed.

\subsubsection{Data Collection}

Each sales manager or owner from the thirteen secondary wood product producers was briefed on the study as well as the types of discussion points that were included in the survey. Upon willingness of the individual to participate in the survey, contact information was then obtained and a time and date to hold the phone survey was scheduled. A follow-up email was sent to all potential respondents that included a short introduction to the study, contact information, and Internal Review Board (IRB) recognition. Additionally, an interview guide that outlined the major discussion topics was attached in the email.

The final interview guide consisted of six major discussion topics and was distributed to the respondents several days prior to the interview. Interviews were conducted via telephone and Skype (Skype 2014a). The duration of the Skype/telephone interviews was between 13.5 minutes and 37 minutes (average time of interviews $=26$ minutes 08 seconds). The interviews were 
recorded using the MP3 Skype recorder (Skype 2014b) and promptly transcribed for further analysis. Theoretical saturation was achieved by the 13 respondents. Theoretical saturation was determined by repetitive data submittal by different respondents and the lack of new data being presented by subsequent respondents.

\subsection{RESULTS AND DISCUSSION}

\subsubsection{Thematic Analysis}

Initially, 757 separate references were extracted from the respondent data. Of those 757 references, two major categories and five prominent themes were identified (Table 5-1). Three themes in the "Wood Product Use" category were: 1) "Supports for Wood Use", 2) "Barriers for Wood Use", and 3) "Future Wood Product Use". Additionally, two themes in "Wood Products Markets and Marketing Efforts" category were: 1) "Green Building Market" and 2) "Marketing and Promotion". 
Table 5-1. Thematic Analysis Results of Secondary Wood Product Producer Interviews

\begin{tabular}{|c|c|c|}
\hline Major Categories & Themes & Dimensions \\
\hline \multirow{3}{*}{ Wood Product Use } & Supports for Wood Use & $\begin{array}{l}\text { Customability } \\
\text { Physical Attributes } \\
\text { Environmental Attributes } \\
\text { Aethetics }\end{array}$ \\
\hline & Barriers for Wood Use & $\begin{array}{l}\text { Competing Materials } \\
\text { Cost } \\
\text { Physical Properties } \\
\text { Public Perception } \\
\end{array}$ \\
\hline & Future Wood Product Use & $\begin{array}{l}\text { Demand Shifts } \\
\text { Meeting Future Demand } \\
\text { CWP Demand }\end{array}$ \\
\hline \multirow[b]{2}{*}{$\begin{array}{c}\text { Wood Product Markets and } \\
\text { Marketing Efforts }\end{array}$} & Green Building Market & $\begin{array}{l}\text { Future Market Shifts } \\
\text { Market Areas }\end{array}$ \\
\hline & Marketing and Promotion & $\begin{array}{l}\text { Target Audiances } \\
\text { Future Target Audience } \\
\text { Current Marketing } \\
\text { Future Marketing } \\
\text { Product advantages in } \\
\text { promotions }\end{array}$ \\
\hline
\end{tabular}

\subsubsection{Wood Product Use}

\subsubsection{Supports for Wood Use}

The environmental benefits of wood such as natural product, landfill friendly or recyclable, and renewable resource were a popular remark for respondents when discussing the supports for wood use in commercial green building projects. Some respondents suggested that the insulating properties of wood as compared to concrete or steel are another benefit of wood's use in commercial green building projects along with aesthetic qualities, price as compared to alternative materials, and availability. Although these same attributes could be used to describe supporting influence for wood use in general construction, the availability of wood products in relation to the location of a commercial green building project can help reduce the environmental 
impacts of transportation as well as gain points towards green building certification if sourced and manufactured within a local region (i.e. 500 miles for LEED versions 2009 and earlier).

“...when you're talking about LEED points, one of the things with people like with us is that we are sourcing our wood literally within 20 miles of where we are located."

One respondent suggested that the customization of wood products such as cabinetry was another support for its use and that finding particle board that contributed to LEED certification was generally easy. In general, the ability to easily customize wood products was often mentioned by respondents, especially during manufacturing, installation, and in later modifications. Respondents commented that they could customize wood materials by: 1) changing the aesthetics through species selection or applying a stain to the material, 2) varying the size of the end product to meet unique situations, 3) reducing environmental impacts through the selections of binding agents, 4) increasing durability through chemical application, and 5) decreasing flammability through chemical application. Having the ability to customize their products helped manufacturers to compete with alternative materials on both a cost and durability basis.

“The texture in the grain pattern. You can change species and probably accomplish... What you're after...if you need a smooth surface you probably gonna go with your hard maple or if you are wanting the real wide grain you'd go with the red oak or an ash".

“...years down the line...we're going to inlay a touch panel into this countertop that we had you make. When it is a wood product you can send somebody out with a router and a 
template, rip it in there for them real quick and we're out of there. It cleans up easy, and doesn't have sharp corners, and it looks like it was just meant to be like that all the time."

"with a steel door... Or most any door that's manufactured by anyone else...they come in standard sizes. Every carpenter or contractor is not perfect. And they make doors opening sometimes long. We can accommodate any size door."

“...there is one thing that we do actually to our product that increases as durability or makes it less susceptible to moisture changes... Like seasonal moisture changes...we use a moisture barrier sealant on some of our products.”

The customizations by respondents were not indicated as being performed to sell only to the commercial green building industry. However, a couple of larger flooring manufacturers indicated efforts such as CARB compliance and reduction of VOCs in flooring adhesives. The remarks indicate that these manufacturers alter their process specifically to lower the environmental impacts of their products to broaden the potential markets of their products. It was not indicated that these alterations were made specifically to sell to the commercial green building market, but being able to supply products with these attributes may increase their opportunity to do so.

Manufacturers also felt that the environmental friendliness of wood-based materials and the renewability of U.S. forests are strong advantages for its use in green commercial buildings when compared to other substitute materials. Many respondents commented on wood being a natural material that is easily recycled and that wood naturally decomposes in landfills. However, it was also mentioned that the ability to refinish the material was a great reuse of natural resources as opposed to removing a product completely and discarding it. 
“...everybody kind of falls into the understanding that wood is something that you can grow. We've gotten a lot better in the U.S. as far as replenishing forests as we harvest."

“...it is our only renewable resource..."

Although respondents identified wood as an environmentally-friendly material, only a small number mentioned environmentally certified wood products (CWPs) as an advantage for wood products in general.

“...we see the advantages of use and FSC certified materials and things like that because we don't want people just going in and getting lumber from...cutting down all the trees and not going to have anything left or anything."

The physical attributes of wood, both as a material and as a product, were also identified as a major support for wood use in general markets. When working with wood, respondents noted advantages such as the ease of: machining, handling, and repairing. Also mentioned, was the ability to make repairs easily to small sections of an in-use wood product when compared to an alternative material such as concrete.

“...If you had a bad piece of wood, it's easier to replace that then if it's a piece of concrete or something."

“...it's a whole lot easier to work with wood than it is other materials. It's more forgiving and it's easier to switch out in the field which makes it more cost effective." 
Other supports for wood use mentioned for general markets were strength and the ease of handling of the material as compared to plastic substitutes. Attributes such as the durability of the material were mentioned, but often restricted to interior applications unless other measures such as coatings to increase durability or the selection of a particular wood species were used. Additionally, some respondents identified higher insulation attributes of wood products, when compared to concrete or steel, as a support for wood use.

“...it’s [wood] obviously a better insulator than the concrete or the steel would be."

Aesthetic quality of wood products was also mentioned by the large majority of respondents as a supporting attribute to the material's use. Much like the specifier respondents from the Chapter 4 study, manufacturer respondents also felt that wood materials offered a warm and inviting atmosphere when used in visible applications. Manufacturers commented that aesthetics were a major driver in wood product selection and use, as well as adding value to the structure. Uniqueness was also an attribute mentioned in that "no two pieces of wood are the same...it's going to be different every time". Additionally, the traditional and rustic feel that wood can bring to a building or home was cited. One comment in particular that stood out was that the use of wood in a building made it look non-commercial. This insight may have been driven by the respondent's perception that more wood products were used in residential than in commercial projects. However, many respondents suggested that the use of wood products for aesthetic reasons, in commercial applications, hinged on the type of "look" the building was designed to reflect. Warm and inviting atmospheres such as hotel lobbies may use wood products where environments such as a hospital were more associated with colder materials like steel or concrete. 
Other attributes, although less mentioned, were noted as supports for wood product use. In particular, respondents identified "competitive pricing" as a positive driver for wood use and that the ability to customize a product to meet the unique needs of the client was more cost effective than compared to metal product customizations. Additionally, respondents mentioned the high availability of domestic, wood-based products as a support.

“... a lot of the guys that need more workstations and specialty things cut into them or added to them they don't want to look at the metal because it's not cost effective to customize those."

The large majority of respondents felt that the aesthetic quality of wood was a major support to wood's use. The variety of species available for product use gave consumers a wide range of durability attributes, grain patterns, and colors. The uniqueness of wood and the warm, inviting feeling the material adds to a room was often cited. Similarly, specifier respondents also praised wood products for their aesthetic qualities - again for wood's warm feel and its ability to provide a stately and refined atmosphere. The aesthetic characteristic of wood products is a major driver for their use and should be promoted accordingly. Providing opportunities for specifiers to see these characteristics in promotional materials such as websites, brochures, and magazine advertisements may help to increase specifier demand. Also, providing additional information that highlight these benefits when compared to substitute material like concreate and steel may help increase wood's material market share in the green building industry.

The use of wood in commercial projects, however, was indicated, in general, as minimal with the exception of restaurants and hotels - where owners wanted the warm 
and inviting atmosphere wood products could help provide. Contrarily, specifier respondents readily used wood products for interior use in their commercial projects to achieve the same warm atmosphere. Further research would be needed to determine quantity, but based on statements from both manufacturers and specifiers, there may be greater demand for wood product use in commercial green building than manufacturers perceive.

Manufacturer respondents felt that wood as a material was favored due to its ease of customization during manufacturing, installation, and in-use modifications. Some respondents mentioned that a long-length wood product, when compared to longlength plastic substitute products, was much easier to handle during installation. Additionally, the incorporation of various chemical treatments could be used to increase wood's durability, aesthetic value, and fire resistance. Respondents also felt that the environmentally-friendly attributes of wood products was another advantage over substitute materials. In addition to the natural renewability of trees themselves, the ability to refinish, reuse, and recycle wood products was also praised by some respondents.

Few respondents mentioned CWPs to be a positive attribute of wood products. Many felt that environmental certification was not necessary and that the addition of the certification often brought increased price and confusion. This group of responses differed from those of the specifier respondents from Chapter 4. Many specifier respondents found CWPs as a support for wood use because they could prove the sustainability of the material as well as gain points towards building certification for its use. These findings suggest a gap in manufacturer and specifier perceptions of wood 
products. Based on conversations with both groups, manufacturers feel more comfortable with the environmental impact of non-certified wood, potentially because they are more familiar with the harvesting and production techniques used on both certified and non-certified wood materials. Specifiers, who are potentially less familiar with the harvesting and manufacturing process, may prefer to rely on a certification that "proves" the sustainability of a product and can use this certification towards their goal of meeting a building certification standard. Bridging this gap will likely take a change in green building certification standards or greater adoption of wood product certification by manufacturers. Similar to the findings of a previous study (Vlosky et al. 2003), many manufacturing respondents have indicated a more reactive approach, rather than proactive, to meeting market demand. Therefore, an increase in CWPs demand from specifiers will likely push manufactures to initiate or increase their production and help to bridge the gap between demand and supply.

\subsubsection{Barriers for Wood Use}

Respondents indicated that wood's physical properties, costs, the general public's negative perception toward the forest products industry, and the look of the project were major barriers for wood product use in green commercial building projects. Respondents identified steel, concrete, plastic, and, in a few cases, medium density fiberboard (MDF) as the main competing materials they faced. Steel and concrete were mentioned as materials that would not wear like traditional wood-based products and would therefore reduce maintenance costs for the owner since refinishing the product was not necessary. Plastic material substitutes were cited as less expensive, more durable and more stable in exposed applications, often made from recycled 
materials, and didn't require the maintenance and upkeep of wood-based products. Maintenance requirements and costs were also a barrier indicated by specifiers. Since specifers indicated a preference for wood product use, manufacturers may see potential opportunities for increased sales by improving the durability of their products to meet specifier needs.

“...not have to paint it, not have to varnish it, don't have to go back and refinish it in any way."

Some physical properties of wood were mentioned to be inhibiting factors and were a barrier to the use of wood in general as well as the commercial green building market. Primarily, the material's tendency to shrink, swell, warp, etc. due to changing amounts of moisture, the need to maintain the finish and preserve the durability, the lower availability of long lengths of lumber, and flammability were indicated. The majority of negative comments surrounded the stability of wood when in contact with moisture. In most situations, the respondents manufactured products primarily intended for interior use. Although some respondent products were intended for exterior use, all of the manufacturers noted the need to properly and continually increase the durability and moisture resistance of wood through additional product application. In some instances, manufacturers would even recommend and manufacture products out of a substitute material, such as plastic, when the product was going to be placed in weather exposed applications. Specifiers agreed by indicating a major barrier for wood use was in moisture-exposed applications.

"...if it is something that is outdoors we have different products that we recommend...typically we would go with a plastic or King Starboard.” 
Cost was another major barrier to wood product use suggested by manufacturer respondents in general wood use. When compared to substitute materials like plastic and vinyl, the cost of the material alone is a significant consideration. The ability to purchase plastic-type materials cheaper, in all long-lengths (16 feet for example), and reduce the maintenance costs over the life of the product was suggested as appealing to buyers.

“...when you're comparing a walnut veneer with a painted walnut appearance, obviously there's a huge difference in price. So from a pricing standpoint it's often a driver in those cases.”

The general public's perception surrounding the environmental impacts of the material's use was considered a major knowledge gap for respondents. It was suggested that this knowledge gap was due to a lack of communication from the wood products industry as a whole in addition to the lack of communication with individual end-users.

"I think the general perception of tree harvesting... You know, not knowing the concept of trees being a renewable resource... They can't grasp that concept.”

"I think the discouragement would be in the great misunderstanding in the general public about the timber harvesting and how trees grow and how their lifespan... How they are harvested and everything else"

Additionally, some respondents felt that consumers in general assume a product manufactured from steel or plastic is less environmentally impactful than wood. Although a single, small manufacturer may not have budgeting capabilities to spread environmental data on wood products to the general public, they can equip themselves and their marketing materials with this type of information to disperse generously to potential clients. Small manufacturers that 
include quantifiable and scientifically-based information on the low environmental impact of wood materials as compared to steel or concrete may, in turn have a larger effect on the perception of the general public over time.

“A lot of people that I've talked to just assume that something that is steel or plastic or synthetic something would be more green than wood...in reality it's probably the other way around"

Lastly, a barrier to wood uses in general construction and in commercial green building mentioned by respondents was the desired look of the project itself. Traditional uses of wood in applications such as door and window casings are being replaced by more modern appearances where the drywall is run flush to the edge of the opening itself. In these instances, it is not a competing material that is taking the place of wood products, but more so the design itself.

“...it's not so much that we're competing against metal, we're competing against a look that the architect is after..."

In general, respondents indicated a similar barrier to wood's use in commercial green building applications including: physical properties, costs, and the look of the project. Specifiers mentioned wood's susceptibility to moisture (i.e., warpage) as a barrier to use. However, one respondent has made efforts to meet moisture exchange challenges by sealing all six sides of their flooring product. This finishing change was noted as particularly beneficial in high-rise construction where climates are less controllable. Other barriers such as the cost of wood and the desired look of the project were mentioned by manufacturers. Although there will likely be a less expensive alternative to most products in general, manufactures also mentioned that the use of wood 
products in a building can increase the value of the building. Approaching potential clients that may be hesitant about the cost or look of wood products, by presenting the value gain of the overall project may be an avenue to help overcome a pricing issue.

\subsubsection{Future Wood Product Use}

The future of wood product use was described by respondents in three major categories: 1) product demand shifts, 2) manufacturing/business changes to meet future wood products demand, and 3) the reduction in environmentally-certified wood product demand. Future demand shifts for wood-based products varied between respondents. The majority of respondents felt that the overall market for wood product use would expand in the future. Some felt that demand would increase due to wood being a naturally renewable material and that "there will be more and more resistance to mining and that sort of thing to get the other materials' resources out of the ground". Others felt that continual product developments, such as engineered wood products, not only make efficient use of wood by-products like sawdust, but that products like the wood Ijoists also allow for a more environmentally friendly and cost-effective substitute to metal Ibeams. Some respondents mentioned that the increased market for hospitality and restaurant establishments would help drive the demand for wood product use by incorporating the products to present a warm and inviting atmosphere. Additionally, one respondent felt that wood product use would continue to expand due to the ease of working with the material, its low up-front tooling requirements, and the ability to make in-the-field product changes to fit unique situations.

“...you can order a laminated beam that's 3 feet longer than what you need and you can cut it off to size and put it in. That's not the case with steel."

Other perceptions of respondents are that the demand for wood products will remain constant. Some respondents tend to see an established market for wood product use in buildings 
- one that will not increase or decrease in demand. Others have similar thoughts and suggest that instead of the volume of wood changing, it's the species of wood that will fluctuate with design trends being the driver.

“...Years ago, every piece of wood that went into any environment was Red Oak, stained golden...Then everyone kind of got tired of it and they went to a maple. Maple is kind of the new, fashionable wood. And now, designers are going more toward the darker woods...walnut, things like that...It ebbs and flows depending on which species it is."

Another group of perceptions from respondents implies contraction in future wood product demand. Indications given by the respondents suggest that drivers constricting wood product use are: competing material types made to look like wood products but cost less for the consumer; a reduction in the use of wood products as an exterior material; and the public's perception of the wood products industry. Additionally, some respondents feel that the use of steel studs for wall framing is reducing wood stud demand, especially in the commercial market. “...the commercial buildings...you see more metal studs where it used to be everything was wood.”

Following their perceptions to the future demand of wood products, respondents were asked what their company was doing to meet the change in demand. Three main categories were developed based on manufacturers' responses: 1) manufacturing changes, 2) marketing changes, and 3 ) reaction to market change. The manufacturing and business changes implied by some respondents included outsourcing less specialized tasks, changing species to reduce costs and build a new market, using products that have less harmful adhesives, opening a new division of 
manufacturing to meet a growing demand, innovating finishing process to increase durability, and cutting out middle men and increasing direct-to-market sales.

“...one of the reasons we developed the moisture barrier was to innovate for the problems that we saw in the wood products industry particularly in hardwood flooring."

Another strategy to meet the needs of future wood product demand suggested by respondents was to increase their current geographic sales area. Additionally, the tactic to strategically focus on more lucrative sales opportunities, such as the high-end residential sector, or to focus on a particular subsection of an emerging commercial sector was mentioned. By researching and pursuing customers known to purchase their particular product, these manufactures are targeting their efforts to increase the efficiencies of their marketing.

“...looking at emerging markets and there's a lot of stuff that is going on in the hotel industry right now that we are trying to get a bigger presence in."

Almost half of all respondents indicated that they were doing nothing to prepare for future changes in wood product demand. Some feel that they do not have a good enough idea of the direction of the market to invest money in marketing or production improvements. This group also indicated that they are more reactive to the market than proactive and would take necessary steps to meet demand after it impacted them directly.

“...I'm going to say no to just because I just don't have a strong feel for the direction to spend any kind of marketing dollars."

“...I just don't know who the right bodies are to get in front of... So at this time, no because of ignorance and not knowing the right people to approach.” 
The last major factor in the future of wood products centered around the use of environmentally certified wood products (CWPs). Particularly, the large majority of all respondents felt that the demand and use of CWPs has been decreasing over the past few years. Similar to a previous study (Vlosky et al. 2003), some respondents feel that the complication involved with chain-of-custody certifications was a discouraging factor. Moreover, many believe there is no real environmental difference between CWPs and non-certified wood products. Specifiers, alternatively, supported the use of CWPs and like that they could provide evidence of the sustainability of the sourced material.

“...you can't tell me that a tree that was cut a mile away from here at the sawmill and loaded on a truck for $1 / 2$ mile, delivered here, ran into a product efficiently and ready for that customer is it better than what we have to ship from Indiana or Maine because you've got FSC certified, brought it all the way here."

Additionally, respondents indicated that not only was the demand for CWPs too low to justify being certified themselves, but also the increased costs associated with CWPs often pushed consumers to use non-certified wood products instead. Several respondents mentioned that they received interest in the use of CWPs and would quote a job - only to have the client come back and request the same job with non-certified wood used. The majority of the time, the client would choose to use the non-certified wood products.

"In fact for period of time we were FSC certified. We ended up dropping that certification just simply because there wasn't enough business to support it. What we found, more often than not, it is... That we would bid something and that it was an FSC certified supply situation and then the customer would get the price then come back and say well what if this wasn't FSC certified - so then you go 
ahead and bid it that way... And nine times out of 10, they are going to go with lower price."

Manufacturers indicated that the cost of CWPs were a major barrier, not to the use of wood products as a whole, but to the use of CWPs. Specifiers also indicated the cost of CWPs as a barrier to their use and, like manufacturers, often replaced the use of CWPs with non-certified wood products to meet end-user budgets. These results contradict other research findings (Estep et al. 2013, Ozanne et al. 1999, Aguilar and Vlosky 2007) that indicate an increase in consumers' willingness to pay for environmentally certified wood products over non-certified wood products. However, these results support the results of previous research (Anderson and Hansen 2004a, Anderson and Hansen 2004b) where buying behavior shifts toward purchasing nonenvironmentally certified wood products when the price of comparable environmentally certified products are higher.

Other respondents felt that CWPs and their use in green building applications could be a good thing and could help promote the use of wood products. However, much of the reason for the decreased use in CWPs was due to a lack of proper communication on what the certifications mean, how they can support the increased use of wood products, and how their use in green building can help reduce the overall environmental impact of the building itself.

"There are a lot of people that have heard of the LEED certification, FSC...all of those things, but they don't really know what they are. They don't know the benefits of them. They don't understand the process or why that's important or why it's worth paying a little bit more for something that you can go back and check the chain-of-custody on and things like that. They [green building programs and wood certification standards] could do a better job promoting that. If you get 
people more interested in those types of things which could further promote wood because you've got a story behind it, you've got something that people are educated on and excited about."

Although it was suggested that green building programs and wood certification standards should do a better job of promoting its advantages, manufacturers and distributors should also take it upon themselves to educate end-users on these benefits. Manufacturers and distributors could then focus on promoting wood products as it relates to their sales interests instead of relying on other industries that may not promote advantages specific to wood materials.

In general, respondents felt that wood product use would increase in the future and indicated wood's low environmental impact as compared to alternative materials like plastic or steel as well as new developments in engineered wood products. Although most respondents felt that demand for wood products would increase, almost half are doing nothing to approach these perceived future markets. Some respondents indicated that they were being more strategic towards contacting potential clients while others were responding to growing niche demands. This indicates that, in general, manufacturers are doing little to determine future opportunities for wood products and instead, are relying on their ability to react to market demand. Specifier respondents have indicated a demand for durable wood products for both high-traffic areas and weather-exposed applications. Additionally, specifiers have indicated interest in CLTs for use as a structural component in commercial building construction. In addition to these demand areas, it is suggested that manufacturers continue to explore and determine future demand areas for wood products that they perceive. 


\subsubsection{Wood Product Markets and Marketing Efforts}

\subsubsection{The Green Building Market}

Wood product manufacturers in this study were asked to share their perceptions of the green building market as a current and future sales market for the wood products industry. Responses included perceptions toward the green building market expanding, remaining constant, and contracting in the future. Additionally, most respondents indicated the types of areas and general geographic regions where these projects were likely to be found. Respondents who indicated the market for green building would continue to grow felt that government funding toward those projects was a primary driver. Respondents also mentioned that the growth represented a cultural shift and that many people like the idea of reducing the environmental impacts of buildings. Additionally, others thought that building green was the natural progression of the building industry and that "green" building was actually the new norm in construction projects. Likewise, some specifier respondents mentioned that many constructions projects were built to a green building standard, but did not pursue the actual certification. So even though some buildings are not certified as green, it is likely that specifiers are still interested in using green materials in these projects.

“I think it's just going to become the normal. They're not going to be saying this is a green building but maybe this is just the way building is. This is 2015...we're not building buildings like we were in the eighties."

Respondents that felt the green building market would remain stable, without major expansions or contractions, indicated that the preference of green building in general was more based on trends of consumers. Additionally, they felt that a lack of education among consumers 
was one reason the market wasn't growing as much as they had anticipated, and that the amount of money spent towards distributing information on environmental issues would also positively correlate with the demand of green buildings.

“...the whole global warming thing for instance, really, I think that made people be more environmentally conscious in general. But, as that has kind of waned and people are saying you know that's probably not what's really happening, then I think people are less likely to [build green]...”

There was also a group of respondents that felt that the market for green building in general was contracting. Some indicated that only those truly attuned to the green building movement were pursuing those certifications. However, all respondents who felt the market was contracting mentioned costs as the main driving factor. One respondent indicated that only two sections of the commercial building market, education and healthcare, were able to afford green building projects while the rest of the building sector in general was constrained by tighter building budgets.

“...the two areas that I see green buildings is education, predominantly universities, and healthcare. From my perspective, those are the two markets that have kind of unlimited budgets. You know, they're the ones making all the money these days. So they have got the money to say 'Okay, we will build a green building.' I think the rest of the world, is saying, 'Hey I'm on a tight budget here and I just wanna get into my building'..."

When asked if they felt there were any locations more prone to construction of green buildings, all respondents indicated urban areas in general. One respondent felt it was driven by 
certain socio-economic populations found in urban areas or through city regulations. Another mentioned the influence of architects found on "make-over" projects in urban areas.

$$
\begin{aligned}
& \text { “...the areas that are more highly urban where they are doing a makeover on the } \\
& \text { urban environment where it's kind of led by an architect or a team of architects - } \\
& \text { I think you have a higher rate of that [green building] being a core or } \\
& \text { fundamental goal in the design and construction...." }
\end{aligned}
$$

Furthermore, some respondents also felt that certain regions of the U.S. were more popular than others for green building projects. Western areas such as the northwest, North Dakota and South Dakota, western states, and California were mentioned along with eastern areas like the northeast, New York City, and Washington D.C.

In general, respondents are aware of the green commercial building sector and most believe that green building as a whole will continue to grow and particularly will continue to grow in larger urban areas along the East and West coasts of the U.S. This expansion is believed to be fueled by continued government funding, consumer preferences for lowered environmental impact, and as a natural progression in building techniques. The perceptions held by these manufacturers are similar to those of specifiers surveyed in the Chapter 4 study where funding source, owner-directive, and building code advancements were also indicated as major drivers for green building growth. Manufactures should therefore consider marketing their products towards specifiers in these growth areas and place emphasis on the low environmental impacts of wood materials. Manufacturers of innovative wood products, such as CLTs, may consider adding additional information and promotion to emphasize novel product developments from continued research aimed at meeting the structural, green, and fire code requirements of evolving building codes. 


\subsubsection{Marketing and Promotion}

Respondents provided insight into their current marketing and promotional activities and did not differentiate in specifically targeting general markets and the green building market. In general, smaller volume producers such as custom moulding and millwork shops, if marketed at

all, marketed their own products to both end-users as well as material specifiers like architects. There were few instances where a respondent was asked about providing CWPs for green building. Responses suggest that manufacturers therefore did not directly target the green building market due to the lack of relative demand they were receiving from their established customers.

In general, conversations revolved around: 1) their target audience, 2) their future target audience, 3) current marketing strategies, 4) future marketing strategies, and 5) whether or not they included their product's advantages in their promotions. Over half of all respondents targeted, either directly or indirectly through distributors, material specifiers like architects, interior designers, and general contractors for sales of their wood-based products. Others targeted end-users such as the building's owner or upper management of businesses in that manufacturer's niche market. Hardwood flooring manufacturers, however, favored the use of distributors and targeted them as their main marketing audience. These manufacturers then rely on the distributors to promote their products across different regions. Distributors were given marketing materials such as brochures or catalogs from the manufacturers to sell from but based on the conversations with respondents, the distributors were not directed to any one specific market such as the commercial green building market. Some of these larger manufacturers did approach architects, but more as a blanket approach to introduce the products and services they offered instead of specifically focusing on the commercial green building market. Those 
manufacturers interested in penetrating the commercial green building market may need to purposefully target this growing niche market by indicating how their product supports green building ideals such as the utilization of low environmental impact building materials and can also be used to gain points towards certification.

"We go through a distribution channel. It's a two-step process to retail to the market. We really depend on our distributers or sales reps that call on architects and specifiers to disseminate the information about our commercial products, green, what they do...So we depend on our distributor sales reps across the country...”

A few respondents mentioned that they targeted complementary businesses that could use their products. Building a strong relationship with these complementary businesses reduced the marketing efforts of the manufacturers to contact the end user themselves and encouraged repeat business. Another small group of respondents found that providing parts, to downstream manufacturers, for interior wood products like doors, furniture, and cabinetry was more beneficial than marketing towards specifiers or end users. These companies also produced finished products of their own but felt that producing mass quantities of parts to supply larger businesses was more stable and allowed them to take advantage of the economies of scale.

Over half of all respondents indicated that they had no plans or interest in targeting new or additional sales audiences in the near future, green or otherwise. A few suggested that they were already contacting all of the available audiences for their particular product. Some respondents also mentioned that they would consider growing their marketing area but keep their target audiences the same. 
"I don't see us trying to reach a different audience but maybe the same audience in a different geography.”

A few respondents were open to the idea of targeting new audiences and are making plans to do so in the near future. Material specifiers were among the most mentioned as future target audiences and respondents suggested these avenues as a way to break into previously unexplored markets like the commercial sector in general. One respondent indicated future plans to target more commercial projects. One respondent felt that the lack of communication on the environmental issues surrounding the forest products industry is a key barrier to increasing wood product use in general, and suggested that their future target audience would be children - more specifically as educational outreach. The same type of educational outreach may also be beneficial towards material specifiers but will likely need quantifiable justifications like a LCA and/or credible documentation explaining the environmental impacts of wood material utilization to help build confidence.

"It [future target audiences] would be the education arm. To help people understand we're not cutting down all the trees - we are managing them... that you can do that and that's really the way to go rather than locking up all the forestland and making it to where no one can use it...that sort of thing. That would be the other audience that... kids actually. They get inundated on TV and everywhere with the environmental message or the preservation message I should say instead of the conservation..."

Over half of all respondents indicated that they did very little marketing in general. Manufacturer respondents' current marketing activities fell into two broad categories: active and passive marketing. The most popular active marketing strategies indicated by respondents were 
word-of-mouth and face-to-face sales. Word-of-mouth marketing normally takes place outside of the company itself and is often facilitated by previous clients informing future clients of a business's services and product quality. Indicated as a powerful sales driver for many respondents, face-to-face sales were also highly mentioned as the main marketing technique of respondents. In face-to-face sales, a member of the manufacturing business would directly approach a potential client to suggest the benefits and attributes of their product. Many respondents felt this was the most effective marketing technique and that it produced a higher acceptance rate when personally in front of the client.

"The best marketing that we do quite frankly is direct face-to-face sales calls. So I have a proportionately higher number of sales reps per our volume than a lot of companies do. It's in an effort for them to get face-to-face with more people. People still buy from people. And that seems to be the best way to approach that."

Other forms of active marketing were indicated as well, but again, not specifically toward the green building industry. Some respondents would attend trade shows to introduce new products or to nurture relationships with existing clients who host the shows. Also, some respondents relied on their distributors' marketing activities. Although the respondent may have provided passive marketing materials such as brochures and pamphlets, they often supplied prizes for activities hosted by the distributors that are marketing to the architects.

"They [distributors] go to great lengths to market to the architects for instance...they have big open house is an all kinds of sessions available for them. Not just the architects but the contractor and general contractor and flooring contractors...They are the ones that market to them. So a lot of times we will provide the thing for their golf tournament that they're having for all of them or 
we'll provide prizes for a dinner that they are having with the architects. That would be about the only way that we get involved with those audiences.”

To a lesser extent, respondents also used passive marketing techniques to inform potential clients about their company and products. Most respondents mentioned that they had a website but also indicated that they used it more as a general introduction to their company and to provide additional legitimacy of the company. Only two respondents felt that their website had helped them procure sales. One suggestion for this difference may have been that these companies indicated that they were actively maintaining their website. In particular, one of these companies had notable success when they developed a streamlined application (app) for mobile phone users. Clients could research, review, and order products directly in the app.

"Our customers will have the technology to pull this stuff up from an app on their phone. My customers can stand there with our app and pull up their pricing, pull up profiles, take a snapshot, they can order from this app if they want to... I don't think there's any other [product] company out there that is doing what we're doing with technology and phone apps.”

Other passive marketing approaches taken by respondents were the use of printed materials like brochures and pamphlets as well as advertisements in printed pieces like magazines or newspapers. Most of these respondents seem to put little value in these printed marketing pieces and felt that advertisements in print were, in general, not worth the cost. Many suggested that printed magazines and newspapers were a "dying form of advertising". Moreover, some respondents felt that the services or products that they offered were too specific for general advertisements and that the traffic the ads do generate often consists of inquires outside of the company's available offerings. 
"what little bit that I have been associated with...a few ads in previous

years...drags in a lot of busy...we get a lot of busy questions for products that we don't... They try to relate us to things that we do not sell."

Only a few respondents indicated that they would like to try new marketing methods in the future. Some indicated that they would like to try advertisements in print publications such as trade magazines or product specific publications. One respondent suggested introducing coldcalling into their marketing and sales approach. Another respondent, who indicated success with website marketing, proposed an interest in pursuing social media outlets as future marketing activities.

Follow-up conversations were used to determine if respondents included the supportive attributes of wood products they had suggested in an earlier conversation topic in with their promotional materials. The large majority of attributes (i.e., environmental benefits, easy to work with, aesthetic and tactile preference) suggested by manufacturers were also suggested by specifiers. About half of the respondents include some attributes of the wood products they manufacture in their marketing. Although their marketing efforts were not directed specifically at the green building market, some efforts were directed towards architects that may be involved in green building projects. Sometimes, these attributes were included in the printed promotional materials but more often they were discussed in-person with the potential consumer.

Alternatively, about half of the respondents did not mention any supportive attributes of their wood products in their promotional materials or in-person. It was indicated that the attributes of wood products were "pretty much understood" and there was no need for further explanation. Although specifiers and manufactures indicted similar benefits to wood product use, specifiers also indicated a personal responsibility to build low environmental impact structures. 
Including information on the LCA of products may increase product demand by better informing specifiers of the environmental impacts of particular wood products. More commonly, however, respondents felt it was more important to market the company, their service, and other business attributes over the product itself. Often they felt that their main competition was other wood product manufacturers - not alternative material products.

"So we really market our company. We try to get our success stories across to the potential client. Tell them who we are doing business with and the type of longevity we have with them. And then that is established, then we have an opportunity give them samples and things like that to sell them on our quality."

Manufacturers identified large urban centers found in the northeast and northwest regions of the U.S. as growth areas for green building. These results are supported by the findings of Chapter 2. Although manufacturers identified strong market areas for green buildings, and believe that the green building market will increase in the future, little effort is currently given toward pursuing it as a viable market. Moreover, the general marketing tactic most used by manufacturer respondents, face-to-face sales, was not a major education source preferred by specifier respondents from Chapter 4 . The methods often deemed less effective by manufactures (print materials and websites) were frequently cited by specifier respondents to be major educational sources. These results indicate a media for marketing communication gap between manufacturers and specifiers. Although manufacturer respondents rarely singled out the commercial green building sector as a target market, the inclusion of product information based on the attributes suggested by both manufacturers and specifiers in specifier-sought marketing pieces could initiate new relationships between the two groups. Furthermore, the 
inclusion of technical data, such as a life cycle analysis (LCA) of manufacturer products, in promotional materials may also have a positive effect towards specifiers retaining the material (Robichaud et al. 2012).

Discussions with manufacturers have revealed a lack of knowledge that the group has concerning green building certification systems. This lack of knowledge leads to the belief that manufacturers may not know how wood products can play a crucial role in these standards and therefore do not perceive enough opportunity to justify pursuing the green building market. Even though specifiers may not submit a project for green certification, many will use the standards as a guideline for construction. Therefore, manufacturers should consider pursing wood product certification when selling to the green building market. Also, whether or not they carry CWPs, manufactures could specifically identify the sustainable and environmental attributes of their wood products to better meet the material preferences of material specifiers.

\subsection{CONCLUSIONS}

This research focused on exploring marketing efforts by secondary hardwood producers in the Appalachian Region toward the commercial green building industry. Additionally, responses from this study were compared to the response data from the Chapter 4 study to determine if potential marketing gaps may exist between manufacturers and specifiers.

Respondents, in general, perceive similar supporting attributes as specifiers in terms of wood product use in commercial green building projects. The attributes of wood included 1) environmental aspects such as: natural material, low environmental impact, and renewability; 2) physical aspects such as: workability, customization, and aesthetics. However, only about half of 
the respondents that do market their products actually include these attributes in their marketing materials. Based on the perceptions and motivations specifiers indicated in Chapter 4, manufactures are encouraged to include the attributes listed above as they pertain to their specific products. Including attributes that specifiers find appealing has the potential to increase the acceptance and demand of wood products in commercial green building projects.

Manufacturers also had similar perceptions as specifiers towards the growth and driving factors of the commercial green building market. Manufactures anticipate continued growth in this market and that it will likely occur in large urban areas. Although manufacturers anticipate growth in this market as well as growth in the use of forest products in general, few are specifically targeting the commercial green building sector to increase their sales. Manufacturers should consider the growth of this market as opportunity to further diversify their sales markets.

Manufacturers indicated that they were not heavily targeting sales efforts towards commercial green building industry specifically. Instead, incites drawn from responses suggest that the opportunities most manufacturers had to supply products to the commercial green building industry came from indirect marketing efforts and established clients' requests. Many manufacturers indicated that their main form of marketing was based on face-to-face sales and word-of-mouth referrals. In general, manufacturers placed little importance on marketing pieces such as websites, brochures, and print advertisements. However, based on specifier preferences, manufacturers are suggested to include promotional and informational materials in media for marketing communications such as websites and trade magazines. Specifiers also mentioned that they used product demonstrations or lunch-and-learns to learn about new wood products. This media for marketing communication may be preferred by manufactures since this option would 
allow the face-to-face marketing opportunities respondents indicated as most effective in securing sales.

This study employed a purposeful sampling technique where respondents were selected based on their location and the products they produced. Although respondents were involved in manufacturing multiple wood-based building products, perceptions of these manufacturers may not be the same as other wood product manufacturers and therefore a limitation of this study. Inclusion of respondents chosen due to their location outside of the Appalachian Region or production of different wood products may have resulted in different perceptions.

The results offer information to advance theoretical arguments on the marketing efforts of secondary wood product manufacturers in the Appalachian Region, but do not make universal claims to the secondary forest products industry as a whole. Universalizing these results is not achievable, regardless the number of like-minded responses as there will always be unexplored respondents, contexts, or time periods where new results may differ from those found in this study (Thompson and Arsel 2004).

\subsection{FUTURE RESEARCH RECOMMENDATIONS}

Future research recommendations are to expand this research to include distributors of secondary wood products. This group was indicated as a major part of many secondary wood product producers marketing system. Additionally, this group was noted as being the marketing link to many material specifers. Identifying their perceptions as well as current marketing practices toward the commercial green building market, in addition to this study, would provide more inclusive information on the secondary wood products industry. 


\subsection{REFERENCES}

Aguilar, F.X. and R.P. Vlosky. (2007). Consumer willingness to pay price premiums for environmentally certified wood products in the U.S. Forest Policy and Econ. 9: 11001112.

Anderson R. and E. Hansen. (2004a). The impact of environmental certification on preferences for wood furniture: A conjoint analysis. Forest Prod. J. 54(3): 42-50.

Anderson R. and E. Hansen. (2004b). Determining Consumer Preferences for Ecolabeled Forest Products: An Experimental Approach. J. of Forestry 102(4):28-32.

ARC (2015).Appalachian Regional Commission - Counties in Appalachia. http://www.arc.gov/counties.

Bigsby, H., \& Ozanne, L. K. (2002). The purchase decision: consumers and environmentally certified wood products. Forest Products Journal, 52(7-8), 100-105.

Buchanan A. H. and Levine S. B. (1999). Wood-based building materials and atmospheric carbon emissions. Environmental Science \& Policy. 1999. 2:427-437.

Buehlmann, U., Bumgardner, M., \& Sperber, M. (2013). How small firms contrast with large firms regarding perceptions, practices, and needs in the US secondary woodworking industry. BioResources, 8(2), 2669-2680.

ESRI (2012). ArcGIS Desktop: Release 10.1. Redlands, CA: Environmental Systems Research Institute.

Estep GD, DeVallance DB, Grushecky S (2013) Affordable Home Builder Demand for Green and Certified Wood Products. Forest Prod J 63(1):4-11. 
Fraj, E. \& Martinez, E. (2006). Environmental values and lifestyles as determining factors of ecological consumer behaviour: an empirical analysis.Journal of Consumer Marketing, 23(3), 133-144.

FSC (2015). Forest Stewardship Council. https://us.fsc.org/

Grillo N., Tokarczyk J., and Hansen E. (2008). Green advertising developments in the U.S. forest sector .Forest Products Journal, 58 (5), 40-46.

Gustavsson L., Pingoud K., Sathre R. (2006)a. Carbon Dioxide Balance Of Wood Substitution: Comparing Concrete- and Wood-Framed Buildings. Mitigation and Adaptation Strategies for Global Change. 2006. 11: 667-691.

Gustavsson L., Madlener R., Hoen H.-F., Jungmeier G., Karjalainen T., Klohn S., Mahapatra K., Pohjola J., Solberg B., and Spelter H. (2006)b. The Role Ofwood Material For Greenhouse Gas Mitigation. Mitigation and Adaptation Strategies for Global Change. 2006. 11: $1097-1127$.

Ganguly, I., Bowers, T., Eastin, I., \& Cantrell, R. (2013). Role of Green Building Programs in Enhancing the Usage of Environmentally Certified Wood in the US Residential Construction Industry. International Journal of Construction Education and Research, 9(3), 183-202.

Knowles, C., C. Theodoropoulos, C. Griffin, J. Allen. (2011). Oregon design Professionals views on structural building products in green buildings: implications for wood. Canadian Journal of Forest Resources. 41: 390-400. 
Kraxner, B. M. F. (2008). Green building drives construction market and forest certification: Certified forest products markets.

Lippke B., Wilson J., Perez-Garcia J., Bowyer J., and Meil J. (2004). Corrim: Life Cycle Environmental Performance of Renewable Building Materials. Forest Products Journal. 2004. 54(6): 8-19.

McGraw Hill Construction (2013). World Green Building Trends. http://analyticsstore.construction.com/index.php/world-green-building-trendssmartmarket-report-2013.html (15 September 2014).

Miles, M. \& Huberman, A. M. (1994). Qualitative Data Analysis: An Expanded Sourcebook. 2nd ed., Thousand Oaks, CA: Sage.

Owari, T., Juslin, H., Rummukainen, A., \& Yoshimura, T. (2006). Strategies, functions and benefits of forest certification in wood products marketing: Perspectives of Finnish suppliers. Forest Poli and Econ, 9(4), 380-391.

Ozanne, H. Bigsby, and R.P. Vlosky. (1999). New Zealand consumer perceptions and willingness to pay for environmentally certified forest products. NZ J. Forestry. 43(4):17·23.

Patton, M.Q. (2002). Qualitative research. John Wiley \& Sons, Ltd.

Petersen A. K. and Solberg B. (2002). Greenhouse gas emissions, life-cycle inventory and costefficiency of using laminated wood instead of steel construction. Case: beams at Gardermoen airport. Environmental Science \& Policy. 2002. 5:169-182. 
Petersen A. K. and Solberg B. (2003). Substitution between floor constructions in wood and natural stone: comparison of energy consumption, greenhouse gas emissions, and costs over the life cycle. Canadian Journal of Forest Resources. 2003. 33:1061-1075.

Robichaud, F., Kozak, R., \& Richelieu, A. (2009). Wood use in nonresidential construction: a case for communication with architects. FPJ, 59(1/2), 57-65.

Robichaud, F., Richelieu, A., \& Kozak, R. (2012). Wood use in nonresidential construction: An exploratory research of the roles of media and content in direct marketing. Wood and Fiber Sci, 44(4), 394-411.

SFI (2015). Sustainable Forestry Initiative. http://www.sfiprogram.org/

Skype (2014a)_http://www.skype.com/en/.

Skype (2014b). MP3 Skype recorder. http://voipcallrecording.com/MP3_Skype_Recorder.

Tardif P., and O'Connor J. (2009). Selling Wood Products to the Green Building Market - A Guide for Wood Product Manufacturers: Understanding Green Programs (LEED and Green Globes). FPInnovations Version 1.0 - February 2009.

Tokarczyk, J. and E. Hansen. (2006). Creating intangible competitive advantages in the forest products industry. Forest Products Journal 56(7):4-15.

Thompson, C. J., \& Arsel, Z. (2004). The Starbucks brandscape and consumers'(anticorporate) experiences of glocalization. Journal of Consumer Research, 31(3), 631-642.

Vlosky, R. P., Gazo, R., \& Cassens, D. (2003). Certification involvement by selected United States value-added solid wood products sectors. Wood and Fiber Science, 35(4), 560569. 
Wagner, E.R. \& Hansen, E.N. (2002). Methodology for Evaluating Green Advertising of Forest Products in the United States: A Content Analysis. Forest Products Journal, 52 (4), 17-23.

Wagner, E.R. \& Hansen, E.N. (2004). Environmental attributes of wood products: Context and relevance for U.S. architects. Forest Products Journal, 54 (1), 19-25. 


\section{SUMMARY}

A combination of surveying and spatial analysis techniques were used to examine the perceptions and application of wood product use in affordable and commercial green building projects. Based on the results of the research, AH builders, material specifiers in the commercial building sector, and secondary wood product manufacturers concur that the green building market is a growing sector of the building industry. Specific regions in the U.S. and, more specifically, the Appalachian Region have been identified as Hot Spot areas for the location of LEED certified projects that have obtained the certified wood credit. Moreover, the spatial growth of these projects, over time, has shown a strong clustered-type of growth that is likely to continue in the near future. With new projects of this type likely to be located near existing projects, the future building market for this niche has been identified. Additionally, the process used to determine the Hot Spot areas can be replicated to identify more precise area locations of the Hot Spots for the increased efficiencies of targeted marketing efforts.

Both AH builders and material specifiers indicated a positive association with CWPs and will likely continue or increase the use of these types of products in the future. Factors supporting the use of CWPs included: the environmental benefits of the materials, gaining points towards the certification of green building projects, and the documented sustainability of the material. Conversely, manufacturers, in general, felt that the chain-of-custody certification of wood products was unnecessary and that the demand for it was decreasing. Additionally, many of the manufacturers did not currently offer CWPs. Factors discouraging the use of CWPs from the manufacturer's perspective were confusion and complications with the certification standard 
and how it can be used in green building applications, as well as the additional costs associated with providing CWPs.

Builders, material specifiers, and manufacturers all felt that the environmental benefit of wood products was a major support for its use in green building construction. Additionally, the aesthetic qualities of wood products were heavily indicated by both specifiers and manufacturers as a driving factor towards interior wood product. Builders and material specifiers learned about wood products through media for marketing communications such as: local retailers, websites, magazines, and "lunch-and-learns". Most manufacturers indicated that their marketing activities were minimal and that their most used promotion tactic was face-to-face sales. Many relied upon existing relationships or word-of-mouth to continue sales of their products. Most manufacturers indicated that, although they have a website, it is primarily a tool to introduce the company in general and provide online legitimacy of the business. Websites, along with printed ads in magazines were often noted by manufacturers to have little marketing value. Although manufacturers indicated similar findings as the results of Chapter 4 in regard to the general locations of popular green building areas, none specifically targeted them or the green building sector in general.

Based on the findings of this research, there are opportunities to increase the use of wood products in the commercial and affordable green building industry (Appendix E). From a demand-driven approach, this research has indicated prime market areas for future growth along with the positive and negative perceptions of those responsible for material and product selection. Pinpointing this demand and comparing it to the current marketing activities of wood products manufacturers, has identified marketing and product need gaps that, if filled, can increase the use of wood products in the green building industry. To specifically penetrate the 
commercial green building market, manufacturers are suggested to focus their marketing efforts toward material specifiers in this industry through media for marketing communications such as websites, print advertisements, and product demonstrations. Marketing materials should include wood product information focused on environmental benefits and aesthetic attributes to meet the values that specifiers have towards wood. 


\title{
ApPendix A - Survey of Wood Product UsAge IN
}

\author{
AfFordable Housing Construction
}




\section{SURVEY OF}

\section{WOOD PRODUCT USAGE IN}

\section{AFFordable Housing CONSTRUCTION:}

GREEN AND CERTIFIED WOOD PRODUCTS IN THE CENTRAL

\section{APPALACHIAN REGION}

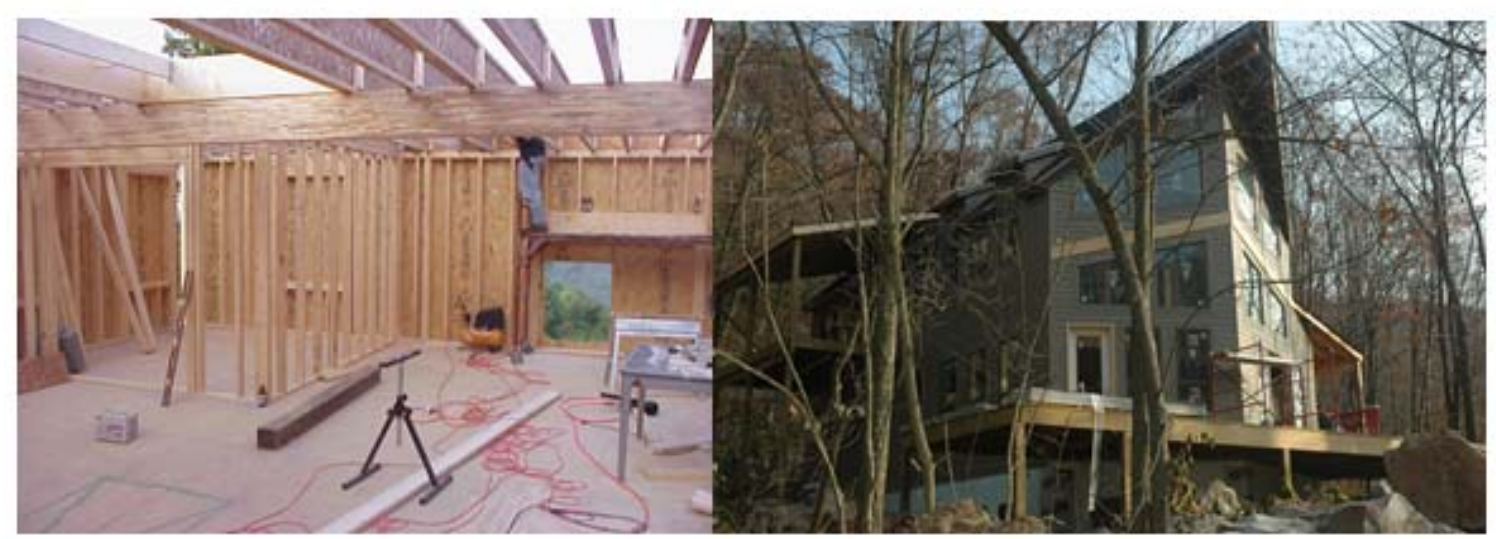

\section{Rural Action}
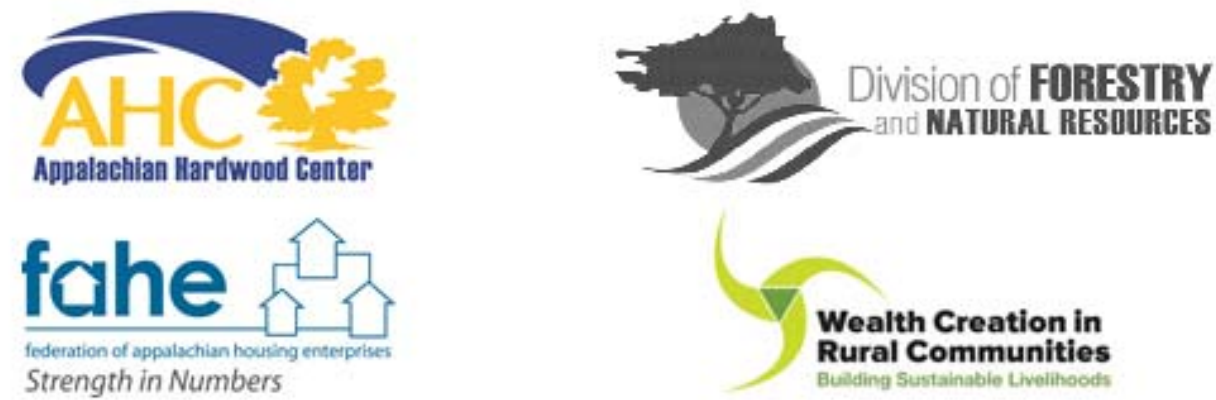

W. WestVirginiaUniversity.

Wealth Creation in

Rural Communities

Funding for this research was provided by The Ford Foundation through the Center for Rural Entrepreneurship 


\section{WestVirginiaUniversity}

Davis College of Agriculture, Natural Resources and Design

\section{We need your help!}

West Virginia University is performing research to evaluate the demand and availability of certified wood products for affordable housing within the Central Appalachian Region. Your experience with construction and your opinion regarding these wood products are critical to our understanding of building trends in our region.

Our research is aimed at providing information to assist builders in purchasing green, certified wood products. The research will also relay to wood products manufacturers the types of products that builders would like to use in their green, certified, and affordable housing projects.

Our records show that you may have been involved in the construction of residential, and possibly affordable, housing in the last five years. Your knowledge is critically important to us to better understand your need for wood products. We therefore ask that you take a moment to complete the enclosed survey and return it in the postage-paid envelope provided. Your answers will be treated with complete confidentiality and will not be linked to you or your business in the final report of the study results. Also, as a reward for your help, we will send you an Appalachian Hardwood Center t-shirt when we receive your completed survey!

Thank you for your assistance. If you have any questions regarding this study, please feel free to contact me by phone at 304/293-0029 or by email (david.devallance@mail.wvu.edu).

Sincerely,

David DeVallance, PhD

Assistant Professor

Forestry and Natural Resources 


\section{Survey Questionnaire:}

Please answer ALL applicable questions and return in enclosed postage-paid envelope.

1. From January through December of 2011, what was the average number of people your construction/building company employed? (Check one.)

\begin{tabular}{|l|l|l|}
\hline$\square 1-5$ & $\square 6-12$ & $\square 13-25$ \\
\hline$\square 26-99$ & $\square 100-249$ & $\square 250$ and above \\
\hline
\end{tabular}

2. For the year 2011, what is the expected Total Revenue (pre-tax) of your construction/building company? (Check one.)

\begin{tabular}{|l|l|l|}
\hline$\square$ Less that $\$ 100,000$ & $\begin{array}{l}\square \$ 100,000 \text { to } \\
\$ 499,999\end{array}$ & $\begin{array}{l}\square \$ 500,000 \text { to } \\
\$ 999,999\end{array}$ \\
\hline $\begin{array}{l}\square \$ 1,000,000 \text { to } \\
\$ 4,999,999\end{array}$ & $\begin{array}{l}\square \$ 5,000,000 \text { or } \\
\text { above }\end{array}$ & \\
\hline
\end{tabular}

3. For 2011, please indicate the approximate percentage of your construction/building business involved with each category. (Write in percentages.)

Single Family Home Renovation

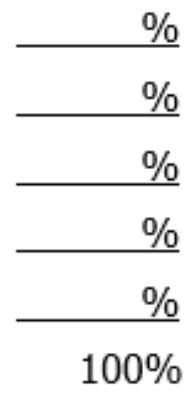


Under federal (HUD) and state programs, Affordable Housing projects are provided with grants and subsidized loans to support new construction and renovation. According to the U.S. Department of Housing and Urban Development (HUD), "the generally accepted definition of affordability is for a household to pay no more than 30 percent of its annual income on housing."

4. During 2011, did your company have construction/renovation projects that would qualify under "Affordable" housing requirements? (Check one.)

$\square$ Yes (Continue to Question 5.)

№ (Skip to Question 19.)

5. Approximately what percentage of your 2011 total construction/building business would classify as "Affordable?" (Check one.)

\begin{tabular}{|l|l|l|}
\hline$\square 0-5 \%$ & $\square 6-10 \%$ & $\square 11-25 \%$ \\
\hline$\square 26-50 \%$ & $\square 51 \%$ or above & \\
\hline
\end{tabular}

6. For each housing category below, what was the total number of units (including "Affordable") your business built during 2011, and how many of those were "Affordable" units? (Write in numbers.)

\begin{tabular}{|l|l|l|}
\hline & $\begin{array}{l}\text { Total Units } \\
\text { Built }\end{array}$ & $\begin{array}{l}\text { Affordable } \\
\text { Units Built }\end{array}$ \\
\hline Single Family Home Renovation & & \\
\hline Single Family Home New Construction & & \\
\hline Multi-Family Home Renovation & & \\
\hline Multi-Family Home New Construction & & \\
\hline
\end{tabular}


Certified Wood Products (CWPs) are wood products that are certified to have been harvested using sustainable forestry practices. They are marked with one of the following trademark logos:

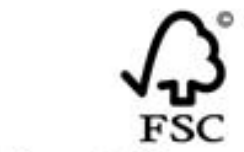

Forest Stewardship Council

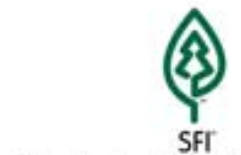

Sustainable Forestry Initiative ristim

American Tree Farm

System

7. With regard to the "Affordable" projects you had in 2011, did you specifically look to purchase Certified Wood Products (CWPs)? (Check one.)

\begin{tabular}{|c|c|c|}
\hline$\square$ Yes & $\square$ No & $\square$ I'm not sure. \\
Continue to Question 8 & Skip to Question 12 & Skip to Question 12 \\
\hline
\end{tabular}

8. If you bought CWPs for "Affordable" projects in 2011, which trademarks were listed on the Certified Wood Products you purchased? (Check all that apply.)

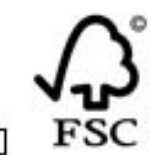

Forest Stewardship Council

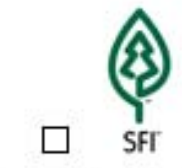

Sustainable Forestry Initiative

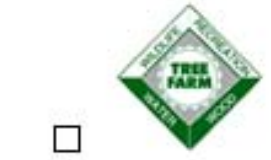

American Tree Farm

System

9. For all your "Affordable" housing projects in 2011, approximately what percentage of your total wood purchases were CWPs? (Check one.)

\begin{tabular}{|l|l|l|}
\hline$\square 1-10 \%$ & $\square 11-20 \%$ & $\square 21-30 \%$ \\
\hline$\square 31-40 \%$ & $\square 41-50 \%$ & $\square 50 \%$ or above \\
\hline
\end{tabular}


10. What CWPs did you buy for your 2011 "Affordable" housing projects? (Check all that apply.)

Solid Lumber:

\begin{tabular}{|l|l|l|}
\hline$\square$ Framing Lumber & $\square$ Moulding & $\square$ Siding \\
\hline$\square$ Hardwood Flooring & $\begin{array}{l}\square \text { Tongue \& Groove } \\
\text { Paneling }\end{array}$ & $\square$ Other (Specify.) \\
\hline
\end{tabular}

Composite Lumber/Panels:

\begin{tabular}{|l|l|}
\hline$\square$ Oriented Strandboard (OSB) & $\square$ Plywood \\
\hline$\square$ Laminated Veneer Lumber (LVL) & $\square$ Moulding \\
\hline$\square$ Parallel Strand Lumber (PSL) & $\square$ Particleboard \\
\hline $\begin{array}{l}\square \text { Oriented/Laminated Strand Lumber } \\
\text { (OSL, LSL) }\end{array}$ & $\begin{array}{l}\square \text { Low-density Fiberboard } \\
\text { (i.e., insulation board) }\end{array}$ \\
\hline$\square$ Structural Insulated Panels (SIPS) & $\square$ Medium Density Fiberboard (MDF) \\
\hline$\square$ Hardboard Paneling & $\square$ Engineered Wood Flooring \\
\hline$\square$ Composite Siding & $\square$ Other (Specify.) \\
\hline
\end{tabular}

\section{Decking Material:}

\begin{tabular}{|l|l|}
\hline$\square$ Non-treated Lumber (IPE, Cedar, etc.) & $\square$ Pressure Treated Lumber \\
\hline$\square$ Wood-Plastic Composites & $\square$ Other (Specify.) \\
\hline
\end{tabular}

\section{Finished Materials:}

\begin{tabular}{|l|l|}
\hline$\square$ Cabinets & $\square$ Stair Parts \\
\hline$\square$ Counters & $\square$ Shelving Units \\
\hline$\square$ Doors & $\square$ Other (Specify.) \\
\hline
\end{tabular}




\section{Where did you purchase these CWPs in 2011? (Check all that apply.)}

\begin{tabular}{|l|l|}
\hline$\square$ Wholesalers/brokers & $\square$ International Brokers \\
\hline $\begin{array}{l}\text { (e.g. Lowe National Big Box Superstores } \\
\text { with multiple state locations) }\end{array}$ & $\begin{array}{l}\square \text { Small Local Retailers } \\
\text { (a.k.a. mom-and-pop stores) }\end{array}$ \\
\hline$\square$ Direct from mill/factory & $\square$ Other: (Please specify.) \\
\hline
\end{tabular}

\section{Do you plan on purchasing CWPs in the future? (Check one.)}

Yes.

No.

I don't know.

13. What are the main reasons that are influencing your decisions on whether or not to purchase CWPs? (Check all that apply.)

\begin{tabular}{|l|l|}
\hline$\square$ Customers request CWPs. & $\square$ Customers don't request CWPs. \\
\hline$\square$ Cost of CWPs is appropriate. & $\square$ Cost of CWPs is too high. \\
\hline$\square$ Aesthetic Quality of CWPs & $\square$ Unattractiveness of CWPs \\
\hline$\square$ Environmental benefit of CWPs & $\begin{array}{l}\square \text { Lack of faith in the certification } \\
\text { process for CWPs }\end{array}$ \\
\hline$\square$ Increased quality of CWPs & $\square$ Quality concerns with CWPs \\
\hline$\square$ Building programs mandate CWPs. & $\begin{array}{l}\square \text { Building programs don't mandate } \\
\text { CWPs. }\end{array}$ \\
\hline$\square$ Experience with CWPs & $\begin{array}{l}\square \text { Lack of experience/knowledge } \\
\text { with CWPs }\end{array}$ \\
\hline$\square$ Other (Please specify.) & \\
\hline
\end{tabular}


14. How much more, if any, are you and/or your clients willing to pay for CWPs in your "Affordable" projects? (Check one.)

\begin{tabular}{|l|l|l|}
\hline$\square 0 \%$ more & $\square 1-4 \%$ more & $\square 5-9 \%$ more \\
\hline$\square 10-15 \%$ more & $\square 16-30 \%$ more & $\square 31 \%$ more or above \\
\hline
\end{tabular}

15. In 2011, did you follow any Green Building Programs in your "Affordable" housing construction/renovation? (Check one.)

\begin{tabular}{|c|c|c|}
\hline$\square$ Yes & $\square$ No & $\square$ I'm not sure. \\
Continue to Question 16 & Skip to Question 19 & Skip to Question 19 \\
\hline
\end{tabular}

16. Was following Green Building Standards required by the client for any of your 2011 "Affordable" housing projects?

\begin{tabular}{|c|c|c|}
\hline$\square$ Yes & $\square$ No & $\square$ I'm not sure. \\
Continue to Question 17 & Skip to Question 19 & Skip to Question 19 \\
\hline
\end{tabular}

\section{What Green Building Programs did you follow in 2011 for your} "Affordable" housing projects? (Check all that apply.)

$\square$ National Green Building Program, National Association of Home Builders

$\square$ Leadership in Energy and Environmental Design (LEED), US Green Building Council (USGBC)

$\square$ Green Globes, Green Building Initiative (GBI)

$\square$ EarthCraft

$\square$ Enterprise Green Communities

$\square$ Other: (Please specify all.) 
18. What type of wood products did you purchase and receive points for under Green Building Standards for your "Affordable" housing projects in 2011? (Check all that apply.)

\section{Solid Lumber:}

\begin{tabular}{|l|l|l|}
\hline$\square$ Framing Lumber & $\square$ Moulding & $\square$ Siding \\
\hline$\square$ Hardwood Flooring & $\begin{array}{l}\square \text { Tongue \& Groove } \\
\text { Paneling }\end{array}$ & $\square$ Other (Specify.) \\
\hline
\end{tabular}

\section{Composite Lumber/Panels:}

\begin{tabular}{|l|l|}
\hline$\square$ Oriented Strandboard (OSB) & $\square$ Plywood \\
\hline$\square$ Laminated Veneer Lumber (LVL) & $\square$ Moulding \\
\hline$\square$ Parallel Strand Lumber (PSL) & $\square$ Particleboard \\
\hline $\begin{array}{l}\square \text { Oriented/Laminated Strand Lumber } \\
\text { (OSL, LSL) }\end{array}$ & $\begin{array}{l}\square \text { Low-density Fiberboard } \\
\text { (i.e., insulation board) }\end{array}$ \\
\hline$\square$ Structural Insulated Panels (SIPS) & $\square$ Medium Density Fiberboard (MDF) \\
\hline$\square$ Hardboard Paneling & $\square$ Engineered Wood Flooring \\
\hline$\square$ Composite Siding & $\square$ Other (Specify.) \\
\hline
\end{tabular}

\section{Decking Material:}

\begin{tabular}{|l|l|}
\hline$\square$ Non-treated Lumber (IPE, Cedar, etc.) & $\square$ Pressure Treated Lumber \\
\hline$\square$ Wood-Plastic Composites & $\square$ Other (Specify.) \\
\hline
\end{tabular}

\section{Finished Materials:}

\begin{tabular}{|l|l|}
\hline$\square$ Cabinets & $\square$ Stair Parts \\
\hline$\square$ Counters & $\square$ Shelving Units \\
\hline$\square$ Doors & $\square$ Other (Specify.) \\
\hline
\end{tabular}


19. How much more, if any, are you and/or your clients willing to pay for wood products verified as green? (Check one.)

\begin{tabular}{|l|l|l|}
\hline$\square 0 \%$ more & $\square 1-4 \%$ more & $\square$ 5-9\% more \\
\hline$\square 10-15 \%$ more & $\square 16-30 \%$ more & $\square 31 \%$ more or above \\
\hline
\end{tabular}

20. With regard to ALL your construction projects, how do you learn about new building products? (Check all that apply.)

\begin{tabular}{|l|l|l|}
\hline$\square$ Websites & $\square$ Professional Societies & $\square$ Trade Shows \\
\hline$\square$ Local Retailers & $\square$ Advertisements & $\square$ Magazines \\
\hline$\square$ Other (Specify.) \\
\end{tabular}

21. How much more, if any, are you and/or your clients willing to pay for locally sourced (i.e., harvested and manufactured within $\mathbf{5 0 0}$ miles) wood products?

\begin{tabular}{|l|l|l|}
\hline$\square 0 \%$ more & $\square 1-4 \%$ more & $\square$ 5-9\% more \\
\hline$\square 10-15 \%$ more & $\square 16-30 \%$ more & $\square 31 \%$ more or above \\
\hline
\end{tabular}

22. Are there any certified or green verified (i.e., labeled) wood products that you would like to buy, but are unable to find in your local markets? (Check one.)

$\square$ Yes (Continue to Question 23.)

$\square$ No (Please stop here and return your survey in the postage-paid envelope. Thank you for completing this survey.) 
23. Which certified or green verified (i.e., labeled) wood products can't you find in your local markets? (Check all that apply.)

Solid Lumber:

\begin{tabular}{|l|l|l|}
\hline$\square$ Framing Lumber & $\square$ Moulding & $\square$ Siding \\
\hline$\square$ Hardwood Flooring & $\begin{array}{l}\square \text { Tongue \& Groove } \\
\text { Paneling }\end{array}$ & $\square$ Other (Specify.) \\
\hline
\end{tabular}

\section{Composite Lumber/Panels:}

\begin{tabular}{|l|l|}
\hline$\square$ Oriented Strandboard (OSB) & $\square$ Plywood \\
\hline$\square$ Laminated Veneer Lumber (LVL) & $\square$ Moulding \\
\hline$\square$ Parallel Strand Lumber (PSL) & $\square$ Particleboard \\
\hline $\begin{array}{c}\square \text { Oriented/Laminated Strand Lumber } \\
\text { (OSL, LSL) }\end{array}$ & $\begin{array}{l}\square \text { Low-density Fiberboard } \\
\text { (i.e., insulation board) }\end{array}$ \\
\hline$\square$ Structural Insulated Panels (SIPS) & $\square$ Medium Density Fiberboard (MDF) \\
\hline$\square$ Hardboard Paneling & $\square$ Engineered Wood Flooring \\
\hline$\square$ Composite Siding & $\square$ Other (Specify.) \\
\hline
\end{tabular}

\section{Decking Material:}

\begin{tabular}{|l|l|}
\hline$\square$ Non-treated Lumber (IPE, Cedar, etc.) & $\square$ Pressure Treated Lumber \\
\hline$\square$ Wood-Plastic Composites & $\square$ Other (Specify.) \\
\hline
\end{tabular}

\section{Finished Materials:}

\begin{tabular}{|l|l|}
\hline$\square$ Cabinets & $\square$ Stair Parts \\
\hline$\square$ Counters & $\square$ Shelving Units \\
\hline$\square$ Doors & $\square$ Other (Specify.) \\
\hline
\end{tabular}

Thank you for completing the survey. Please fill out the next page to receive your t-shirt and return the survey in the postage-paid envelope. 
Please fill out the following information and if you want to receive your t-shirt, please indicate the size:

\begin{tabular}{|c|l|}
\hline \multicolumn{1}{|c|}{ Name } & \multicolumn{1}{|c|}{ Company } \\
\hline & \multicolumn{1}{|c|}{ City } \\
\hline Address & \multicolumn{1}{|c|}{ Zip Code } \\
\hline \multicolumn{1}{|c|}{ State } & \multicolumn{1}{|c|}{} \\
\hline & $\square$ Yes, Size: $\square \mathrm{XL} \square \mathrm{L} \square \mathrm{M} \square \mathrm{S}$ \\
$\begin{array}{l}\text { Would you like to receive your } \\
\text { free Appalachian Hardwood } \\
\text { Center t-shirt? }\end{array}$ & $\square$ No \\
\hline
\end{tabular}




\title{
APPENDIX B - SPATIAL REgRESSION
}

\author{
MatLab Code \\ $\% \%$ \\ \%\% Clear Screen \& Load Dataset \\ clear all \\ clc \\ load('test_data_certwood');
}

\% Nearest neighbor weight matrix

$\% \mathrm{w}=$ make_neighborsw $($ Lat,Long,8);

$\% \mathrm{w}=$ knn_weight_matrix (Lat,Long,10);

[j w j] = xy2cont(Lat,Long);

\% Define dependent variable

$y=$ certwood;

$\mathrm{n}=$ length $(\mathrm{y})$; 
\% Build explanatory variable matrix

$x=[$ ones $(n, 1)$ Degree electric wealth population reuse rmaterial compwood regional

FSConehundred onetwo twofive income];

\% Variable names

vnames $=$

char('certwood','constant','degree','electric','wealth','population','reuse','rmaterial','compwood

','regional','FSConehundred','onetwo','twofive','income');

\%\%Perform LM Tests

$\operatorname{lm} 1=\operatorname{Imlag}(y, x, w)$;

prt_tests(Im1);

$\operatorname{Im} 2=\operatorname{Imerror}(y, x, w)$;

prt_tests(Im2);

Im3=Imlag_robust $(y, x, w)$;

prt_tests $(\operatorname{Im} 3)$;

Im4=Imerror_robust $(\mathrm{y}, \mathrm{x}, \mathrm{w})$;

prt_tests(Im4);

$\% \%$ LR Test - SAR v. SDM 
$k=\operatorname{size}(x, 2)$;

results1 = sdm $(y, x, w)$;

like_sdm = results1.lik

results2 $=\operatorname{sar}(y, x, w)$;

like_sar $=$ results2.lik

$L R=2 *($ like_sdm-like_sar)

pvalue $=1$-chis_prb $(L R, k)$

$\% \%$ LR Test - SEM v. SDM

$k=\operatorname{size}(x, 2)$;

results1 = sdm $(y, x, w)$;

like_sdm = results1.lik

results2 $=\operatorname{sem}(y, x, w)$;

like_sem $=$ results2.lik 
$\mathrm{LR}=2 *$ (like_sdm-like_sem)

pvalue $=1$-chis_prb $($ LR, $k)$

$\% \%$ Wald Test - OLS v. SLX

result3 = ols $(y, x)$

$\operatorname{prt}($ result3);

$x 2=[$ Degree electric wealth population reuse rmaterial compwood regional FSCfifty

FSConehundred onetwo twofive income];

$w x=w^{*} \times 2$

result4 = ols $(y,[x w x])$;

prt(result4);

[fstat fprob] = waldf(result3, result4);

Fstat $=$ fstat

pvalue $=$ fprob

$\% \%$ Test rho=0

result $5=\operatorname{sdm}(y, x, w)$

prt(result5) 


\section{MatLab Results}

LM lag test for omitted spatial lag
LM value
0.49766677
Marginal Probability $\quad 0.48052712$
chi(1) .01 value $\quad 6.64000000$

LM error test for spatial correlation in residuals

LM value $\quad 0.74491675$

Marginal Probability $\quad 0.38809040$

chi(1) .01 value $\quad 6.63500000$

Robust LM lag test

LM value $\quad 0.13848670$

Marginal Probability $\quad 0.70979009$

chi(1) .01 value $\quad 6.64000000$ 
Robust LM error test

LM value

0.38573669

Marginal Probability $\quad 0.53454894$

chi(1) .01 value $\quad 6.64000000$

sdm: negative variances from numerical hessian

sdm: t-statistics may be inaccurate

like_sdm =

$-1.5060 e+03$

sar: negative variances from numerical hessian

sar: t-statistics may be inaccurate 
like_sar =

$-1.5200 e+03$

$L R=$

27.8999

pvalue $=$

0.0093

sdm: negative variances from numerical hessian

sdm: t-statistics may be inaccurate 
like_sdm =

$-1.5060 e+03$

like_sem =

$-1.5198 e+03$

$L R=$

27.6549

pvalue $=$ 
0.0101

Ordinary Least-squares Estimates

R-squared $=0.9186$

Rbar-squared $=0.9172$

$\operatorname{sigma}^{\wedge} 2=8.2326$

Durbin-Watson $=2.0678$

Nobs, Nvars $=718,13$

Variable Coefficient t-statistic t-probability

$\begin{array}{llll}\text { variable } 1 & 2.343879 & 3.427199 & 0.000645\end{array}$

$\begin{array}{llll}\text { variable } 2 & 0.038833 & 2.618566 & 0.009020\end{array}$

$\begin{array}{llll}\text { variable } 3 & -17.768938 & -3.420338 & 0.000661\end{array}$

$\begin{array}{llll}\text { variable } 4 & 0.000747 & 1.488822 & 0.136981\end{array}$

$\begin{array}{llll}\text { variable } 5 & 0.002829 & 10.293956 & 0.000000\end{array}$

$\begin{array}{llll}\text { variable } 6 & 1.316616 & 2.905984 & 0.003776\end{array}$ 


$\begin{array}{llll}\text { variable 7 } & 0.279844 & 4.606326 & 0.000005 \\ \text { variable 8 } & 0.308816 & 4.841591 & 0.000002 \\ \text { variable 9 } & 2.665941 & 36.355090 & 0.000000 \\ \text { variable 10 } & 0.023522 & 3.145732 & 0.001726 \\ & & & \\ \text { variable 11 } & 0.001383 & 0.300037 & 0.764238 \\ \text { variable 12 } & -0.002674 & -2.191903 & 0.028713 \\ \text { variable 13 } & -0.019147 & -1.733928 & 0.083368\end{array}$

Ordinary Least-squares Estimates

R-squared $=0.9224$

Rbar-squared $=0.9196$

sigma^2 $^{\wedge} \quad 7.9971$

Durbin-Watson $=2.1049$

Nobs, Nvars $=718,26$

Variable Coefficient t-statistic t-probability 


\begin{tabular}{|c|c|c|c|}
\hline variable 1 & 3.725471 & 3.866284 & 0.000121 \\
\hline variable 2 & 0.034487 & 2.217929 & 0.026884 \\
\hline variable 3 & 14.211203 & 1.511425 & 0.131137 \\
\hline variable 4 & 0.000820 & 1.553620 & 0.120732 \\
\hline variable 5 & 0.003128 & 10.311164 & 0.000000 \\
\hline variable 6 & 1.333341 & 2.933311 & 0.003465 \\
\hline variable 7 & 0.255732 & 4.048798 & 0.000057 \\
\hline variable 8 & 0.317405 & 4.810901 & 0.000002 \\
\hline variable 9 & 2.621687 & 35.375407 & 0.000000 \\
\hline variable 10 & -0.004499 & -0.221014 & 0.825147 \\
\hline variable 11 & 0.012514 & 0.807470 & 0.419673 \\
\hline variable 12 & 0.005503 & 0.758437 & 0.448448 \\
\hline variable 13 & -0.017808 & -1.458040 & 0.145283 \\
\hline variable 14 & -0.036616 & -1.080372 & 0.280353 \\
\hline variable 15 & -41.261065 & -3.476011 & 0.000541 \\
\hline variable 16 & -0.001545 & -1.455012 & 0.146119 \\
\hline variable 17 & -0.000878 & -1.502865 & 0.133330 \\
\hline
\end{tabular}




$\begin{array}{cccc}\text { variable 18 } & 0.311280 & 0.267769 & 0.788957 \\ \text { variable 19 } & -0.040906 & -0.239673 & 0.810655 \\ \text { variable 20 } & 0.083446 & 0.462865 & 0.643607 \\ \text { variable 21 } & 0.205122 & 1.112526 & 0.266298 \\ \text { variable 22 } & 0.098547 & 2.513070 & 0.012195 \\ \text { variable 23 } & 0.008350 & 0.321885 & 0.747637 \\ \text { variable 24 } & -0.017494 & -0.946026 & 0.344466 \\ \text { variable 25 } & -0.007613 & -0.997302 & 0.318967 \\ \text { variable 26 } & 0.025951 & 1.151021 & 0.250121\end{array}$

Fstat $=$

2.5971

pvalue $=$ 
0.0016

sdm: negative variances from numerical hessian

sdm: t-statistics may be inaccurate

result5 $=$

ndraw: 1000

cflag: 1

p: 12

time2: 0

time1: 0.0460

time4: 0.0090

iter: 15

beta: [25x1 double]

rho: 0.0530 
sige: 7.7661

yhat: [718x1 double]

resid: [718x1 double]

lik: $-1.5060 e+03$

tstat: [26x1 double]

bstd: [25x1 double]

pstd: 0.0198

time3: 0.0870

time5: 0.4480

rsqr: 0.9216

meth: 'sdm'

$y:$ [718x1 double]

total: [1000×12×101 double]

direct: [1000x12×101 double]

indirect: [1000x12×101 double]

nobs: 718

nvar: 25 
rmax: 1

rmin: -1

Iflag: 1

order: 50

miter: 30

rbar: 0.9189

time: 0.5980

Indet: [2001x2 double]

Spatial Durbin model

R-squared $=0.9216$

Rbar-squared $=0.9189$

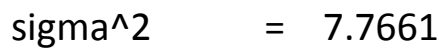

log-likelihood = -1505.9987

Nobs, Nvars $=718,25$

$\#$ iterations $=15$ 


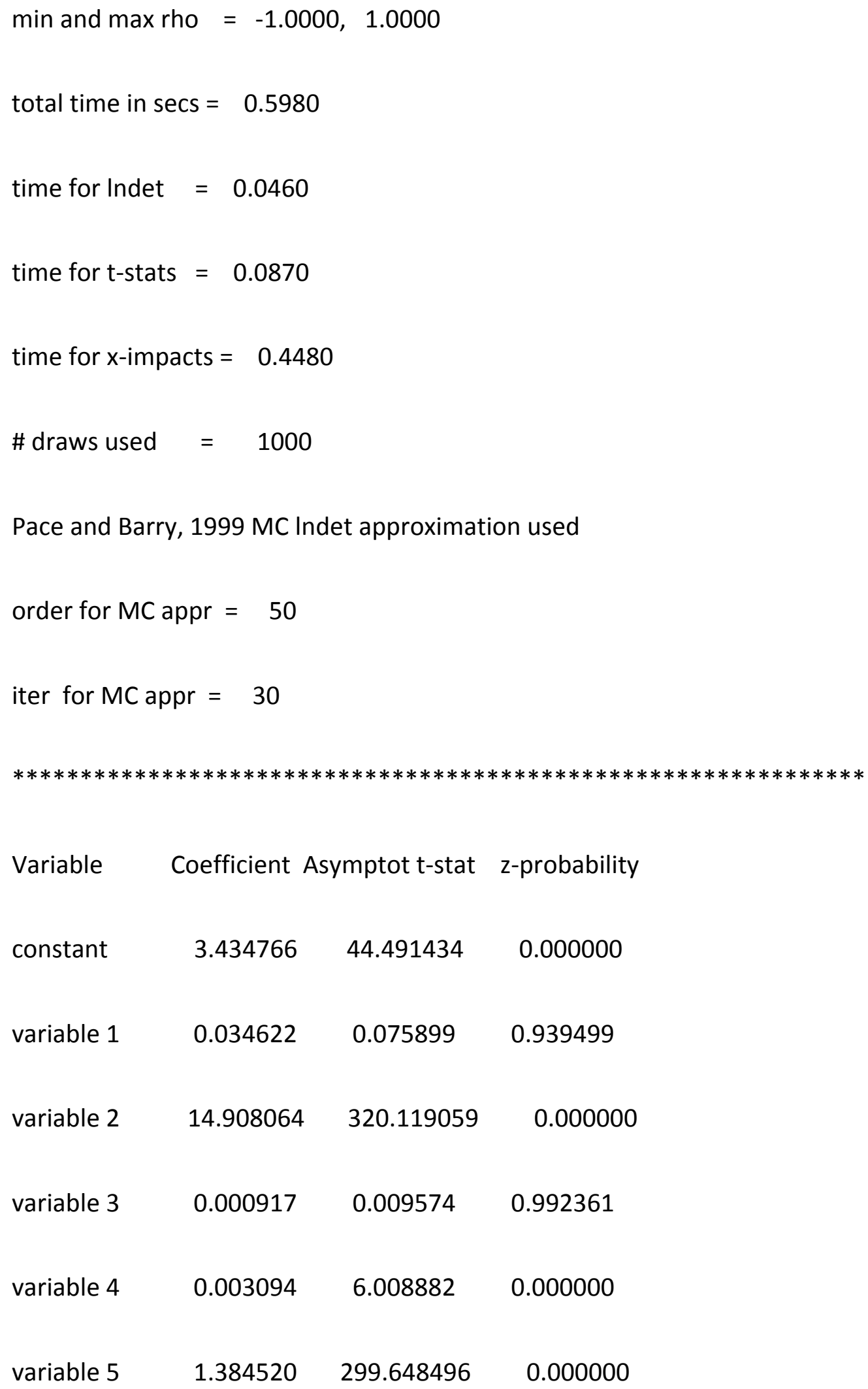




\begin{tabular}{|c|c|c|c|}
\hline variable 6 & 0.263650 & 0.592203 & 0.553715 \\
\hline variable 7 & 0.316273 & 5.212223 & 0.000000 \\
\hline variable 8 & 2.631218 & 40.864298 & 0.000000 \\
\hline variable 9 & -0.003421 & -0.052402 & 0.958208 \\
\hline variable 10 & 0.013200 & 0.681457 & 0.495583 \\
\hline variable 11 & 0.005836 & 0.395195 & 0.692699 \\
\hline variable 12 & -0.016886 & -2.400413 & 0.016377 \\
\hline $\mathrm{W}^{*}$ variable 1 & -0.025055 & -2.095398 & 0.036136 \\
\hline$W^{*}$ variable 2 & -45.272612 & -333.932375 & 0.000000 \\
\hline$W^{*}$ variable 3 & -0.001547 & -0.007280 & 0.994192 \\
\hline$W^{*}$ variable 4 & -0.000859 & -0.850138 & 0.395248 \\
\hline$W^{*}$ variable 5 & 0.122272 & 324.486082 & 0.000000 \\
\hline$W^{*}$ variable 6 & -0.014503 & -0.064124 & 0.948871 \\
\hline$W^{*}$ variable 7 & 0.066685 & 0.423030 & 0.672273 \\
\hline$W^{*}$ variable 8 & 0.046444 & 0.272239 & 0.785439 \\
\hline$W^{*}$ variable 9 & 0.036549 & 0.134068 & 0.893349 \\
\hline $\mathrm{W}^{*}$ variable 10 & -0.018015 & -0.794279 & 0.427033 \\
\hline
\end{tabular}




$$
\begin{array}{lrrr}
\text { W*variable } 11 & -0.008028 & -0.459167 & 0.646114 \\
\text { W*variable } 12 & 0.029462 & 4.039871 & 0.000053 \\
\text { rho } & 0.052965 & 2.672485 & 0.007529
\end{array}
$$

Direct Coefficient t-stat t-prob lower 01 upper 99

$$
\begin{array}{llllll}
\text { variable } 1 & 0.033615 & 2.253447 & 0.024532 & -0.003299 & 0.071793
\end{array}
$$$$
\begin{array}{llllll}
\text { variable } 2 & 14.384463 & 1.514691 & 0.130291 & -9.902965 & 37.263110
\end{array}
$$$$
\begin{array}{llllll}
\text { variable } 3 & 0.000937 & 1.793182 & 0.073365 & -0.000457 & 0.002348
\end{array}
$$$$
\begin{array}{llllll}
\text { variable } 4 & 0.003083 & 10.349227 & 0.000000 & 0.002215 & 0.003895
\end{array}
$$$$
\begin{array}{llllll}
\text { variable } 5 & 1.398903 & 3.204873 & 0.001411 & 0.277061 & 2.478759
\end{array}
$$$$
\begin{array}{llllll}
\text { variable } 6 & 0.263267 & 4.192551 & 0.000031 & 0.099889 & 0.422041
\end{array}
$$$$
\begin{array}{llllll}
\text { variable } 7 & 0.316413 & 4.866081 & 0.000001 & 0.127104 & 0.479960
\end{array}
$$

$\begin{array}{llllll}\text { variable } 8 & 2.632324 & 36.235533 & 0.000000 & 2.441227 & 2.811412\end{array}$

$\begin{array}{llllll}\text { variable } 9 & -0.003630 & -0.184767 & 0.853464 & -0.053511 & 0.046083\end{array}$

$\begin{array}{llllll}\text { variable } 10 & 0.012913 & 0.829519 & 0.407086 & -0.029030 & 0.050188\end{array}$

$\begin{array}{llllll}\text { variable } 11 & 0.005834 & 0.814281 & 0.415754 & -0.013243 & 0.023611\end{array}$

$\begin{array}{llllll}\text { variable } 12 & -0.016465 & -1.412813 & 0.158144 & -0.046339 & 0.013654\end{array}$ 


\begin{tabular}{|c|c|c|c|c|c|}
\hline Indirect & Coefficient & t-stat & prob & $\operatorname{er} 01$ & 99 \\
\hline variable 1 & -0.023226 & -0.646040 & 0.518460 & -0.119707 & 0.067163 \\
\hline variable 2 & -46.768299 & -3.876260 & 0.000116 & -77.474655 & -14.802471 \\
\hline variable 3 & -0.001592 & -1.451590 & 0.147052 & -0.004538 & 0.000827 \\
\hline variable 4 & -0.000706 & -1.148124 & 0.251300 & -0.002360 & 0.000847 \\
\hline variable 5 & 0.157970 & 0.132512 & 0.894616 & -2.859444 & 3.142173 \\
\hline variable 6 & 0.004548 & 0.025235 & 0.979874 & -0.496845 & 0.495976 \\
\hline variable 7 & 0.086095 & 0.449860 & 0.652947 & -0.404785 & 0.573177 \\
\hline variable 8 & 0.191817 & 0.945830 & 0.344553 & -0.338104 & 0.707497 \\
\hline variable 9 & 0.038308 & 1.691409 & 0.091193 & -0.020198 & 0.094963 \\
\hline variable 10 & -0.017765 & -0.933319 & 0.350969 & -0.067484 & 0.029183 \\
\hline variable 11 & -0.008193 & -1.089446 & 0.276323 & -0.027011 & 0.011270 \\
\hline variable 12 & 0.029265 & 1.260446 & 0.207918 & -0.033025 & 0.089483 \\
\hline
\end{tabular}

Total Coefficient t-stat t-prob lower 01 upper 99

$\begin{array}{llllll}\text { variable } 1 & 0.010390 & 0.291915 & 0.770436 & -0.089699 & 0.099174\end{array}$ 


$\begin{array}{cccccc}\text { variable 2 } & -32.383836 & -4.400736 & 0.000012 & -51.928711 & -13.860142 \\ \text { variable 3 } & -0.000655 & -0.573208 & 0.566683 & -0.003526 & 0.001984 \\ \text { variable 4 } & 0.002377 & 4.087400 & 0.000049 & 0.000878 & 0.003896 \\ \text { variable 5 } & 1.556874 & 1.199052 & 0.230903 & -1.837609 & 4.819936 \\ \text { variable 6 } & 0.267816 & 1.276481 & 0.202198 & -0.311518 & 0.856754 \\ \text { variable 7 } & 0.402508 & 1.829123 & 0.067796 & -0.186117 & 0.964460 \\ \text { variable 8 } & 2.824141 & 12.974284 & 0.000000 & 2.195263 & 3.372842 \\ \text { variable 9 } & 0.034678 & 3.021316 & 0.002606 & 0.005735 & 0.062539 \\ \text { variable 12 } & 0.012800 & 0.543001 & 0.587297 & -0.051118 & 0.078395\end{array}$




\section{APPENDIX C - SPECIFIER SURVEY}

\section{West VirginiaUniversity.}

DAVIS COLLEGE OFAGRICULTURE, NATURAL RESOURCES, ANDDESIGN

Please take a moment to review the following six survey topics and how they relate to you as a material specifier. These six topics/questions are intended to be the discussion base for the survey, but not the boundaries. Please feel free to ask for clarification or to elaborate on your personal experiences.

Question \#1: What motivated or discouraged your use of wood materials in previous LEED certified projects?

Question \#2: Do you see the market for green building standards expanding or contracting in your area? What about the use of the LEED standard specifically?

Question \#3: $\quad$ Assuming a wood-based product meets required end-use specifications, do you foresee increased use of structural and/or interior finished wood products in future green building projects? Why?

Question \#4: Describe a product application where you would like to use wood based materials but cannot due to lack of availability or inferior properties?

Question \#5: Were you required to build to the LEED green building standard? If required, what were the driving influences? (ex. funding source, city law, etc.) If not required, would you still have built to the LEED green building standard?

Question \#6: What incentives or motivations do you have to build to a green standard? If there are no existing incentives or motivations, what ones would you propose?

\section{WOOD SCIENCE AND TECHNOLOGY}

\section{Erepary D. Estep \\ POBax6125 \\ Momantban, wy $26506-6125$}

B $304: 293.0052$ B $304: 293.2441$ 


\section{APPENDiX D - MANUFACTURER SURVEY}

\section{West VirginiaUniversity.}

DAVIS COLLEGE OFAGRICULTURE, NATURAL RESOURCES, ANDDESIGN

Please take a moment to review the following six survey topics and how they relate to you as a material manufacturer. These six topics/questions are intended to be the discussion base for the survey, but not the boundaries. Please feel free to ask for clarification or to elaborate on your personal experiences.

Question \#1: What do you feel motivates or discourages the use of wood as a MATERIAL in commercial green building projects?

Question \#2: What physical attributes are needed in wood PRODUCTS to compete with substitute material products in commercial green building projects?

Question \#3: Do you see the market for commercial green building projects expanding or contracting?

Question \#4: Do you foresee increased use of wood products in future commercial green building projects?

Question \#5: What marketing channels do you use when promoting your wood product(s) to the commercial green building industry?

Question \#6: What audience(s) do you target when promoting your wood product(s) to the commercial green building industry? 


\section{APPENDIX E - SPECIFIER AND MANUFACTURER PERCEPTIONS}

\begin{tabular}{|c|c|c|}
\hline GB Market & Specifiers & Manufacturers \\
\hline Why Wood & $\begin{array}{c}\text { The green building market will } \\
\text { continue to expand } \\
\text { Environmental Benefits } \\
\text { CWPs }\end{array}$ & $\begin{array}{c}\text { The green building market will } \\
\text { continue to expand } \\
\text { Focus marketing efforts in GB }\end{array}$ \\
\hline $\begin{array}{c}\text { How to } \\
\text { learn about } \\
\text { wood? }\end{array}$ & $\begin{array}{c}\text { Aesthetic Values } \\
\text { Environmental Benefits } \\
\text { Become more familiar with } \\
\text { standards and pursue demand }\end{array}$ \\
\hline & $\begin{array}{c}\text { Technical Detail } \\
\text { Retailers } \\
\text { Magazines } \\
\text { Websites }\end{array}$ & $\begin{array}{c}\text { Face-to-Face } \\
\text { Include structural and } \\
\text { environmental detail }\end{array}$ \\
\hline
\end{tabular}

